\title{
Population modelling of the He II energy levels in tokamak plasmas. I : Collisional excitation model
}

\author{
K D Lawson ${ }^{1}, \mathrm{~K} \mathrm{M} \mathrm{Aggarwal}^{2}$, I H Coffey ${ }^{1,2}$, F P Keenan ${ }^{2}, \mathrm{M} \mathrm{G} \mathrm{O'Mullane}^{3}$ \& JET \\ Contributors*
}

EUROfusion Consortium, JET, Culham Science Centre, Abingdon, OX14 3DB, UK

${ }^{1}$ UKAEA/CCFE, Culham Science Centre, Abingdon, OX14 3DB, UK

${ }^{2}$ Astrophysics Research Centre, School of Mathematics and Physics, Queen's University Belfast, Belfast, BT7 INN, Northern Ireland, UK

${ }^{3}$ Department of Physics, University of Strathclyde, Glasgow, G4 0NG, UK

* See the author list of X. Litaudon et al., 2017, Nuclear Fusion, 57, 102001

\begin{abstract}
Helium is widely used as a fuel or minority gas in laboratory fusion experiments, and will be present as ash in DT thermonuclear plasmas. It is therefore essential to have a good understanding of its atomic physics. To this end He II population modelling has been undertaken for the spectroscopic levels arising from shells with principal quantum number $n=$ 1 to 5. This paper focuses on a collisional excitation model; ionization and recombination will be considered in a subsequent article. Heavy particle collisional excitation rate coefficients have been generated to supplement the currently-available atomic data for He II, and are presented for proton, deuteron, triton and $\alpha$-particle projectiles. The widely-used criterion for levels within an $n$ shell being populated in proportion to their statistical weights is reassessed with the most recent atomic data, and found not to apply to the He II levels at tokamak densities $\left(10^{18}-10^{21} \mathrm{~m}^{-3}\right)$. Consequences of this and other likely sources of errors are quantified, as is the effect of differing electron and ion temperatures. Line intensity ratios, including the so-called 'branching ratios' and the fine-structure $\beta_{1}, \beta_{2}, \beta_{3}$ and $\gamma$ ratios, are discussed, the latter with regard to their possible use as diagnostics.
\end{abstract}

\section{Introduction}

To limit the heat and particle fluxes reaching plasma-facing surfaces, contemporary large tokamak plasma machines employ a divertor box, in which a cold, dense plasma acts as a buffer between the hot thermonuclear plasma and the device's solid surfaces. The plasma densities will be lower, $10^{18}$ to $10^{21} \mathrm{~m}^{-3}$, than those under which local thermodynamic equilibrium (LTE) applies, with temperatures ranging from $\sim 0.2$ to $30 \mathrm{eV}$. Hence detailed population modelling is required to describe the behaviour of the cold plasma, and allow predictions to be made for tokamaks such as ITER and DEMO. Consequently, it is essential to understand the atomic physics of the fuel and of any seeded gases used to increase the radiation and enhance the cooling of the divertor plasma. To this end, a study has been undertaken of the atomic physics of $\mathrm{H}$ plus its isotopes, and of hydrogen-like $\mathrm{He}$ (He II). This ion is very similar in behaviour to $\mathrm{H}$, but its atomic physics is more tractable in that the collisions with heavy particles are ion-ion rather ion-neutral atom interactions. It is important to note that $\mathrm{He}$ is the proposed fuel for the first phase of ITER, and will be present as ash from the DT fusion reaction in later ITER experiments and also in DEMO.

The most complete population model, which will then allow the reliable calculation of line intensities, includes as many populating processes as possible. A difficulty arises in that 
the atomic data for both $\mathrm{H}$ and He II are incomplete. For example, although some authors have used heavy particle collisional excitation rate coefficients in their studies (e.g. Sampson, 1977, Tallents, 1984, 1985) there are no listings of these data available for either H or He II. However, these collisions are important for transitions between the near-degenerate energy levels within a shell defined by the principal quantum number $n$, i.e. the fine-structure transitions.

In cases where the fine-structure components of the observed spectral lines are not resolved, one approach which overcomes this difficulty in low density, non-LTE plasmas is to assume that the fine structure levels within the individual $n$ shells (the levels being defined by the quantum numbers $n, l$ and $J$ ) are populated in proportion to their statistical weights,

$$
n_{n, l, J}=\frac{2 J+1}{2 n^{2}} n_{n} .
$$

Here $l$ and $J$ are the orbital and total angular momenta, respectively. Indeed, this approach has been adopted to the extent that some recent calculations of electron collisional rate coefficients for $\mathrm{H}$ do not include fine-structure collisions (Anderson et al., 2000, 2002). Although this assumption is expected to be accurate for higher $n$ shells, for example as considered by Burgess and Summers (1976), it is less certain for the spectroscopic levels within the $n=1$ to 5 shells studied here. Given the advances made in the calculation of electron collisional cross sections, it is appropriate to reassess the criterion for which the statistical weighting of the populations within $n$ shells is valid. Sampson (1977), who investigated this topic, used a semi-classical description of both electron and heavy particle cross sections. Tallents (1985) found that significantly higher densities for He II than those of Sampson were needed to ensure a statistical population. In the present study, the semiclassical method of Walling and Weisheit (1988) is used to generate improved heavy particle cross sections, which are then combined with recent R-matrix electron collisional data.

A collisional-radiative model has been used which includes electron and heavy particle rate coefficients for both intershell and fine-structure transitions. Such a model is essential when the fine-structure components of the spectral lines are resolved, but is also useful for assessing the importance of different aspects of the population modelling. Here results based on a collisional excitation model are presented for the spectroscopic levels of He II. At low temperatures $\left(T_{e}<\sim 3 \mathrm{eV}\right)$ processes such as recombination become important and can dominate the populating channels. These will be considered in a subsequent paper.

Section 2 assesses the available electron collisional data for He II, while section 3 presents heavy particle cross sections for He II generated from the implementation of the Walling and Weisheit (1988) method. The collisional-radiative population model, including both electron and heavy particle collisional channels, is described in section 4 . This section also discusses the importance of the different channels, and the criterion determined for the validity of the assumption of the statistical population of the $n$ shells. Spectral line intensity ratios can be useful for diagnosing certain plasma parameters, and these are discussed in section 5, while section 6 assesses the effect of differing electron and ion temperatures. Section 7 contains a comparison with previous work, and finally section 8 presents our conclusions.

\section{Published atomic data for He II}

In addition to the previously mentioned collisional excitation rate coefficients, a collisional-radiative model requires transition probabilities for spontaneous emission (Avalues) for each transition. These radiative decay rates for the intershell transitions are found in the NIST database (Kramida et al., 2015), which incorporates the extensive listing of 
Wiese and Fuhr (2009). Additional A-values for the fine-structure transitions within an $n$ shell are given by Aggarwal et al. (2017) and Jitrik and Bunge (2004). Aggarwal et al. adopt the fully relativistic GRASP (General-purpose Relativistic Atomic Structure Package) code to generate the atomic structure, which gives wave functions, energy levels and A-values, while Jitrik and Bunge use a point-nucleus Dirac Hamiltonian model. For He II, the available data are expected to be reliable, being more accurate than the collisional results and therefore not limiting the accuracy of the population model.

For electron collisions, R-matrix calculations are expected to be more accurate than older methods and hence we focus on these. The earliest R-matrix calculation for He II is that of Aggarwal et al. (1991), while Callaway (1994) reviews the various calculations for $\mathrm{H}$ and hydrogen-like ions available up to the time of publication, the latter forming the basis of the 1997 dataset within the ADAS database (Summers, 2004). Both Aggarwal et al. and Callaway present data for the so-called 'spectroscopic levels', $n=1-5$. These data are $l$ resolved, therefore including 15 levels, and are for the intershell transitions only. Aggarwal et al. cover a temperature interval of 0.43 to $8.6 \mathrm{eV}$, while Callaway's formula for the effective collision strengths range from $0.5 \mathrm{eV}$ up to a high temperature limit of $10 \mathrm{keV}$.

For the IRON project, Kisielius et al. (1996) performed a $J$-resolved He II calculation for the 16 levels of the $n=1-4$ shells. Data are presented for both intershell and fine-structure transitions, although only for a very limited temperature range from 0.137 to $1.72 \mathrm{eV}$. The more recent work by Ballance et al. (2003) is an $l$-resolved, 15 level calculation providing data for intershell transitions for $n$ up to 5, covering a temperature range of $1-86.2 \mathrm{eV}$. Unusually, Hamada et al. (2010) present data only for the fine-structure transitions. The calculations are $J$-resolved, including the 25 levels of the $n=1-5$ shells for a wide range of atomic number $Z$. For He, the temperature range covered is $0.86-8.62 \mathrm{eV}$.

Of most use for the present study are the calculations of Aggarwal et al. (2017), with the $25 J$-resolved levels of shells $n=1-5$ included, and both intershell and fine-structure transitions treated over the temperature range $0.34-21.7 \mathrm{eV}$. The scattering calculation is performed using the DARC (Dirac Atomic R-matrix Code) program to calculate collision strengths, $\Omega$, as a function of incident projectile energy.

All authors present their collisional data in terms of the effective collision strength, $Y$, since this provides a more concise listing than is possible for collision strengths or cross sections, $\sigma$, given the very fine energy resolution necessary to capture as many resonances as possible, particularly near the threshold energy. The collision strength of a transition from a lower level $i$ to an upper level $j$ is given by

$$
\Omega_{i j}=\frac{\sigma_{i j}}{\pi a_{0}^{2}} \omega_{i} \frac{E_{i}}{I_{H}}
$$

where $E_{i}$ is the initial free electron energy, $\omega_{i}$ the statistical weight of level $i\left(\omega_{i}=2 J+1\right), a_{o}$ is the Bohr radius and $I_{H}$ the Rydberg unit of energy. It is a dimensionless parameter and symmetrical between the initial and final states. To obtain the effective collision strength, $\Omega_{i j}$ is convolved with a Maxwellian electron energy distribution, this implicitly supposing a Local Kinetic Equilibrium (LKE),

$$
\mathrm{Y}_{i j}=\int_{0}^{\infty} \Omega_{i j} \exp \left(-\frac{E_{j}}{k T_{e}}\right) d\left(\frac{E_{j}}{k T_{e}}\right)
$$

Here $E_{j}$ is the final free electron energy after excitation, $T_{e}$ the electron temperature and $k$ the Boltzmann constant. From $Y_{i j}$ the collisional excitation rate coefficient $q_{i j}$ can be derived using the expression 


$$
q_{i j}=2 \pi^{1 / 2} \alpha c a_{0}^{2}\left(\frac{I_{H}}{k T_{e}}\right)^{1 / 2} \frac{\mathrm{Y}_{i j}}{\omega_{i}} \exp \left(-\frac{\Delta E}{k T_{e}}\right)
$$

with the corresponding deexcitation rate coefficient $q_{j i}$ given by

$$
q_{j i}=q_{i j} \frac{\omega_{i}}{\omega_{j}} \exp \left(\frac{\Delta E}{k T_{e}}\right)
$$

These are the parameters used in the collisional-radiative model, where $\alpha$ is the fine-structure constant, $c$ the velocity of light and $\Delta E$ the transition energy. As previously noted, there are no listings of heavy particle collisional excitation data available for He II.

\section{Heavy particle collisional data}

To provide heavy particle collisional excitation rate coefficients for this study, the method of Walling and Weisheit (1988) for ion impact bound-state excitation of ions has been implemented fully for electric dipole and electric quadrupole transitions. This semi-classical treatment extends the work of Seaton (1964), the trajectory of the ions being determined from classical equations, but with the probability of excitation from quantum mechanical formulae.

The semi-classical cross section, a function of the relative velocity $v$, is obtained by integrating the excitation probability, $P_{i j}$, over all impact parameters, $b$, i.e.

$$
\sigma_{i j}(v)=2 \pi \int_{0}^{\infty} P_{i j}(v, b) b d b
$$

It is found that at small impact parameters, the first-order expression for the excitation probability becomes invalid, with $P_{i j}>1$, and hence it is necessary to limit $P_{i j}$ to obtain meaningful results. Seaton (1964) imposed a limit of $P_{i j} \leq 0.5$ on the first order probability into any one state. A further consideration is the projectile penetrating the target ion and, in this situation, the probability will again be overestimated. Another limit was therefore imposed by Seaton that $P_{i j} \leq$ the smaller of 0.5 and $P_{T}$, where $P_{T}=P_{i j}\left(b_{T}\right)$, the distance of closest approach being greater than the size of the target ion for all impact parameters less than $b_{T}$. The cross section can now be defined as

$$
\sigma_{i j}(v)=2 \pi \int_{b_{c}}^{\infty} P_{i j}(v, b) b d b+\pi b_{c}^{2} P_{c}
$$

where $P_{c}$ is a limiting excitation probability and $b_{c}$ the corresponding limiting impact parameter. For numerical calculations it is convenient to change the integration variable from the impact parameter, $b$, to the Coulomb trajectory's eccentricity, $\varepsilon$, and introducing the multipole strength factor $\chi_{i j}$ and the adiabaticity parameter $\xi$, where

$$
\xi=r_{0} \frac{\Delta E}{\hbar v},
$$

$r_{0}$ being half the distance of closest approach in a collision at zero impact parameter. The cross section can be written as 


$$
\sigma_{i j}(v)=\pi r_{0}^{2}\left[\chi_{i j}^{(\lambda)} \Psi^{(\lambda)}\left(\varepsilon_{c}, \xi\right)+\left(\varepsilon_{c}^{2}-1\right) P_{c}\right]
$$

In this equation $\lambda$ indicates the multipole of the transition, 1 corresponding to an electric dipole transition and 2 an electric quadrupole transition, while $\varepsilon_{c}$ is the eccentricity corresponding to the limiting impact parameter $b_{c}$ and

$$
\Psi^{(\lambda)}\left(\varepsilon_{c}, \xi\right)=2 \int_{\varepsilon_{c}}^{\infty} R^{(\lambda)}(\varepsilon, \xi) \varepsilon d \varepsilon
$$

where $R^{(\lambda)}$ is a relative excitation probability.

To facilitate the implementation of their approach, Walling and Weisheit (1988) provide tables of $\log _{10} R^{(\lambda)}$ and $\log _{10} \Psi^{(\lambda)}$ as functions of $\varepsilon$ and $\xi$. Initially, the tabulated values were used, but the necessary two-dimensional interpolation of these led to cross sections being generated that did not vary smoothly. Consequently, the method was implemented fully allowing $\log _{10} R^{(\lambda)}$ and $\log _{10} \Psi^{(\lambda)}$ to vary smoothly as continuous functions of $\varepsilon$ and $\xi$. The tables of $\log _{10} R^{(\lambda)}$ were reproduced exactly, but small differences were found with the tabulated values of the integral $\log _{10} \Psi^{(\lambda)}$. These were generally $\leq 3 \%$, although could be larger (up to $\sim 40 \%$ ) when the logarithm changed sign, and in the case of electric dipole transitions for large $\varepsilon$ and small $\xi$. The present integrations are preferred.

As for the electron data, the cross sections are converted into collisional excitation rate coefficients for use in the collisional-radiative model. In this case, there is an additional factor involving the reduced mass $\mu$, where

$$
\begin{gathered}
\frac{1}{\mu}=\frac{1}{m_{p}}+\frac{1}{m_{t}}, \\
q_{i j}=\frac{2 \alpha c}{\left(\pi I_{H} k T_{p}\right)^{1 / 2}}\left(\frac{m_{e}}{\mu}\right)^{1 / 2} \exp \left(-\frac{\Delta E}{k T_{p}}\right) \int_{0}^{\infty} \sigma_{i j} E_{i} \exp \left(-\frac{E_{j}}{k T_{p}}\right) d\left(\frac{E_{j}}{k T_{p}}\right),
\end{gathered}
$$

and $m_{e}, m_{p}, m_{t}$ are the electron, projectile and target masses, respectively, and $T_{p}$ the projectile temperature.

The multipole strength factor, $\chi_{i j}$, depends only on the atomic properties and requires knowledge of the line strength, which in turn can be calculated from the A-value. These are available for 58 of the 70 fine-structure transitions in the $n=2-5$ shells. Of the 12 transitions for which there are no A-values, 10 transitions are electric dipole between near-degenerate levels. A reasonable estimate of the A-value of one of these, the $2 p{ }^{2} \mathrm{P}_{1 / 2}-2 s^{2} \mathrm{~S}_{1 / 2}$ transition, was made via a comparison of proton impact cross sections for He II with the results of Zygelman and Dalgarno (1987) as described below. Estimates were also made for the ${ }^{2} \mathrm{P}_{1 / 2}-$ ${ }^{2} \mathrm{~S}_{1 / 2}$ transitions in the higher $n$ shells, as detailed in section 4 , although these are expected to have a greater uncertainty.

In total, cross sections were generated for 20 electric dipole and 25 electric quadrupole transitions. The other transitions are either between near-degenerate levels for which there are no A-values, higher electric multipole transitions, which are expected to be less important, or magnetic multipole transitions. Figure 1 shows $d$ - and $\alpha$-particle collisional excitation data which have been generated for the fine-structure transitions within the $n=2$ shell of He II. There are two electric dipole transitions, $2 \mathrm{p}{ }^{2} \mathrm{P}_{1 / 2}-2 \mathrm{~s}{ }^{2} \mathrm{~S}_{1 / 2}$ and $2 \mathrm{~s}{ }^{2} \mathrm{~S}_{1 / 2}-2 \mathrm{p}{ }^{2} \mathrm{P}_{3 / 2}$, and an electric quadrupole transition, $2 \mathrm{p}\left({ }^{2} \mathrm{P}_{1 / 2}-{ }^{2} \mathrm{P}_{3 / 2}\right)$ in this shell. Table 1 details the energy levels 
used in the present calculations with energies taken from NIST (Kramida et al., 2015). Those in units of $\mathrm{cm}^{-1}$, which are given to a higher precision than those listed in $\mathrm{eV}$, are of use in determining the energy separation of the near-degenerate levels. The ordering of the levels used is that given by NIST apart from $4 \mathrm{~d}^{2} \mathrm{D}_{5 / 2}$ and $4 \mathrm{f}^{2} \mathrm{~F}_{5 / 2}$, where that of Aggarwal et al. (2017) is followed.

Tables 2 to 5 list the collisional excitation rate coefficients for the fine-structure electric dipole transitions of He II for collisions with the projectiles $p, d, t$ and $\alpha$-particles. These optically allowed transition rate coefficients are both larger, and expected to be more reliable than those for the forbidden transitions. We note that heavy particle collisional data for the intershell transitions were also checked, but their rate coefficients are small compared with the electron rate coefficients, being at least two orders of magnitude lower at the highest temperature considered in the present study $(21.7 \mathrm{eV})$. This is because the rate coefficients tend to peak when the momentum of the projectile, either electron or heavy particle, matches the change of momentum of the electron being excited. In electron collisions, with the projectile and target electrons having the same mass, this condition is met when the projectile energy, which must be sufficient to excite the transition, is $\sim k T_{e}$, this being of the order of the intershell transition energies. For heavy particles with their greater mass, the most favourable velocities are a factor $m_{e} / m_{p}$ smaller, this corresponding to energies that are lower by this fraction. Heavy particles are therefore most efficient at exciting transitions with smaller transition energies.

Significant differences are found between the proton impact results of Zygelman and Dalgarno (1987) and the present calculations for the $2 \mathrm{p}\left({ }^{2} \mathrm{P}_{1 / 2}-{ }^{2} \mathrm{P}_{3 / 2}\right)$ transition of He II. Hence it is important to consider the expected accuracy of the semi-empirical approach and the effect on the He II level populations of any discrepancies. Some indication is provided via comparisons with full quantal calculations, and several have been undertaken by Walling and Weisheit (1988). Their first is with Heil et al. (1982) for the proton impact excitation of the $2 s^{2} 2 p\left({ }^{2} \mathrm{P}_{1 / 2}-{ }^{2} \mathrm{P}_{3 / 2}\right)$ fine-structure ground state transition of $\mathrm{O} I V$, for which there is excellent agreement, to within a few per cent (see figure 4 of Walling and Weisheit). A second comparison is with the quantum mechanical calculations of Heil et al. (1983) for excitation of the fine-structure ground state $3 \mathrm{~s}^{2} 3 \mathrm{p}\left({ }^{2} \mathrm{P}_{1 / 2}{ }^{2} \mathrm{P}_{3 / 2}\right)$ transition of $\mathrm{Fe} \mathrm{XIV}$ by protons, the heavy particle collision first studied by Seaton (1964). Agreement is again within a few per cent at collision energies less than the ionization potential of Fe XIV (392 eV) the difference increasing to only $\sim 10 \%$ at energies of twice this value (see figure 5 of Walling and Weisheit).

A limitation of the semi-classical approach is evident in the treatment of the excitation of the fine-structure transitions within the $3 \mathrm{~s}^{2} 3 \mathrm{p}^{23} \mathrm{P}$ multiplet of Fe XIII. Since to first order the $3 \mathrm{~s}^{2} 3 \mathrm{p}^{2}\left({ }^{3} \mathrm{P}_{0-}{ }^{3} \mathrm{P}_{1}\right)$ transition does not occur, the two-state semi-classical cross section is zero. A close-coupling calculation for this three-state problem allows the ${ }^{3} \mathrm{P}_{0}{ }^{3} \mathrm{P}_{1}$ transition to be treated via the intermediate $J=2$ state, and Faucher (1975) provides quantal close-coupled results for proton impact excitation of these transitions. At low collision energies, up to the ionization potential of $361 \mathrm{eV}$, agreement for the $3 \mathrm{~s}^{2} 3 \mathrm{p}^{2}\left({ }^{3} \mathrm{P}_{1}{ }^{3} \mathrm{P}_{2}\right)$ transition is within $\sim 10 \%$. However, for the $3 \mathrm{~s}^{2} 3 \mathrm{p}^{2}\left({ }^{3} \mathrm{P}_{0^{-}}{ }^{3} \mathrm{P}_{2}\right)$ transition there are larger differences at all energies, the loss of flux due to the coupling with the forbidden $3 \mathrm{~s}^{2} 3 \mathrm{p}^{2}\left({ }^{3} \mathrm{P}_{0}{ }^{3} \mathrm{P}_{1}\right)$ transition having a greater effect (see figure 6 of Walling and Weisheit). A more recent paper by Burgess and Tully (2005) note an error in Faucher's derivation of the Born formula used to give the high energy behaviour of his cross sections. Burgess and Tully consider high energy proton excitation of electric quadrupole transitions, combining a semi-classical approach with the Born approximation (the initial and final states of the projectile being defined by plane waves) to give the correct high energy behaviour.

The same limitation of the semi-classical approach found for Fe XIII is seen for 
transitions within the $2 \mathrm{~s} 2 \mathrm{p}{ }^{3} \mathrm{P}$ multiplet of C III. Ryans et al. (1998) calculate the heavy particle rates for the fine-structure transitions within this multiplet using a close-coupled impact parameter method. Again, the $2 \mathrm{~s} 2 \mathrm{p}\left({ }^{3} \mathrm{P}_{0-}{ }^{3} \mathrm{P}_{1}\right)$ transition cannot be treated with the Walling and Weisheit (1988) semi-classical approach and, as for Fe XIII, a larger discrepancy is found for ${ }^{3} \mathrm{P}_{0}-{ }^{3} \mathrm{P}_{2}$ than for ${ }^{3} \mathrm{P}_{1}{ }^{3} \mathrm{P}_{2}$. In this case the comparisons are valuable in that they can be made for four projectiles, namely protons, deuterons, tritons and $\alpha$-particles, and similar results are obtained in all cases. Typically the cross sections agree within $\sim 25 \%$ and $40 \%$ up to collision energies of $\sim 150 \mathrm{eV}$ for the $2 \mathrm{~s} 2 \mathrm{p}\left({ }^{3} \mathrm{P}_{1}-{ }^{3} \mathrm{P}_{2}\right)$ and $2 \mathrm{~s} 2 \mathrm{p}\left({ }^{3} \mathrm{P}_{0}-{ }^{3} \mathrm{P}_{2}\right)$ transitions, respectively, and the rate coefficients within $\sim 20 \%$ and $35 \%$ up to temperatures of $90 \mathrm{eV}$, respectively. Figure 2 shows a comparison of the deuteron and $\alpha$-particle excitation cross sections and rate coefficients for some representative transitions.

Of particular relevance to the present study is a comparison with the quantum mechanical calculations of Zygelman and Dalgarno (1987) for the proton impact excitation of the $n=2$ shell fine-structure transitions of several H-like ions, including He II and Ar XVIII. As seen in figure 1, all three transitions occur in first-order and comparisons for Ar XVIII made by Walling and Weisheit (1988; see their figure 7) reveal good agreement (within 10\%) for the $2 p{ }^{2} \mathrm{P}_{1 / 2}-2 s{ }^{2} \mathrm{~S}_{1 / 2}$ transition, whose cross section is by far the largest. There is poorer agreement for the weaker excitations, particularly the $2 \mathrm{p}\left({ }^{2} \mathrm{P}_{1 / 2}{ }^{2} \mathrm{P}_{3 / 2}\right)$ quadrupole transition, the discrepancies decreasing with energy as the close-coupling effects diminish. For He II the discrepancies for the $2{ }^{2} \mathrm{~S}_{1 / 2}-2 \mathrm{p}{ }^{2} \mathrm{P}_{3 / 2}$ transition are similar to those found for Ar XVIII. However, there is no A-value available for the strong He II $2 p^{2} \mathrm{P}_{1 / 2}-2 \mathrm{~s}{ }^{2} \mathrm{~S}_{1 / 2}$ transition and an estimate is made by assuming good agreement with the results of Zygelman and Dalgarno, this being found for the transition in Ar XVIII. As can be seen in figure 3, which compares results for all three transitions of He II, more severe discrepancies are found for the weak electric quadrupole $2 \mathrm{p}\left({ }^{2} \mathrm{P}_{1 / 2}-{ }^{2} \mathrm{P}_{3 / 2}\right)$ transition than for Ar XVIII. Consequently, checks must be made in the population modelling for sensitivity to the quadrupole transitions.

\section{The collisional-radiative population model}

The energy levels within an ion are populated chiefly by electron collisional excitation and deexcitation and by radiative decay, as illustrated in the schematic energy level diagram shown in figure 4 . Within an $n$ shell, heavy particle collisions may also play a role. The population of the $i^{\text {th }}$ level, $n_{i}$, is therefore given by the rate equation

$$
\frac{d n_{i}}{d t}=n_{e} \sum_{j \neq i} n_{j} q_{j i}-n_{e} \sum_{j \neq i} n_{i} q_{i j}+n_{h p} \sum_{j \neq i} n_{j} q_{j i}^{h p}-n_{h p} \sum_{j \neq i} n_{i} q_{i j}^{h p}+\sum_{j>i} n_{j} A_{j i}-\sum_{j<i} n_{i} A_{i j}+n_{e} n_{z+1} \alpha_{R i}-n_{e} n_{z} s_{i} .
$$

Here $n_{e}$ and $n_{h p}$ are the electron and heavy particle densities, respectively, and $A_{i j}$ the A-values of a transition from level $i$ to $j$. The terms $n_{z}$ and $n_{z+1}$ are the densities of the hydrogenic species and fully stripped ions, respectively, with $\alpha_{R i}$ and $s_{i}$ representing recombination and ionization rate coefficients to and from level $i$, respectively. These processes are not included in the present analysis, and will be discussed in a subsequent paper. Recombination in particular is expected to have a significant effect on the level populations at temperatures below $\sim 3 \mathrm{eV}$. The adjustment of the populations within an ion due to collisions and radiative decay is usually rapid compared with processes such as the transport of ions within the plasma. Hence, steady-state will be assumed, i.e.

$$
\frac{d n_{i}}{d t}=0
$$

This leads to a set of simultaneous linear equations, which can be solved by matrix inversion 
for $n_{i} / n_{g}$, where $n_{g}$ is the ground-state population.

Figure 5 shows the populations as a fraction of the ground-state population calculated for levels within the $n=2-4$ shells of He II for a range of densities $\left(n_{e}=10^{16}-10^{22} \mathrm{~m}^{-3}\right)$ at a temperature of $3.4 \mathrm{eV}$, and in the case of the $n=4$ shell these are normalized to $n_{e}$. We note that $\alpha$-particle collisions are included in the calculation, with the assumption that the He ion density is $47 \%$ of the electron density. This allows both for the small number of He particles that are not fully stripped and for the low impurity concentrations normally observed in tokamak discharges fuelled only by He. It can be seen that the $2 \mathrm{~s}^{2} \mathrm{~S}_{1 / 2}$ level is metastable, the radiative decay to the $1 \mathrm{~s}^{2} \mathrm{~S}_{1 / 2}$ ground-state being small $\left(5.3 \times 10^{2} \mathrm{~s}^{-1}\right)$. This corresponds to the two photon decay (Tallents 1984) instead of the magnetic dipole transition for which the Avalue is $2.6 \times 10^{-3} \mathrm{~s}^{-1}$. Consequently, with decreasing density and fewer collisions, the population of this level flattens and becomes independent of density, rather than matching the $2 p{ }^{2} \mathrm{P}_{1 / 2}$ level population as occurs at higher densities. Despite its enhanced population, $2 \mathrm{~s}$ ${ }^{2} \mathrm{~S}_{1 / 2}$ has no significant effect on the radiation given the very low transition probabilities for its radiative decays. Its fractional population reached at low densities in this steady-state solution is dependent on the coupling of this level to $2 \mathrm{p}^{2} \mathrm{P}_{1 / 2}$, which was found as described in section 3. Similarly, the $3 \mathrm{~s}{ }^{2} \mathrm{~S}_{1 / 2}, 4 \mathrm{~s}{ }^{2} \mathrm{~S}_{1 / 2}$ and $5 \mathrm{~s}{ }^{2} \mathrm{~S}_{1 / 2}$ level populations are sensitive to the corresponding ${ }^{2} \mathrm{P}_{1 / 2}{ }^{2} \mathrm{~S}_{1 / 2}$ transition in the higher shells. Although no A-values are published for these transitions, estimates have been made by assuming a similar ${ }^{2} \mathrm{P}_{1 / 2}{ }^{2} \mathrm{~S}_{1 / 2} /{ }^{2} \mathrm{~S}_{1 / 2}{ }^{2} \mathrm{P}_{3 / 2}$ ratio in the cross sections as has been found for the $n=2$ shell, and $\alpha$-particle excitation rate coefficients calculated accordingly. The full and dashed lines in figure 5 indicate the differences found when these rates are included in the population model.

\subsection{The importance of fine-structure transitions}

The most reliable populations will be those derived using as many populating channels as possible. Consequently, it is of interest to determine the errors when the available atomic data are incomplete and without the imposition of any assumptions. Two cases will be considered. The first when only intershell electron collisional data are available, the second when both intershell and fine-structure electron collisional rate coefficients are included in the population model, but heavy particle rate coefficients are not used. Comparisons will be made with the full population model, which includes electron intershell transitions, plus electron and $\alpha$-particle impact rate coefficients for the fine-structure transitions. The $\alpha$ particle impact rate coefficients for the ${ }^{2} \mathrm{P}_{1 / 2}{ }^{2} \mathrm{~S}_{1 / 2}$ transitions, which particularly affect the populations of the ${ }^{2} \mathrm{~S}_{1 / 2}$ levels, are determined as described above. Figure 6 shows ratios of populations in the $n=2$ and 3 levels for the two cases considered along with the results from the full population model. It is clear from the figure that there are very significant differences (up to two orders of magnitude) when the atomic data are incomplete. Much reliance is therefore being placed on the assumption of the populations within an $n$ shell being in proportion to the statistical weights when incomplete sets of atomic data are used.

\subsection{Sensitivity to transitions between near-degenerate levels}

Another source of error investigated to ensure it will not seriously affect the accuracy of the results of the full population model is the sensitivity of the populations to the collisional rate coefficients between near-degenerate levels. An inspection of figure 5 reveals that including the rate coefficients of the transitions between the near-degenerate ${ }^{2} \mathrm{P}_{1 / 2}$ and ${ }^{2} \mathrm{~S}_{1 / 2}$ levels in the population model affects the derived populations. The ${ }^{2} \mathrm{D}_{3 / 2}$ and ${ }^{2} \mathrm{P}_{3 / 2},{ }^{2} \mathrm{~F}_{5 / 2}$ and ${ }^{2} \mathrm{D}_{5 / 2}$ and ${ }^{2} \mathrm{G}_{7 / 2}$ and ${ }^{2} \mathrm{~F}_{7 / 2}$ levels also form pairs with near-degeneracy. These levels are better connected to neighbouring ones and, hence, transitions between them are expected to be less 
important than in the case of the ${ }^{2} \mathrm{P}_{1 / 2}$ and ${ }^{2} \mathrm{~S}_{1 / 2}$. However, the question arises as to whether the high rate coefficients associated with these small energy transitions could affect the results. A check was undertaken by assuming that the same rate coefficients applied to these transitions as for ${ }^{2} \mathrm{P}_{1 / 2}-{ }^{2} \mathrm{~S}_{1 / 2}$ in the particular shell. Figure 7 shows the ratios of populations at a temperature of $3.4 \mathrm{eV}$ for levels in the $n=3$ and 4 shells, both including and excluding rate coefficients for all transitions between the near-degenerate $J=3 / 2,5 / 2$ and $7 / 2$ levels. It can be seen that at densities above $\sim 10^{18} \mathrm{~m}^{-3}$ the differences are $<5 \%$, and this is the case for most temperatures. The largest differences occur at either low $(\sim 0.34 \mathrm{eV})$ or high $(\sim 22 \mathrm{eV})$ temperatures, typically of up to $\sim 10 \%$, although greater discrepancies are found for the $4 \mathrm{f}$ ${ }^{2} \mathrm{~F}_{5 / 2}$ and $4 \mathrm{~d}{ }^{2} \mathrm{D}_{3 / 2}$ levels $(\sim 17 \%)$ and for $3 \mathrm{~d}^{2} \mathrm{D}_{3 / 2}(\sim 20 \%)$ at the highest temperatures considered. These discrepancies rapidly decrease with increasing density.

\subsection{Sensitivity to electric quadrupole transition rate coefficients}

A significant difference was found between the results of Zygelman and Dalgarno (1987) and the present heavy particle calculations for proton impact of the $2 \mathrm{p}\left({ }^{2} \mathrm{P}_{1 / 2}-{ }^{2} \mathrm{P}_{3 / 2}\right)$ electric quadrupole transition of He II, illustrated in figure 3c. This can result in up to two orders of magnitude difference in the derived excitation rate coefficients. To check the sensitivity of the population modelling to the electric quadrupole transition rate coefficients, comparisons were made in which all electric quadrupole rate coefficients were increased by a factor of 100 . Comparisons of populations for levels in the $n=3$ and 4 shells at a temperature of $3.4 \mathrm{eV}$ are shown in figure 8 . The differences are smaller than $10 \%$, and above densities of $\sim 10^{18} \mathrm{~m}^{-3}$ the discrepancies are typically $\sim 5 \%$ or less.

\subsection{Criterion for the statistical population of the $n$ shells}

Given the significant differences found when the atomic data are incomplete, as illustrated in section 4.1, it is important to reassess the validity of the assumption that the level populations within an $n$ shell are in proportion to the statistical weights for the densities encountered in large plasma machines. Figure 9 shows the minimum densities required to ensure a statistical population, plotted as a function of temperature, with the full lines the results of the present population modelling. In all shells, it is the ${ }^{2} \mathrm{~S}_{1 / 2}$ level that sets the limit needed to achieve a statistical population. However, note that transitions from this level are weak and, therefore, contribute little to the observed line radiation. Consequently, the densities required to ensure that the ${ }^{2} \mathrm{P}_{1 / 2}$ level was populated statistically compared with all levels apart from ${ }^{2} \mathrm{~S}_{1 / 2}$ was checked, but were found to be very similar.

Since there are various uncertainties in the calculations, it is reasonable to allow a $5 \%$ error margin in the populations from a strict statistical population. These results are also shown in figure 9 together with the results of Sampson (1977) and Tallents (1985); the latter two will be discussed in section 7.2. It can be seen from the figure that for the densities of interest, $\sim 10^{18}-10^{21} \mathrm{~m}^{-3}$, the populations, particularly in the lower shells, are not in statistical equilibrium even allowing for a $5 \%$ error margin in the populations.

In applications of the theoretical results to observed spectra, calculations of line intensities are important rather than those for the level populations. The spectrally-unresolved He II lines consist of a number of components, and it is expected that the transitions forming these may to some extent compensate for deviations in the individual level populations. It is therefore appropriate to consider the errors that would result in the intensities from making the assumption of statistical populations, even at densities where this does not hold. Figure 10 shows the ratio of line intensities when this assumption is made to those when the full population model is used for the first four lines of the Lyman series at the lowest density of 
interest $\left(10^{18} \mathrm{~m}^{-3}\right)$. It can be seen that the errors are less than $\sim 15 \%$, except at the lowest temperature of $0.34 \mathrm{eV}$. In particular the Lyman- $\alpha$ intensity, which provides most of the spectral line power radiated by He II ( $90 \%)$, differs by at most $3 \%$. That this line and hence the total He II line power are not significantly affected is a valuable result, given the wide use made of the contribution of the total line power to the energy loss in transport studies. The line showing the biggest errors is the Lyman- $\delta, n=1-5$, and figure 11 shows the ratio for this feature as a function of density. Again, the differences are smaller than $11 \%$ at all but the lowest temperature, and, as is the case for the other lines, the ratio rapidly approaches unity with increasing density. These errors are expected to be similar to the typical accuracies of the R-matrix calculations of electron collisional rate coefficients. Differences between the various calculations of these coefficients, which give some indication of their likely accuracies, are discussed in section 7.1.

\section{Spectral line intensity ratios}

Although in a number of applications it is necessary to use absolutely-calibrated spectral line intensities when comparing theory and experiment, there is an advantage in using line intensity ratios whenever possible. Such ratios avoid the need for an absolutely calibrated spectrometer, a relative calibration with wavelength being sufficient. If the lines are from the same ionization stage of a particular element then the emitting volume is usually the same. This avoids the need for determining the volume and its electron density, both of which can have significant uncertainties. There can also be advantages with regard to the atomic physics, since factors such as the ionization balance that can influence level populations will largely cancel when line intensity ratios are taken. All of these aspects lead to more accurate measurements for comparison with theory.

\subsection{Intershell transition ratios}

In many instances the observed $\mathrm{H}$-like spectral features are not resolved into their individual component transitions. However, ratios of the unresolved, intershell transitions are still of interest, as they are, for example, temperature sensitive. Examples are shown in figures 12 and 13, namely the $n=1-2 / 1-3$ ratio at wavelengths of $303.8 \AA$ and $256.3 \AA$ and $n$ $=3-4 / 3-5$ ratio at $4685.8 \AA$ and $3203.1 \AA$, respectively. In these figures the full lines represent the results of a population model that includes $\alpha$-particle impact rate coefficients, the dashed lines a model that only considers electron collisions, and the dotted lines only intershell transitions. Black lines indicate the high density limit of these ratios, calculated at $10^{27} \mathrm{~m}^{-3}$, when the states are populated strictly in proportion to their statistical weights. Transition energies are significant compared to the electron temperatures considered, requiring a term to be included relating to the Boltzmann distribution, $\exp \left(-\Delta E / k T_{e}\right)$, where $\Delta E$ is the transition energy. The ratio of these Boltzmann terms gives the high density limit curve its exponential shape. Of the He II lines in the spectrum, the $n=1-2$ (303.8 $\AA)$ and 1-3 $(256.3 \AA)$ are the most intense, and hence should be useful for electron temperature measurements and calibration purposes. It can be seen from figure 12 that $\alpha$-particle impact has a comparatively small effect on this ratio, although a model that includes even electron fine-structure transitions is much closer to the expected high density behaviour than an intershell only model and approaches the high density limit with increasing density. In the case of $n=3-4$ / 3-5 (figure 13), the ratio is still seen to be strongly temperature sensitive, in this case below temperatures of $\sim 8 \mathrm{eV}$, and the dependence on density is more important than the population model in determining the ratio. 


\subsection{Branching ratios}

When lines in a ratio have common upper levels, it is described as a branching ratio. In the absence of opacity, the value of the ratio depends only on the A-values of the transitions involved. Such ratios are particularly valuable in connecting different spectral regions. One common use is in the sensitivity calibrations of short wavelength spectrometers, for which the implementation of a standard source is experimentally difficult. In the case of the H-like spectra in which the lines are not resolved into their components, these ratios are not true branching ratios, since additional transitions are included in the longer wavelength line, the corresponding short wavelength transitions being forbidden and consequently weak. This means that, unlike true branching ratios that are temperature insensitive, the so-called 'branching ratios' in H-like spectra can depend on temperature. They hence require full population modelling at densities where the assumption of the level populations being in proportion to their statistical weights does not apply. Figure 14 shows the He II 'branching ratio', $n=1-4$ / 3-4, connecting the visible spectral region at a wavelength of $4685.8 \AA$ with the VUV at $243.0 \AA$. At a density of $10^{18} \mathrm{~m}^{-3}$ the ratio as determined using the full population model is nearly $50 \%$ higher than if a statistical population of the fine-structure levels is assumed. The inclusion of rate coefficients for both electron and $\alpha$-particle impact finestructure transitions in the population model is important in bringing the ratio closer to the high density limit of 1.42 .

\subsection{Fine structure ratios}

In a high resolution spectrum it is possible to resolve the two components of the Lyman- $\alpha$ line at $303.8 \AA$, in which case a full $\mathrm{j}$-resolved population model is essential in calculating their ratio. Figure 15 a shows the ratio of the two components, $\beta_{1}=\left(1 \mathrm{~s}^{2} \mathrm{~S}_{1 / 2}-2 \mathrm{p}^{2} \mathrm{P}_{1 / 2} / 1 \mathrm{~s}^{2} \mathrm{~S}_{1 / 2}\right.$ $2 p^{2} \mathrm{P}_{3 / 2}$ ), as a function of density at a number of different temperatures. Densities outside the immediate range of interest are illustrated to show the full behaviour of the ratio. It can be seen that there is both a temperature and, for limited density ranges, a density dependence. At high densities the ratio approaches the value $(0.5)$ corresponding to the states being populated statistically, although in this case the Boltzmann terms cancel leading to a temperatureindependent ratio. By contrast, at low densities collisions between excited states become unimportant in determining the populations and the ratio tends to that of the collisional excitation rate coefficients from the ground state, collisional excitation being immediately followed by a radiative decay. This is often referred to as the coronal regime. The collisional excitation rate coefficients from the ground state are in the ratio of 1:2 (to within a few per cent), leading to a line ratio of 0.5 at low densities. In the intermediate regime, with densities of $\sim 10^{11}-10^{22} \mathrm{~m}^{-3}$, collisions between the excited states within an $n$ shell are important in determining the populations, and hence line ratios. It is interesting to contrast this behaviour with more highly ionized ions of elements such as $\mathrm{C}$ and $\mathrm{N}$. The stronger nuclear forces and wider spacing of the energy levels in these ions reduces the importance of the collisions between excited states compared with radiative decay. This results in the coronal regime occurring at the higher densities typical of tokamak plasmas (e.g. see Lawson et al., 2011 for C IV).

Although the Balmer- $\alpha$ and Balmer- $\beta$ lines at wavelengths of 1640.5 and $1215.2 \AA$, respectively, are both formed from 7 significant components, their wavelengths are such that they separate into 2 groups of lines, one ending in the $2 \mathrm{p}^{2} \mathrm{P}_{3 / 2}$ level and the other in $2 \mathrm{p}{ }^{2} \mathrm{P}_{1 / 2}$ and $2 \mathrm{~s}{ }^{2} \mathrm{~S}_{1 / 2}$. Again, determining the ratio of the two groups requires full $J$-resolved population modelling. The $\beta_{2}$ ratio is defined as $\left(2 \mathrm{p}{ }^{2} \mathrm{P}_{3 / 2}-3 \mathrm{~s}, 3 \mathrm{p}, 3 \mathrm{~d}\right) /\left(2 \mathrm{p}{ }^{2} \mathrm{p}_{1 / 2}, 2 \mathrm{~s}{ }^{2} \mathrm{~S}_{1 / 2}-\right.$ $3 \mathrm{~s}, 3 \mathrm{p}, 3 \mathrm{~d})$ and the $\beta_{3}$ ratio as $\left(2 \mathrm{p}^{2} \mathrm{P}_{3 / 2}-4 \mathrm{~s}, 4 \mathrm{p}, 4 \mathrm{~d}\right) /\left(2 \mathrm{p}^{2} \mathrm{p}_{1 / 2}, 2 \mathrm{~s}{ }^{2} \mathrm{~S}_{1 / 2}-4 \mathrm{~s}, 4 \mathrm{p}, 4 \mathrm{~d}\right)$. Figures $15 \mathrm{~b}$ and 
$15 \mathrm{c}$ show the dependence of $\beta_{2}$ and $\beta_{3}$ as a function of density at a number of temperatures. It can be seen that the smaller energy separations in the higher $n$ shells ensures that a statistical population is achieved at progressively lower densities.

The Paschen- $\alpha$ line occurs in the visible at a wavelength of $4685.8 \AA$. In this region a high spectral resolution is easily achieved, making this line well suited to profile studies. The $\gamma$ ratio is defined as that of the two components which dominate the Paschen- $\alpha$ line profile. The first includes the transitions $3 \mathrm{p}^{2} \mathrm{P}_{1 / 2}-4 \mathrm{~d}^{2} \mathrm{D}_{3 / 2}$ and $3 \mathrm{~s}^{2} \mathrm{~S}_{1 / 2}-4 \mathrm{p}{ }^{2} \mathrm{P}_{3 / 2}$, and the second $3 \mathrm{p}^{2} \mathrm{P}_{3 / 2^{-}}$ $4 d^{2} \mathrm{D}_{3 / 2}, 4 \mathrm{~d}^{2} \mathrm{D}_{5 / 2}, 3 \mathrm{~d}^{2} \mathrm{D}_{3 / 2}-4 \mathrm{p}^{2} \mathrm{P}_{3 / 2}, 4 \mathrm{f}^{2} \mathrm{~F}_{5 / 2}$ and $3 \mathrm{~d}^{2} \mathrm{D}_{5 / 2}-4 \mathrm{f}^{2} \mathrm{~F}_{5 / 2}, 4 \mathrm{f}^{2} \mathrm{~F}_{7 / 2}$. Note that this excludes the weaker $3 p{ }^{2} \mathrm{P}_{1 / 2}-4 s^{2} \mathrm{~S}_{1 / 2}$ and $3 \mathrm{~s}^{2} \mathrm{~S}_{1 / 2}-4 \mathrm{p}{ }^{2} \mathrm{P}_{1 / 2}$ transitions, and also $3 \mathrm{~d}^{2} \mathrm{D}_{5 / 2}-4 \mathrm{p}^{2} \mathrm{P}_{3 / 2}, 3 \mathrm{p}^{2} \mathrm{P}_{3 / 2}-$ $4 s^{2} \mathrm{~S}_{1 / 2}$ and $3 \mathrm{~d}^{2} \mathrm{D}_{3 / 2}-4 \mathrm{p}{ }^{2} \mathrm{P}_{1 / 2}$, these forming 2 groups of lines at somewhat longer wavelengths to the main components. Although weaker, the difference when these transitions are included in the ratio is significant as can be seen in figure $15 \mathrm{~d}$, which shows the $\gamma$ ratio modelled in a similar way and for similar parameters to the other fine-structure ratios. For all these ratios, $\alpha$-particle impact rate coefficients were included in the population modelling with an assumed ion density of $47 \%$ of the electron density.

Whereas the $\beta_{1}$ line ratio for He II can be used at tokamak densities as a diagnostic of density and temperature, it can be seen from figures $15 b-15 d$ that $\beta_{2}, \beta_{3}$ and $\gamma$ have similar temperature and density behaviours, but falling at lower densities. They are shown here for completeness, but would not be expected to be useful for diagnosing tokamak plasmas. The results of Tallents (1985) are included in figure 15 for comparison as they will be discussed in section 7.3.

\section{Differing electron and ion temperatures}

The sensitivity of the population model to differing ion and electron temperatures is considered by comparing results with the ion temperature set to be twice the electron temperature with those calculated for equal temperatures. As would be expected the ${ }^{2} \mathrm{~S}_{1 / 2}$ levels are the most sensitive to changes in the $\alpha$-particle rate coefficients. The higher rate coefficients resulting from the higher ion temperatures provide a better connection of these levels with adjacent ones, thereby depleting their populations. However, as shown in figure 16 , where we plot the ratio of the level populations with the increased ion temperature to those for equal temperatures, the differences for $2 \mathrm{~s}{ }^{2} \mathrm{~S}_{1 / 2}$ and $3 \mathrm{~s}{ }^{2} \mathrm{~S}_{1 / 2}$ are less than $25 \%$ in the parameter space of interest. This translates into a smaller variation in the intensities of observable lines, with the greatest (which is at most $5 \%$ ) being for the $1 \mathrm{~s}{ }^{2} \mathrm{~S}_{1 / 2}-2 \mathrm{p}{ }^{2} \mathrm{P}_{1 / 2}$ transition. It follows that changes to the line intensity ratios are also small, the largest being $\sim 9 \%$ for $\beta_{1}$ (figure 17 ). Other line ratios show no more than a $\sim 4 \%$ change resulting from a factor of 2 variation in ion temperature.

\section{Comparisons with previous work}

As outlined in section 2, there are only a few published atomic physics calculations for He II, despite the importance of this ion in both laboratory experiments and astrophysical applications. It is of interest to make comparisons with the available data and analyses, particularly with the inclusion of heavy particle collisions in the present collisional-radiative population model.

\subsection{R-matrix calculations of electron collisional excitation rate coefficients}

Our comparison with previous publications containing electron collisional excitation rate 
coefficients is undertaken in two ways. Firstly, it is interesting to see the differences in the results from the available calculations, and we do this via a comparison of the published effective collision strengths. However, since these data are used within a population model to obtain line intensities, combined with the fact that most of the calculations are expected to be employed under the assumption of a statistical population of the levels within $n$ shells, the effective collision strengths do not translate directly into intershell line intensities. Consequently, it is also of interest to compare the spectrally-unresolved line intensities calculated under this assumption with those derived using the calculations of Aggarwal et al. (2017), for which this assumption is unnecessary. This will highlight differences that a user of the atomic data will encounter.

The most reliable calculations are expected for transitions between the $n=1$ to 4 shells. Hence our comparison will focus on these, even if results are also given for transitions to $n=$ 5. These calculations should provide data accurate to $\sim 10-20 \%$ for the stronger transitions, and the compensation already noted between the different components when deriving a line intensity should ensure that the latter show a similar degree of reliability. However, what is very apparent in this comparison is the variation between the results of different calculations.

The l-resolved, He II atomic data contained in the ADAS 97, ADF04 dataset (hlike_mom97\#he1.dat) are based on the assessment given by Callaway (1994) of the calculations available at that time. Although there is agreement (to within $\sim 15 \%$ ) between the ADAS 97 effective collision strengths and those of Aggarwal et al. (2017) for some transitions, there are also a number showing differences of up to a factor of 2 , while 7 show even larger discrepancies, notably factors of $12,5,5$, and 7 for $1 \mathrm{~s}^{2} \mathrm{~S}-4 \mathrm{f}^{2} \mathrm{~F}, 3 \mathrm{~s}{ }^{2} \mathrm{~S}-4 \mathrm{~s}{ }^{2} \mathrm{~S}, 3 \mathrm{p}$ ${ }^{2} \mathrm{P}-4 \mathrm{p}{ }^{2} \mathrm{P}$ and $3 \mathrm{~d}^{2} \mathrm{D}-4 \mathrm{f}{ }^{2} \mathrm{~F}$, respectively. In his survey, Callaway includes the earlier calculations of Aggarwal et al. (1991). A comparison of their data with the Aggarwal et al. (2017) results shows agreement, generally, to within a factor of 2 , although there are a few transitions showing larger differences. In particular, the $1 \mathrm{~s}^{2} \mathrm{~S}-$ and $2 \mathrm{~s}{ }^{2} \mathrm{~S}-4 \mathrm{~s}^{2} \mathrm{~S}$ transitions differ by factors of 3.4, while $1 \mathrm{~s}{ }^{2} \mathrm{~S}-, 2 \mathrm{~s}{ }^{2} \mathrm{~S}$ and $3 \mathrm{~s}{ }^{2} \mathrm{~S}-4 \mathrm{p}{ }^{2} \mathrm{P}$ differ by factors of 3.8, 2.9 and 2.6 , respectively. These comparisons show systematic differences in that the effective collision strengths for the earlier calculations for transitions from the ${ }^{2} \mathrm{~S}$ levels tend to be smaller than the later results, whereas those for transitions from other levels tend to be larger. Ballance et al. (2003), whose full results are available in the ADAS database (ADF04 dataset hlike_cpb03\#he1.dat), investigate the importance of continuum coupling using the R-matrix with pseudo-states method for several hydrogenic ions, again presenting $l$-resolved effective collision strengths. There is agreement for all transitions to within a factor of 2 and typically within $30 \%$. However, again, there is a tendency for the effective collision strengths for transitions from the ${ }^{2} \mathrm{~S}$ levels to be smaller than those of Aggarwal et al. (2017), and those from other levels to be larger. Since the introduction of pseudo-states is expected, if anything, to lead to a decrease in the effective collision strength, the differences found cannot simply be due to the use of pseudo-states. The coupling to high bound and continuum states is expected to be greatest at higher temperatures for transitions with the largest energy separation and which end in states close to the ionization limit. Similar discrepancies are observed at all temperatures. The wide variation between different calculations is illustrated in figure $18 \mathrm{a}$, where we plot ratios of the effective collision strengths from these three datasets to the results of Aggarwal et al. (2017) for transitions from the ground state, these being crucial for accurately modelling the populations of the excited levels.

Although they only have a small temperature range $(0.137-1.72 \mathrm{eV})$, the results of Kisielius et al. (1996) are of interest as they are the only other calculations of effective collision strengths that are $J$-resolved. Over this limited temperature range good agreement (within $\sim 10 \%$ ) is found for many transitions with the results of Aggarwal et al. (2017). The most significant exceptions are transitions to the $4 \mathrm{~d}^{2} \mathrm{D}_{5 / 2}$ and $4 \mathrm{f}^{2} \mathrm{~F}_{5 / 2}$ levels, and in two cases 
to $4 \mathrm{f}^{2} \mathrm{~F}_{7 / 2}$, where the differences can be up to a factor of 3.7 . Figure $18 \mathrm{~b}$ illustrates this by showing the ratio of the effective collision strengths of Kisielius et al. to those of Aggarwal et $a l$. for transitions from the ground state.

In the case of the line intensities, results using the calculations of Ballance et al. (2003) and the widely-employed ADAS 97 dataset are compared with those of Aggarwal et al. (2017). For the former datasets, line intensities are calculated assuming that states within an $n$ shell are statistically populated, although the comparison is with line intensities derived from the calculations of Aggarwal et al. (2017) for which this assumption is not used. Heavy particle collisions are also included in the latter.

Again, concentrating on transitions between the $n=1$ to 4 shells, there are differences between the results of Ballance et al. (2003) and Aggarwal et al. (2017) of up to a factor of 2, with the former being smaller. Although not expected from a comparison of the effective collision strengths, the agreement of Aggarwal et al. with the ADAS 97 data is somewhat better (within $\sim 35 \%$ ). Except for the Lyman- $\alpha, n=1-2$ transition, the ADAS 97 line intensities are again found to be smaller than those of Aggarwal et al. Figure 19a shows ratios of intensities from the two calculations compared with those of Aggarwal et al. for lines that form the Lyman series, $n=1-2$ to 4 . In figure $19 \mathrm{~b}$ we present a comparison of the Balmer series, $n=2-3$ and 4 lines, together with the first member of the Paschen series, $n=$ $3-4$. These are shown at densities ranging from $10^{18}-10^{22} \mathrm{~m}^{-3}$. For completeness, figure 20 shows the corresponding diagram for the Lyman series for ratios of line intensities derived from the ADAS 97 and Ballance et al. datasets. The latter intensities are smaller than those from ADAS 97, with differences of up to $\sim 40 \%$. Note that only ratios of the Lyman series lines are illustrated, since both the ADAS 97 and Ballance et al. calculations require a statistical population of the levels in the $n$ shells. Hence, ratios of the Balmer and Paschen series lines overlay those of the Lyman series.

Of importance in this comparison is the good agreement (within 10\%) found for the Lyman- $\alpha, n=1-2$ transition among all calculations. This line accounts for $\sim 90 \%$ of the power radiated by He II over a wide temperature range, and is therefore a crucial input to the various transport simulations that involve He fuel. However, it is also apparent that there are increasing differences for higher series members, typically $\sim 20 \%$ for lines from the $n=3$ levels and $\sim 25-35 \%$ for those from the $n=4$ ones.

As would be expected the differences are greater for transitions involving the $n=5$ levels. The effective collision strengths of ADAS 97 show discrepancies of typically up to a factor of 5 when compared with the Aggarwal et al. (2017) data, whereas the differences are smaller (factors of up to 4) for the comparison with the Ballance et al. results. Of more importance for users are comparisons of the line intensities. At densities of $10^{18}-10^{20} \mathrm{~m}^{-3}$, the ADAS 97 and Ballance et al. intensities differ by typically a factor of 2 from those of Aggarwal et al.

The discrepancies among the various calculations of effective collision strength summarised above are discussed further and explained in detail by Aggarwal et al. (2017). These authors also assess the accuracy of their results, which they estimate to be probably better than $20 \%$ for the majority of transitions, and 30\% for the remainder. Hence the He II models presented here based on the Aggarwal et al. atomic data should be the most reliable.

\subsection{Criterion for the statistical population of the $n$ shells}

Given the importance placed on the assumption that the level populations within an $n$ shell are in proportion to their statistical weights, a comparison with previously published criteria is of interest. Sampson (1977) used a semi-classical approach based on the impact parameter method of Seaton (1962) to derive rate coefficients for both electron and heavy 
particle collisions. Using these coefficients, he derived a formula giving the criterion for a statistical population over a wide range of atomic number $Z$. For He, the formula, with the units of $T_{e}$ and $n_{e}$ converted to $\mathrm{eV}$ and $\mathrm{m}^{-3}$, respectively, is

$$
3.73 \times 10^{-24} n^{8.5} T_{e}^{1 / 4} n_{e} \geq 1,
$$

the limiting densities for the $n=2-5$ shells being included in figure 9 . It can be seen that there are significant differences between these data and the present results, even allowing for a 5\% error margin. Since the A-values used by Sampson are expected to be similar to those employed in the present study, the discrepancies must be due to differences in the collisional excitation rate coefficients. As might be expected, the limiting densities are not particularly sensitive to the intershell excitation rate coefficients, but are to the fine-structure ones. The present rate coefficients, both electron and heavy particle, need to be increased by a factor of $\sim 100$ to match the magnitude of the Sampson result for the $n=2$ shell and its gradient with $T_{e}$. We note that Sampson derives minimum densities of $\sim 10^{21}$ and $2 \times 10^{19} \mathrm{~m}^{-3}$ for the $n=2$ and 3 shells, respectively. This implies that for the densities of interest in tokamaks $\left(10^{18}-10^{21} \mathrm{~m}^{-3}\right)$ neither the $n=2$ or 3 levels are in local thermodynamic equilibrium. However, the present results set the minimum densities significantly higher at $\sim 7 \times 10^{22}$ and $5 \times 10^{21} \mathrm{~m}^{-3}$.

Tallents (1985) also gives formulae for the densities below which the level populations of the $n=2-4$ shells deviate from a statistical weighting. In this case the fine-structure coefficients are evaluated following Shevelko et al. (1977), who use the Born approximation for dipole allowed transitions. Intershell rate coefficients are taken from Golden et al. (1981) and Clark et al. (1982), who employ the Coulomb-Born-Oppenheimer method. No temperature dependence is included by Tallents, the critical density being given as $\sim 3 \times 10^{20} Z^{8}$ $\mathrm{m}^{-3}, 3 \times 10^{19} \mathrm{Z}^{8} \mathrm{~m}^{-3}$ and $3 \times 10^{18} \mathrm{Z}^{8} \mathrm{~m}^{-3}$ for the $n=2,3$ and 4 shells, respectively. These data are also included in figure 9 and are seen to be in better agreement with the present calculations.

\subsection{Fine-structure line ratios}

Tallents (1985) investigated the $\beta_{1}, \beta_{2}, \beta_{3}$ and $\gamma$ fine-structure line ratios in the H-like ions of $\mathrm{He}, \mathrm{C}$ and $\mathrm{Mg}$. His analysis considered both a recombining plasma, such as would be found, for example, in a laser-produced plasma, and the steady-state case in which there is a significant population in the ground state of the ion. A comparison is made with his steadystate case in which the He ions are fully ionized, the ion density being $50 \%$ of $n_{e}$. As can be seen in figure 15, good agreement between the results of Tallents and the present study is found for the $\beta$ ratios in the intermediate density regime. The discrepancies for $\beta_{1}$ and $\beta_{2}$ are less than $\sim 10 \%$, and for $\beta_{3}$ only $\sim 14 \%$, although there is a much larger difference for the $\gamma$ ratio of a factor of $\sim 3$. This is unexpected since both $\beta_{3}$ and $\gamma$ involve transitions from the $n=$ 4 shell. However, the ratios are dominated by transitions from different levels within the shell; in particular both $4 \mathrm{f}^{2} \mathrm{~F}$ levels are important for transitions in the $\gamma$ ratio but are absent from $\beta_{3}$. A difference in the calculated populations of a factor of 4 for these two levels would explain this discrepancy.

\section{Conclusions}

The importance of helium as a fuel, minority gas and product of DT fusion reactions makes an understanding of its atomic physics essential. An assessment of the available atomic data for the H-like species of helium, He II, highlights a need for heavy particle collisional excitation rate coefficients to enable the level populations to be modelled fully to 
determine reliable line intensities. Heavy particle collisional excitation data has been generated using the method of Walling and Weisheit (1988), and are listed for the optically allowed fine-structure transitions with projectiles $\mathrm{p}, \mathrm{d}, \mathrm{t}$ and $\alpha$-particles. Population modelling demonstrates the importance of fine-structure transition rate coefficients, and allows the assumption of the statistical population of levels within an $n$ shell to be reassessed with the most recent atomic data. This assumption is often made when the atomic data for the fine-structure transitions are not available. In agreement with the study of Tallents (1985), it is found that this assumption is not valid for the spectroscopic levels (within shells $n=1-5$ ) at tokamak densities $\left(10^{18}-10^{21} \mathrm{~m}^{-3}\right)$. However, fortuitously, different components within the spectroscopically-unresolved He II lines do tend to compensate, allowing this technique to be used at densities at which the assumption no longer applies. The effect this has on line intensities is quantified, as are a number of other possible sources of error in the population modelling. Mechanisms such as ionization and recombination will be considered in a subsequent paper.

Line intensity ratios can provide a more accurate comparison with experiment than absolutely-calibrated line intensities, and the intershell, the so-called 'branching ratios', plus the $\beta_{1}, \beta_{2}, \beta_{3}$ and $\gamma$ fine-structure ratios are discussed. Of the latter, only $\beta_{1}$ is likely to be of diagnostic use at tokamak densities, while the intershell ratios are found to be temperature dependent. It is shown that differing ion and electron temperatures are not expected to lead to significant errors in the calculated ratios beyond those expected from other sources. Comparisons of previously published R-matrix calculations of electron collisional rate coefficients highlight significant variations, which in turn lead to differences in the resultant line intensities for all but the $n=2$ shell. These differences, typically $\sim 20 \%$ for $n=3$ levels, $\sim 25-35 \%$ for $n=4$ and a factor of $\sim 2$ for transitions involving $n=5$, are larger than other expected uncertainties. Of the available calculations, the results of Aggarwal et al. (2017) are considered to be the most reliable, these authors suggesting an accuracy of better than $20 \%$ for the majority of the transitions. It is noted, however, that all the calculations agree to within $10 \%$ for the intensity of the Lyman- $\alpha$ line and there is good compensation between the two components of this line when a statistical population is supposed. This is an important result given the contribution of this line $(\sim 90 \%)$ to the total He II line power, which is widely used to predict the power loss term in transport modelling.

This work has been carried out within the framework of the EUROfusion Consortium and has received funding from the Euratom research and training programme 2014-2018 under grant agreement No. 633053 and from the RCUK [grant number EP/P012450/1]. To obtain further information on the data and models underlying this paper please contact PublicationsManager@ukaea.uk. The views and opinions expressed herein do not necessarily reflect those of the European Commission. 


\section{References}

Aggarwal K M, Berrington K A, Kingston A E and Pathak A, 1991, J. Phys. B, 24, 1757

Aggarwal K M, Igarashi A, Keenan F P and Nakazaki S, 2017, Atoms, 5, 19

Anderson H, Ballance C P, Badnell N R and Summers H P, 2000, J. Phys. B, 33, 1255

Anderson H, Ballance C P, Badnell N R and Summers H P, 2002, J. Phys. B, 35, 1613

Ballance C P, Badnell N R and Smyth E S, 2003, J. Phys. B, 36, 3707

Burgess A and Summers H P, 1976, Mon. Not. R. Astron. Soc., 174, 345

Burgess A and Tully J A, 2005, J. Phys. B, 38, 2629

Callaway J, 1994, ADNDT, 57, 9

Clarke R E H, Sampson D H and Goett S J, 1982, Astrophys. J. Suppl., 49, 545

Faucher P, 1975, J. Phys. B, 8, 1886

Golden L B, Clark R E H, Goett S J and Sampson D H, 1981, Astrophys. J. Suppl., 45, 603

Hamada K, Aggarwal K M, Akita K, Igarashi A, Keenan F P and Nakazaki S, 2010, ADNDT, 96, 481

Heil T G, Green S and Dalgarno A, 1982, Phys Rev A, 26, 3293

Heil T G, Kirby K and Dalgarno A, 1983, Phys Rev A, 27, 2826

Jitrik O and Bunge C F, 2004, J. Phys. Chem. Ref. Data, 33, 1059

Kisielius R, Berrington K A and Norrington P H, 1996, Astron. Astrophys. Suppl. Ser., 118, 157

Kramida A, Ralchenko Yu, Reader J and NIST Team, 2015, NIST Atomic Spectra Database (ver. 5.3), http://physics.nist.gov/asd, National Institute of Standards and Technology, Gaithersburg, MD

Lawson K D, Aggarwal K M, Coffey I H, Keenan F P, O'Mullane M G, Ryć L and Zacks J, 2011, Plasma Phys. Control. Fusion, 53, 015002

Ryans R S I, Foster-Woods V J, Copeland F, Keenan F P, Matthews A and Reid R H G, 1998, ADNDT, 70, 179

Sampson D H, 1977, J. Phys. B, 10, 749

Seaton M J, 1962, Proc. Phys. Soc. 79, 1105

Seaton M J, 1964, Mon. Not. R. Astron. Soc., 127, 191

Shevelko V P, Skobelev I Y and Vinogradov A V, 1977, Phys. Scr. 16, 123

Summers H P, 2004, 'The ADAS User Manual, version 2.6, http://adas.phys.strath.ac.uk'

Tallents G J, 1984, J.Phys. B, 17, 3677

Tallents G J, 1985, J. Phys. B, 18, 3299

Walling R S, Weisheit J C, 1988, Physics Reports, 162, 1

Wiese W L and Fuhr J R, 2009, J. Phys. Chem. Ref. Data, 38, 565

Zygelman B and Dalgarno A, 1987, Phys Rev A, 35, 4085 
Table 1. He II energy levels with energies from the NIST database.

\begin{tabular}{|c|c|c|c|c|}
\hline Index & Configuration & Level & Energy (cm & Energy (eV) \\
\hline $\mathbf{1}$ & $1 \mathrm{~s}$ & ${ }^{2} \mathrm{~S}_{1 / 2}$ & 0.0 & 0.0 \\
\hline $\mathbf{2}$ & $2 \mathrm{p}$ & ${ }^{2} \mathrm{P}_{1 / 2}$ & 329179.29359 & 40.8130305 \\
\hline $\mathbf{3}$ & $2 \mathrm{~s}$ & ${ }^{2} \mathrm{~S}_{1 / 2}$ & 329179.76197 & 40.8130886 \\
\hline $\mathbf{4}$ & $2 \mathrm{p}$ & ${ }^{2} \mathrm{P}_{3 / 2}$ & 329185.15075 & 40.8130305 \\
\hline $\mathbf{5}$ & $3 \mathrm{p}$ & ${ }^{2} \mathrm{P}_{1 / 2}$ & 390140.82463 & 48.3712970 \\
\hline $\mathbf{6}$ & $3 \mathrm{~s}$ & ${ }^{2} \mathrm{~S}_{1 / 2}$ & 390140.96418 & 48.3713143 \\
\hline $\mathbf{7}$ & $3 \mathrm{~d}$ & ${ }^{2} \mathrm{D}_{3 / 2}$ & 390142.55723 & 48.3715118 \\
\hline $\mathbf{8}$ & $3 \mathrm{p}$ & ${ }^{2} \mathrm{P}_{3 / 2}$ & 390142.56009 & 48.3715122 \\
\hline $\mathbf{9}$ & $3 \mathrm{~d}$ & ${ }^{2} \mathrm{D}_{5 / 2}$ & 390143.13567 & 48.3715835 \\
\hline $\mathbf{1 0}$ & $4 \mathrm{p}$ & ${ }^{2} \mathrm{P}_{1 / 2}$ & 411477.12241 & 51.0166608 \\
\hline $\mathbf{1 1}$ & $4 \mathrm{~s}$ & ${ }^{2} \mathrm{~S}_{1 / 2}$ & 411477.18141 & 51.0166681 \\
\hline $\mathbf{1 2}$ & $4 \mathrm{~d}$ & ${ }^{2} \mathrm{D}_{3 / 2}$ & 411477.85334 & 51.0166608 \\
\hline $\mathbf{1 3}$ & $4 \mathrm{p}$ & ${ }^{2} \mathrm{P}_{3 / 2}$ & 411477.85456 & 51.0167514 \\
\hline $\mathbf{1 4}$ & $4 \mathrm{~d}$ & ${ }^{2} \mathrm{D}_{5 / 2}$ & 411478.09737 & 51.0167816 \\
\hline $\mathbf{1 5}$ & $4 \mathrm{f}$ & ${ }^{2} \mathrm{~F}_{5 / 2}$ & 411478.09693 & 51.0167816 \\
\hline $\mathbf{1 6}$ & $4 \mathrm{f}$ & ${ }^{2} \mathrm{~F}_{7 / 2}$ & 411478.21894 & 51.0167967 \\
\hline $\mathbf{1 7}$ & $5 \mathrm{p}$ & ${ }^{2} \mathrm{P}_{1 / 2}$ & 421352.67859 & 52.2410737 \\
\hline $\mathbf{1 8}$ & $5 \mathrm{~s}$ & ${ }^{2} \mathrm{~S}_{1 / 2}$ & 421352.70883 & 52.2410774 \\
\hline $\mathbf{1 9}$ & $5 \mathrm{~d}$ & ${ }^{2} \mathrm{D}_{3 / 2}$ & 421353.05282 & 52.2411201 \\
\hline $\mathbf{2 0}$ & $5 \mathrm{p}$ & ${ }^{2} \mathrm{P}_{3 / 2}$ & 421353.05345 & 52.2411202 \\
\hline $\mathbf{2 1}$ & $5 \mathrm{f}$ & ${ }^{2} \mathrm{~F}_{5 / 2}$ & 421353.17753 & 52.2411355 \\
\hline $\mathbf{2 2}$ & $5 \mathrm{~d}$ & ${ }^{2} \mathrm{D}_{5 / 2}$ & 421353.17776 & 52.2411356 \\
\hline $\mathbf{2 3}$ & $5 \mathrm{~g}$ & ${ }^{2} \mathrm{G}_{7 / 2}$ & 421353.23988 & 52.2411433 \\
\hline $\mathbf{2 4}$ & $5 \mathrm{f}$ & ${ }^{2} \mathrm{~F}_{7 / 2}$ & 421353.24000 & 52.2411433 \\
\hline $\mathbf{2 5}$ & $5 \mathrm{~g}$ & ${ }^{2} \mathrm{G}_{9 / 2}$ & 421353.27737 & 52.2411479 \\
\hline
\end{tabular}


Table 2a. Proton collisional excitation rate coefficients for $\mathrm{He} I I\left(\mathrm{~m}^{3} \mathrm{~s}^{-1}\right)$.

\begin{tabular}{|c|c|c|c|c|c|c|c|c|c|}
\hline \multicolumn{2}{|c|}{$\begin{array}{c}\text { Temperature } \\
(\mathrm{eV})\end{array}$} & \multirow[t]{2}{*}{0.273} & \multirow[t]{2}{*}{0.43} & \multirow[t]{2}{*}{0.69} & \multirow[t]{2}{*}{1.09} & \multirow[t]{2}{*}{1.72} & \multirow[t]{2}{*}{2.73} & \multirow[t]{2}{*}{4.33} & \multirow[t]{2}{*}{6.86} \\
\hline $\begin{array}{l}\text { Lower } \\
\text { index }\end{array}$ & $\begin{array}{l}\text { Upper } \\
\text { index }\end{array}$ & & & & & & & & \\
\hline 2 & 3 & $3.52 \mathrm{e}-11$ & $3.86 \mathrm{e}-11$ & $4.00 \mathrm{e}-11$ & $3.95 \mathrm{e}-11$ & $3.78 \mathrm{e}-11$ & $3.52 \mathrm{e}-11$ & $3.21 \mathrm{e}-11$ & $2.89 \mathrm{e}-11$ \\
\hline 3 & 4 & $4.33 \mathrm{e}-12$ & $7.28 \mathrm{e}-12$ & $1.09 \mathrm{e}-11$ & $1.48 \mathrm{e}-11$ & $1.86 \mathrm{e}-11$ & $2.19 \mathrm{e}-11$ & $2.44 \mathrm{e}-11$ & $2.58 \mathrm{e}-11$ \\
\hline 5 & 6 & $2.75 \mathrm{e}-10$ & $2.82 \mathrm{e}-10$ & $2.78 \mathrm{e}-10$ & $2.65 \mathrm{e}-10$ & $2.47 \mathrm{e}-10$ & $2.26 \mathrm{e}-10$ & $2.04 \mathrm{e}-10$ & $1.83 \mathrm{e}-10$ \\
\hline 5 & 7 & $3.46 \mathrm{e}-11$ & $4.91 \mathrm{e}-11$ & $6.44 \mathrm{e}-11$ & $7.90 \mathrm{e}-11$ & $9.12 \mathrm{e}-11$ & $9.97 \mathrm{e}-11$ & $1.04 \mathrm{e}-10$ & $1.04 \mathrm{e}-10$ \\
\hline 6 & 8 & $5.30 \mathrm{e}-11$ & $7.64 \mathrm{e}-11$ & $1.03 \mathrm{e}-10$ & $1.29 \mathrm{e}-10$ & $1.54 \mathrm{e}-10$ & $1.72 \mathrm{e}-10$ & $1.83 \mathrm{e}-10$ & $1.87 \mathrm{e}-10$ \\
\hline 8 & 9 & $1.10 \mathrm{e}-10$ & $1.33 \mathrm{e}-10$ & $1.50 \mathrm{e}-10$ & $1.62 \mathrm{e}-10$ & $1.66 \mathrm{e}-10$ & $1.63 \mathrm{e}-10$ & $1.56 \mathrm{e}-10$ & $1.46 \mathrm{e}-10$ \\
\hline 10 & 11 & $1.06 \mathrm{e}-09$ & $1.06 \mathrm{e}-09$ & $1.02 \mathrm{e}-09$ & $9.56 \mathrm{e}-10$ & $8.79 \mathrm{e}-10$ & $7.98 \mathrm{e}-10$ & $7.18 \mathrm{e}-10$ & $6.42 \mathrm{e}-10$ \\
\hline 10 & 12 & $1.93 \mathrm{e}-10$ & $2.59 \mathrm{e}-10$ & $3.28 \mathrm{e}-10$ & $3.90 \mathrm{e}-10$ & $4.39 \mathrm{e}-10$ & $4.70 \mathrm{e}-10$ & $4.81 \mathrm{e}-10$ & $4.77 \mathrm{e}-10$ \\
\hline 11 & 13 & $2.64 \mathrm{e}-10$ & $3.59 \mathrm{e}-10$ & $4.60 \mathrm{e}-10$ & $5.56 \mathrm{e}-10$ & $6.35 \mathrm{e}-10$ & $6.89 \mathrm{e}-10$ & $7.17 \mathrm{e}-10$ & $7.20 \mathrm{e}-10$ \\
\hline 12 & 15 & $4.01 \mathrm{e}-10$ & $4.56 \mathrm{e}-10$ & $4.90 \mathrm{e}-10$ & $5.03 \mathrm{e}-10$ & $4.97 \mathrm{e}-10$ & $4.76 \mathrm{e}-10$ & $4.47 \mathrm{e}-10$ & $4.12 \mathrm{e}-10$ \\
\hline 13 & 14 & $5.63 e-10$ & $6.58 \mathrm{e}-10$ & $7.26 \mathrm{e}-10$ & $7.61 \mathrm{e}-10$ & $7.66 \mathrm{e}-10$ & $7.46 \mathrm{e}-10$ & $7.09 \mathrm{e}-10$ & $6.63 \mathrm{e}-10$ \\
\hline 14 & 16 & $6.42 \mathrm{e}-10$ & $6.76 \mathrm{e}-10$ & $6.81 \mathrm{e}-10$ & $6.63 \mathrm{e}-10$ & $6.27 \mathrm{e}-10$ & $5.81 \mathrm{e}-10$ & $5.31 \mathrm{e}-10$ & $4.81 \mathrm{e}-10$ \\
\hline 17 & 18 & $2.87 \mathrm{e}-09$ & $2.81 \mathrm{e}-09$ & $2.67 \mathrm{e}-09$ & $2.48 \mathrm{e}-09$ & $2.27 \mathrm{e}-09$ & $2.05 \mathrm{e}-09$ & $1.85 \mathrm{e}-09$ & $1.64 \mathrm{e}-09$ \\
\hline 17 & 19 & $6.62 \mathrm{e}-10$ & $8.64 \mathrm{e}-10$ & $1.06 \mathrm{e}-09$ & $1.23 \mathrm{e}-09$ & $1.36 \mathrm{e}-09$ & $1.43 \mathrm{e}-09$ & $1.45 \mathrm{e}-09$ & $1.43 \mathrm{e}-09$ \\
\hline 18 & 20 & $8.68 \mathrm{e}-10$ & $1.14 \mathrm{e}-09$ & $1.42 \mathrm{e}-09$ & $1.66 \mathrm{e}-09$ & $1.86 \mathrm{e}-09$ & $1.98 \mathrm{e}-09$ & $2.03 \mathrm{e}-09$ & $2.03 \mathrm{e}-09$ \\
\hline 19 & 21 & $1.53 \mathrm{e}-09$ & $1.71 \mathrm{e}-09$ & $1.82 \mathrm{e}-09$ & $1.86 \mathrm{e}-09$ & $1.83 \mathrm{e}-09$ & $1.75 \mathrm{e}-09$ & $1.65 \mathrm{e}-09$ & $1.53 \mathrm{e}-09$ \\
\hline 20 & 22 & $1.82 \mathrm{e}-09$ & $2.07 \mathrm{e}-09$ & $2.23 \mathrm{e}-09$ & $2.30 \mathrm{e}-09$ & $2.29 \mathrm{e}-09$ & $2.22 \mathrm{e}-09$ & $2.10 \mathrm{e}-09$ & $1.96 \mathrm{e}-09$ \\
\hline 21 & 23 & $1.58 \mathrm{e}-09$ & $1.61 \mathrm{e}-09$ & $1.58 \mathrm{e}-09$ & $1.51 \mathrm{e}-09$ & $1.40 \mathrm{e}-09$ & $1.29 \mathrm{e}-09$ & $1.17 \mathrm{e}-09$ & $1.06 \mathrm{e}-09$ \\
\hline 22 & 24 & $2.40 \mathrm{e}-09$ & $2.51 \mathrm{e}-09$ & $2.51 \mathrm{e}-09$ & $2.43 e-09$ & $2.30 \mathrm{e}-09$ & $2.14 \mathrm{e}-09$ & $1.96 \mathrm{e}-09$ & $1.78 \mathrm{e}-09$ \\
\hline 24 & 25 & $2.02 \mathrm{e}-09$ & $1.98 \mathrm{e}-09$ & $1.88 \mathrm{e}-09$ & $1.75 \mathrm{e}-09$ & $1.60 \mathrm{e}-09$ & $1.45 \mathrm{e}-09$ & $1.30 \mathrm{e}-09$ & $1.16 \mathrm{e}-09$ \\
\hline
\end{tabular}


Table 2b. Proton collisional excitation rate coefficients for $\mathrm{He} \mathrm{II}\left(\mathrm{m}^{3} \mathrm{~s}^{-1}\right)$.

\begin{tabular}{|c|c|c|c|c|c|c|c|c|}
\hline \multicolumn{2}{|c|}{$\begin{array}{c}\text { Temperature } \\
(\mathrm{eV})\end{array}$} & \multirow[t]{2}{*}{10.87} & \multirow[t]{2}{*}{17.23} & \multirow[t]{2}{*}{27.31} & \multirow[t]{2}{*}{43.29} & \multirow[t]{2}{*}{68.61} & \multirow[t]{2}{*}{108.74} & \multirow[t]{2}{*}{136.90} \\
\hline $\begin{array}{l}\text { Lower } \\
\text { index }\end{array}$ & $\begin{array}{l}\text { Upper } \\
\text { index }\end{array}$ & & & & & & & \\
\hline 2 & 3 & $2.57 \mathrm{e}-11$ & $2.28 \mathrm{e}-11$ & $2.00 \mathrm{e}-11$ & $1.75 \mathrm{e}-11$ & $1.52 \mathrm{e}-11$ & $1.31 \mathrm{e}-11$ & $1.21 \mathrm{e}-11$ \\
\hline 3 & 4 & $2.61 \mathrm{e}-11$ & $2.55 \mathrm{e}-11$ & $2.42 \mathrm{e}-11$ & $2.26 \mathrm{e}-11$ & $2.08 \mathrm{e}-11$ & $1.90 \mathrm{e}-11$ & $1.80 \mathrm{e}-11$ \\
\hline 5 & 6 & $1.62 \mathrm{e}-10$ & $1.43 \mathrm{e}-10$ & $1.26 \mathrm{e}-10$ & $1.09 \mathrm{e}-10$ & $9.41 \mathrm{e}-11$ & $8.02 \mathrm{e}-11$ & $7.37 \mathrm{e}-11$ \\
\hline 5 & 7 & $1.00 \mathrm{e}-10$ & $9.48 \mathrm{e}-11$ & $8.82 \mathrm{e}-11$ & $8.11 \mathrm{e}-11$ & $7.37 \mathrm{e}-11$ & $6.64 \mathrm{e}-11$ & $6.27 \mathrm{e}-11$ \\
\hline 6 & 8 & $1.85 \mathrm{e}-10$ & $1.78 \mathrm{e}-10$ & $1.68 \mathrm{e}-10$ & $1.56 \mathrm{e}-10$ & $1.44 \mathrm{e}-10$ & $1.30 \mathrm{e}-10$ & $1.24 \mathrm{e}-10$ \\
\hline 8 & 9 & $1.34 \mathrm{e}-10$ & $1.22 \mathrm{e}-10$ & $1.10 \mathrm{e}-10$ & $9.81 \mathrm{e}-11$ & $8.70 \mathrm{e}-11$ & $7.63 \mathrm{e}-11$ & $7.12 \mathrm{e}-11$ \\
\hline 10 & 11 & $5.69 \mathrm{e}-10$ & $5.00 \mathrm{e}-10$ & $4.36 \mathrm{e}-10$ & $3.76 \mathrm{e}-10$ & $3.20 \mathrm{e}-10$ & $2.69 \mathrm{e}-10$ & $2.46 \mathrm{e}-10$ \\
\hline 10 & 12 & $4.61 \mathrm{e}-10$ & $4.38 \mathrm{e}-10$ & $4.09 \mathrm{e}-10$ & $3.76 \mathrm{e}-10$ & $3.42 \mathrm{e}-10$ & $3.06 \mathrm{e}-10$ & $2.88 \mathrm{e}-10$ \\
\hline 11 & 13 & $7.04 \mathrm{e}-10$ & $6.74 \mathrm{e}-10$ & $6.35 \mathrm{e}-10$ & $5.88 \mathrm{e}-10$ & $5.37 \mathrm{e}-10$ & $4.82 \mathrm{e}-10$ & $4.54 \mathrm{e}-10$ \\
\hline 12 & 15 & $3.76 \mathrm{e}-10$ & $3.40 \mathrm{e}-10$ & $3.05 \mathrm{e}-10$ & $2.70 \mathrm{e}-10$ & $2.37 \mathrm{e}-10$ & $2.06 \mathrm{e}-10$ & $1.91 \mathrm{e}-10$ \\
\hline 13 & 14 & $6.11 \mathrm{e}-10$ & $5.57 \mathrm{e}-10$ & $5.03 \mathrm{e}-10$ & $4.48 \mathrm{e}-10$ & $3.95 \mathrm{e}-10$ & $3.44 \mathrm{e}-10$ & $3.19 \mathrm{e}-10$ \\
\hline 14 & 16 & $4.32 \mathrm{e}-10$ & $3.85 \mathrm{e}-10$ & $3.39 \mathrm{e}-10$ & $2.97 \mathrm{e}-10$ & $2.57 \mathrm{e}-10$ & $2.19 \mathrm{e}-10$ & $2.01 \mathrm{e}-10$ \\
\hline 17 & 18 & $1.45 \mathrm{e}-09$ & $1.27 \mathrm{e}-09$ & $1.10 \mathrm{e}-09$ & $9.39 \mathrm{e}-10$ & $7.91 \mathrm{e}-10$ & $6.61 \mathrm{e}-10$ & $6.02 \mathrm{e}-10$ \\
\hline 17 & 19 & $1.38 \mathrm{e}-09$ & $1.31 \mathrm{e}-09$ & $1.22 \mathrm{e}-09$ & $1.12 \mathrm{e}-09$ & $1.01 \mathrm{e}-09$ & $8.95 \mathrm{e}-10$ & $8.37 \mathrm{e}-10$ \\
\hline 18 & 20 & $1.97 \mathrm{e}-09$ & $1.88 \mathrm{e}-09$ & $1.76 \mathrm{e}-09$ & $1.62 \mathrm{e}-09$ & $1.46 \mathrm{e}-09$ & $1.30 \mathrm{e}-09$ & $1.21 \mathrm{e}-09$ \\
\hline 19 & 21 & $1.40 \mathrm{e}-09$ & $1.27 \mathrm{e}-09$ & $1.14 \mathrm{e}-09$ & $1.01 \mathrm{e}-09$ & $8.77 \mathrm{e}-10$ & $7.53 \mathrm{e}-10$ & $6.94 \mathrm{e}-10$ \\
\hline 20 & 22 & $1.81 \mathrm{e}-09$ & $1.65 \mathrm{e}-09$ & $1.48 \mathrm{e}-09$ & $1.31 \mathrm{e}-09$ & $1.14 \mathrm{e}-09$ & $9.82 \mathrm{e}-10$ & $9.05 \mathrm{e}-10$ \\
\hline 21 & 23 & $9.45 \mathrm{e}-10$ & $8.37 \mathrm{e}-10$ & $7.33 \mathrm{e}-10$ & $6.35 \mathrm{e}-10$ & $5.43 \mathrm{e}-10$ & $4.58 \mathrm{e}-10$ & $4.19 \mathrm{e}-10$ \\
\hline 22 & 24 & $1.60 \mathrm{e}-09$ & $1.43 \mathrm{e}-09$ & $1.26 \mathrm{e}-09$ & $1.09 \mathrm{e}-09$ & $9.36 \mathrm{e}-10$ & 7.91e-10 & $7.23 \mathrm{e}-10$ \\
\hline 24 & 25 & $1.03 \mathrm{e}-09$ & $9.00 \mathrm{e}-10$ & $7.81 \mathrm{e}-10$ & $6.69 \mathrm{e}-10$ & $5.65 \mathrm{e}-10$ & $4.73 \mathrm{e}-10$ & $4.31 \mathrm{e}-10$ \\
\hline
\end{tabular}


Table 3a. Deuteron collisional excitation rate coefficients for He II $\left(\mathrm{m}^{3} \mathrm{~s}^{-1}\right)$.

\begin{tabular}{|c|c|c|c|c|c|c|c|c|c|}
\hline \multicolumn{2}{|c|}{$\begin{array}{c}\text { Temperature } \\
(\mathrm{eV})\end{array}$} & \multirow[t]{2}{*}{0.273} & \multirow[t]{2}{*}{0.43} & \multirow[t]{2}{*}{0.69} & \multirow[t]{2}{*}{1.09} & \multirow[t]{2}{*}{1.72} & \multirow[t]{2}{*}{2.73} & \multirow[t]{2}{*}{4.33} & \multirow[t]{2}{*}{6.86} \\
\hline $\begin{array}{l}\text { Lower } \\
\text { index }\end{array}$ & $\begin{array}{l}\text { Upper } \\
\text { index }\end{array}$ & & & & & & & & \\
\hline 2 & 3 & $3.25 \mathrm{e}-11$ & $3.73 \mathrm{e}-11$ & $4.01 \mathrm{e}-11$ & $4.10 \mathrm{e}-11$ & $4.03 \mathrm{e}-11$ & $3.84 \mathrm{e}-11$ & $3.56 \mathrm{e}-11$ & $3.25 \mathrm{e}-11$ \\
\hline 3 & 4 & $2.77 \mathrm{e}-12$ & $4.95 \mathrm{e}-12$ & $7.83 e-12$ & $1.13 \mathrm{e}-11$ & $1.51 \mathrm{e}-11$ & $1.89 \mathrm{e}-11$ & $2.22 \mathrm{e}-11$ & $2.47 \mathrm{e}-11$ \\
\hline 5 & 6 & $2.63 \mathrm{e}-10$ & $2.82 \mathrm{e}-10$ & $2.88 \mathrm{e}-10$ & $2.83 \mathrm{e}-10$ & $2.69 \mathrm{e}-10$ & $2.51 \mathrm{e}-10$ & $2.29 \mathrm{e}-10$ & $2.08 \mathrm{e}-10$ \\
\hline 5 & 7 & $2.40 \mathrm{e}-11$ & $3.60 \mathrm{e}-11$ & $5.01 \mathrm{e}-11$ & $6.52 \mathrm{e}-11$ & $7.97 \mathrm{e}-11$ & $9.19 \mathrm{e}-11$ & $1.00 \mathrm{e}-10$ & $1.05 \mathrm{e}-10$ \\
\hline 6 & 8 & $3.58 \mathrm{e}-11$ & $5.44 \mathrm{e}-11$ & 7.71e-11 & $1.03 \mathrm{e}-10$ & $1.29 \mathrm{e}-10$ & $1.54 \mathrm{e}-10$ & $1.72 \mathrm{e}-10$ & $1.84 \mathrm{e}-10$ \\
\hline 8 & 9 & $8.75 \mathrm{e}-11$ & $1.12 \mathrm{e}-10$ & $1.35 \mathrm{e}-10$ & $1.53 \mathrm{e}-10$ & $1.64 \mathrm{e}-10$ & $1.68 \mathrm{e}-10$ & $1.65 \mathrm{e}-10$ & $1.58 \mathrm{e}-10$ \\
\hline 10 & 11 & $1.04 \mathrm{e}-09$ & $1.08 \mathrm{e}-09$ & $1.07 \mathrm{e}-09$ & $1.03 \mathrm{e}-09$ & $9.70 \mathrm{e}-10$ & $8.96 \mathrm{e}-10$ & $8.18 \mathrm{e}-10$ & $7.39 \mathrm{e}-10$ \\
\hline 10 & 12 & $1.36 \mathrm{e}-10$ & $1.94 \mathrm{e}-10$ & $2.59 \mathrm{e}-10$ & $3.27 \mathrm{e}-10$ & $3.89 \mathrm{e}-10$ & $4.39 \mathrm{e}-10$ & $4.72 \mathrm{e}-10$ & $4.88 \mathrm{e}-10$ \\
\hline 11 & 13 & $1.83 \mathrm{e}-10$ & $2.63 \mathrm{e}-10$ & $3.56 \mathrm{e}-10$ & $4.56 \mathrm{e}-10$ & $5.51 \mathrm{e}-10$ & $6.33 \mathrm{e}-10$ & $6.92 \mathrm{e}-10$ & $7.27 \mathrm{e}-10$ \\
\hline 12 & 15 & $3.38 \mathrm{e}-10$ & $4.07 \mathrm{e}-10$ & $4.61 \mathrm{e}-10$ & $4.96 \mathrm{e}-10$ & $5.09 \mathrm{e}-10$ & $5.03 \mathrm{e}-10$ & $4.84 \mathrm{e}-10$ & $4.57 \mathrm{e}-10$ \\
\hline 13 & 14 & $4.59 \mathrm{e}-10$ & $5.68 \mathrm{e}-10$ & $6.62 \mathrm{e}-10$ & $7.31 \mathrm{e}-10$ & $7.68 \mathrm{e}-10$ & $7.75 \mathrm{e}-10$ & $7.60 \mathrm{e}-10$ & $7.27 \mathrm{e}-10$ \\
\hline 14 & 16 & $5.90 \mathrm{e}-10$ & $6.53 \mathrm{e}-10$ & $6.86 \mathrm{e}-10$ & $6.91 \mathrm{e}-10$ & $6.72 \mathrm{e}-10$ & $6.37 \mathrm{e}-10$ & $5.93 e-10$ & $5.45 \mathrm{e}-10$ \\
\hline 17 & 18 & $2.89 \mathrm{e}-09$ & $2.92 \mathrm{e}-09$ & $2.85 \mathrm{e}-09$ & $2.71 \mathrm{e}-09$ & $2.53 \mathrm{e}-09$ & $2.33 \mathrm{e}-09$ & $2.12 \mathrm{e}-09$ & $1.91 \mathrm{e}-09$ \\
\hline 17 & 19 & $4.78 \mathrm{e}-10$ & $6.57 \mathrm{e}-10$ & $8.54 \mathrm{e}-10$ & $1.05 \mathrm{e}-09$ & $1.22 \mathrm{e}-09$ & $1.36 \mathrm{e}-09$ & $1.45 \mathrm{e}-09$ & $1.49 \mathrm{e}-09$ \\
\hline 18 & 20 & $6.18 \mathrm{e}-10$ & $8.57 \mathrm{e}-10$ & $1.13 \mathrm{e}-09$ & $1.40 \mathrm{e}-09$ & $1.65 \mathrm{e}-09$ & $1.86 \mathrm{e}-09$ & $2.01 \mathrm{e}-09$ & $2.09 \mathrm{e}-09$ \\
\hline 19 & 21 & $1.29 \mathrm{e}-09$ & $1.53 \mathrm{e}-09$ & $1.72 \mathrm{e}-09$ & $1.83 \mathrm{e}-09$ & $1.88 \mathrm{e}-09$ & $1.86 \mathrm{e}-09$ & $1.80 \mathrm{e}-09$ & $1.71 \mathrm{e}-09$ \\
\hline 20 & 22 & $1.51 \mathrm{e}-09$ & $1.82 \mathrm{e}-09$ & $2.07 \mathrm{e}-09$ & $2.24 \mathrm{e}-09$ & $2.33 \mathrm{e}-09$ & $2.33 \mathrm{e}-09$ & $2.28 \mathrm{e}-09$ & $2.18 \mathrm{e}-09$ \\
\hline 21 & 23 & $1.51 \mathrm{e}-09$ & $1.60 \mathrm{e}-09$ & $1.63 \mathrm{e}-09$ & $1.60 \mathrm{e}-09$ & $1.53 \mathrm{e}-09$ & $1.43 \mathrm{e}-09$ & $1.33 \mathrm{e}-09$ & $1.21 \mathrm{e}-09$ \\
\hline 22 & 24 & $2.22 \mathrm{e}-09$ & $2.43 e-09$ & $2.53 e-09$ & $2.54 \mathrm{e}-09$ & $2.47 \mathrm{e}-09$ & $2.35 \mathrm{e}-09$ & $2.20 \mathrm{e}-09$ & $2.04 \mathrm{e}-09$ \\
\hline 24 & 25 & $2.02 \mathrm{e}-09$ & $2.05 \mathrm{e}-09$ & $2.01 \mathrm{e}-09$ & $1.91 \mathrm{e}-09$ & $1.79 \mathrm{e}-09$ & $1.64 \mathrm{e}-09$ & $1.50 \mathrm{e}-09$ & $1.35 \mathrm{e}-09$ \\
\hline
\end{tabular}


Table 3b. Deuteron collisional excitation rate coefficients for $\mathrm{He}$ II $\left(\mathrm{m}^{3} \mathrm{~s}^{-1}\right)$.

\begin{tabular}{|c|c|c|c|c|c|c|c|c|}
\hline \multicolumn{2}{|c|}{$\begin{array}{c}\text { Temperature } \\
(\mathrm{eV})\end{array}$} & \multirow[t]{2}{*}{10.87} & \multirow[t]{2}{*}{17.23} & \multirow[t]{2}{*}{27.31} & \multirow[t]{2}{*}{43.29} & \multirow[t]{2}{*}{68.61} & \multirow[t]{2}{*}{108.74} & \multirow[t]{2}{*}{136.90} \\
\hline $\begin{array}{l}\text { Lower } \\
\text { index }\end{array}$ & $\begin{array}{l}\text { Upper } \\
\text { index }\end{array}$ & & & & & & & \\
\hline 2 & 3 & $2.93 \mathrm{e}-11$ & $2.62 \mathrm{e}-11$ & $2.32 \mathrm{e}-11$ & $2.05 \mathrm{e}-11$ & $1.79 \mathrm{e}-11$ & $1.56 \mathrm{e}-11$ & $1.45 \mathrm{e}-11$ \\
\hline 3 & 4 & $2.61 \mathrm{e}-11$ & $2.64 \mathrm{e}-11$ & $2.59 \mathrm{e}-11$ & $2.47 \mathrm{e}-11$ & $2.32 \mathrm{e}-11$ & $2.15 \mathrm{e}-11$ & $2.06 \mathrm{e}-11$ \\
\hline 5 & 6 & $1.87 \mathrm{e}-10$ & $1.67 \mathrm{e}-10$ & $1.47 \mathrm{e}-10$ & $1.29 \mathrm{e}-10$ & $1.12 \mathrm{e}-10$ & $9.66 \mathrm{e}-11$ & $8.91 \mathrm{e}-11$ \\
\hline 5 & 7 & $1.05 \mathrm{e}-10$ & $1.02 \mathrm{e}-10$ & $9.74 \mathrm{e}-11$ & $9.13 \mathrm{e}-11$ & $8.44 \mathrm{e}-11$ & $7.70 \mathrm{e}-11$ & $7.32 \mathrm{e}-11$ \\
\hline 6 & 8 & $1.90 \mathrm{e}-10$ & $1.89 \mathrm{e}-10$ & $1.83 \mathrm{e}-10$ & $1.75 \mathrm{e}-10$ & $1.64 \mathrm{e}-10$ & $1.51 \mathrm{e}-10$ & $1.44 \mathrm{e}-10$ \\
\hline 8 & 9 & $1.49 \mathrm{e}-10$ & $1.37 \mathrm{e}-10$ & $1.26 \mathrm{e}-10$ & $1.14 \mathrm{e}-10$ & $1.02 \mathrm{e}-10$ & $9.04 \mathrm{e}-11$ & $8.47 \mathrm{e}-11$ \\
\hline 10 & 11 & $6.62 \mathrm{e}-10$ & $5.88 \mathrm{e}-10$ & $5.18 \mathrm{e}-10$ & $4.50 \mathrm{e}-10$ & $3.86 \mathrm{e}-10$ & $3.27 \mathrm{e}-10$ & $3.00 \mathrm{e}-10$ \\
\hline 10 & 12 & $4.88 \mathrm{e}-10$ & $4.77 \mathrm{e}-10$ & $4.56 \mathrm{e}-10$ & $4.29 \mathrm{e}-10$ & $3.96 \mathrm{e}-10$ & $3.59 \mathrm{e}-10$ & $3.40 \mathrm{e}-10$ \\
\hline 11 & 13 & $7.39 \mathrm{e}-10$ & $7.30 \mathrm{e}-10$ & $7.05 \mathrm{e}-10$ & $6.67 \mathrm{e}-10$ & $6.19 \mathrm{e}-10$ & $5.64 \mathrm{e}-10$ & $5.35 \mathrm{e}-10$ \\
\hline 12 & 15 & $4.24 \mathrm{e}-10$ & $3.90 \mathrm{e}-10$ & $3.54 \mathrm{e}-10$ & $3.17 \mathrm{e}-10$ & $2.81 \mathrm{e}-10$ & $2.46 \mathrm{e}-10$ & $2.29 \mathrm{e}-10$ \\
\hline 13 & 14 & $6.85 \mathrm{e}-10$ & $6.36 \mathrm{e}-10$ & $5.82 \mathrm{e}-10$ & $5.26 \mathrm{e}-10$ & $4.69 \mathrm{e}-10$ & $4.12 \mathrm{e}-10$ & $3.84 \mathrm{e}-10$ \\
\hline 14 & 16 & $4.96 \mathrm{e}-10$ & $4.47 \mathrm{e}-10$ & $3.99 \mathrm{e}-10$ & $3.52 \mathrm{e}-10$ & $3.07 \mathrm{e}-10$ & $2.64 \mathrm{e}-10$ & $2.44 \mathrm{e}-10$ \\
\hline 17 & 18 & $1.71 \mathrm{e}-09$ & $1.51 \mathrm{e}-09$ & $1.32 \mathrm{e}-09$ & $1.13 \mathrm{e}-09$ & $9.61 \mathrm{e}-10$ & $8.05 \mathrm{e}-10$ & $7.35 \mathrm{e}-10$ \\
\hline 17 & 19 & $1.48 \mathrm{e}-09$ & $1.45 \mathrm{e}-09$ & $1.38 \mathrm{e}-09$ & $1.29 \mathrm{e}-09$ & $1.18 \mathrm{e}-09$ & $1.06 \mathrm{e}-09$ & $9.97 \mathrm{e}-10$ \\
\hline 18 & 20 & $2.11 \mathrm{e}-09$ & $2.07 \mathrm{e}-09$ & $1.98 \mathrm{e}-09$ & $1.86 \mathrm{e}-09$ & $1.71 \mathrm{e}-09$ & $1.54 \mathrm{e}-09$ & $1.45 \mathrm{e}-09$ \\
\hline 19 & 21 & $1.60 \mathrm{e}-09$ & $1.47 \mathrm{e}-09$ & $1.33 \mathrm{e}-09$ & $1.19 \mathrm{e}-09$ & $1.05 \mathrm{e}-09$ & $9.09 \mathrm{e}-10$ & $8.41 \mathrm{e}-10$ \\
\hline 20 & 22 & $2.05 \mathrm{e}-09$ & $1.90 \mathrm{e}-09$ & $1.73 \mathrm{e}-09$ & $1.55 \mathrm{e}-09$ & $1.37 \mathrm{e}-09$ & $1.19 \mathrm{e}-09$ & $1.10 \mathrm{e}-09$ \\
\hline 21 & 23 & $1.10 \mathrm{e}-09$ & $9.82 \mathrm{e}-10$ & $8.69 \mathrm{e}-10$ & $7.60 \mathrm{e}-10$ & $6.56 \mathrm{e}-10$ & $5.57 \mathrm{e}-10$ & $5.11 \mathrm{e}-10$ \\
\hline 22 & 24 & $1.86 \mathrm{e}-09$ & $1.67 \mathrm{e}-09$ & $1.49 \mathrm{e}-09$ & $1.31 \mathrm{e}-09$ & $1.13 \mathrm{e}-09$ & $9.61 \mathrm{e}-10$ & $8.82 \mathrm{e}-10$ \\
\hline 24 & 25 & $1.21 \mathrm{e}-09$ & $1.07 \mathrm{e}-09$ & $9.32 \mathrm{e}-10$ & $8.05 \mathrm{e}-10$ & $6.86 \mathrm{e}-10$ & $5.77 \mathrm{e}-10$ & $5.27 \mathrm{e}-10$ \\
\hline
\end{tabular}


Table 4a. Triton collisional excitation rate coefficients for He II $\left(\mathrm{m}^{3} \mathrm{~s}^{-1}\right)$.

\begin{tabular}{|c|c|c|c|c|c|c|c|c|c|}
\hline \multicolumn{2}{|c|}{$\begin{array}{c}\text { Temperature } \\
(\mathrm{eV})\end{array}$} & \multirow[t]{2}{*}{0.273} & \multirow[t]{2}{*}{0.43} & \multirow[t]{2}{*}{0.69} & \multirow[t]{2}{*}{1.09} & \multirow[t]{2}{*}{1.72} & \multirow[t]{2}{*}{2.73} & \multirow[t]{2}{*}{4.33} & \multirow[t]{2}{*}{6.86} \\
\hline $\begin{array}{l}\text { Lower } \\
\text { index }\end{array}$ & $\begin{array}{l}\text { Upper } \\
\text { index }\end{array}$ & & & & & & & & \\
\hline 2 & 3 & $3.06 \mathrm{e}-11$ & $3.60 \mathrm{e}-11$ & $3.97 \mathrm{e}-11$ & $4.14 \mathrm{e}-11$ & $4.13 e-11$ & $3.99 \mathrm{e}-11$ & $3.74 \mathrm{e}-11$ & $3.44 \mathrm{e}-11$ \\
\hline 3 & 4 & $2.17 \mathrm{e}-12$ & $4.01 \mathrm{e}-12$ & $6.51 \mathrm{e}-12$ & $9.65 \mathrm{e}-12$ & $1.33 \mathrm{e}-11$ & $1.71 \mathrm{e}-11$ & $2.07 \mathrm{e}-11$ & $2.36 \mathrm{e}-11$ \\
\hline 5 & 6 & $2.52 \mathrm{e}-10$ & $2.77 \mathrm{e}-10$ & $2.89 \mathrm{e}-10$ & $2.89 \mathrm{e}-10$ & $2.79 \mathrm{e}-10$ & $2.63 \mathrm{e}-10$ & $2.43 \mathrm{e}-10$ & $2.21 \mathrm{e}-10$ \\
\hline 5 & 7 & $1.96 \mathrm{e}-11$ & $3.02 \mathrm{e}-11$ & $4.32 \mathrm{e}-11$ & $5.78 \mathrm{e}-11$ & $7.28 \mathrm{e}-11$ & $8.63 e-11$ & $9.67 \mathrm{e}-11$ & $1.03 \mathrm{e}-10$ \\
\hline 6 & 8 & $2.89 \mathrm{e}-11$ & $4.50 \mathrm{e}-11$ & $6.56 \mathrm{e}-11$ & $8.98 \mathrm{e}-11$ & $1.16 \mathrm{e}-10$ & $1.42 \mathrm{e}-10$ & $1.64 \mathrm{e}-10$ & $1.80 \mathrm{e}-10$ \\
\hline 8 & 9 & $7.69 \mathrm{e}-11$ & $1.01 \mathrm{e}-10$ & $1.25 \mathrm{e}-10$ & $1.46 \mathrm{e}-10$ & $1.60 \mathrm{e}-10$ & $1.67 \mathrm{e}-10$ & $1.68 \mathrm{e}-10$ & $1.63 \mathrm{e}-10$ \\
\hline 10 & 11 & $1.02 \mathrm{e}-09$ & $1.08 \mathrm{e}-09$ & $1.09 \mathrm{e}-09$ & $1.06 \mathrm{e}-09$ & $1.01 \mathrm{e}-09$ & $9.42 \mathrm{e}-10$ & $8.66 \mathrm{e}-10$ & $7.89 \mathrm{e}-10$ \\
\hline 10 & 12 & $1.13 \mathrm{e}-10$ & $1.64 \mathrm{e}-10$ & $2.25 \mathrm{e}-10$ & $2.92 \mathrm{e}-10$ & $3.58 \mathrm{e}-10$ & $4.16 \mathrm{e}-10$ & $4.59 \mathrm{e}-10$ & $4.86 \mathrm{e}-10$ \\
\hline 11 & 13 & $1.50 \mathrm{e}-10$ & $2.21 \mathrm{e}-10$ & $3.07 \mathrm{e}-10$ & $4.03 \mathrm{e}-10$ & $5.02 \mathrm{e}-10$ & $5.93 \mathrm{e}-10$ & $6.66 \mathrm{e}-10$ & $7.17 \mathrm{e}-10$ \\
\hline 12 & 15 & $3.04 \mathrm{e}-10$ & $3.76 \mathrm{e}-10$ & $4.39 \mathrm{e}-10$ & $4.84 \mathrm{e}-10$ & $5.08 \mathrm{e}-10$ & $5.13 \mathrm{e}-10$ & $5.01 \mathrm{e}-10$ & $4.78 \mathrm{e}-10$ \\
\hline 13 & 14 & $4.05 \mathrm{e}-10$ & $5.16 \mathrm{e}-10$ & $6.19 \mathrm{e}-10$ & $7.02 \mathrm{e}-10$ & $7.56 \mathrm{e}-10$ & $7.81 \mathrm{e}-10$ & $7.79 \mathrm{e}-10$ & $7.56 \mathrm{e}-10$ \\
\hline 14 & 16 & $5.54 \mathrm{e}-10$ & $6.30 \mathrm{e}-10$ & $6.79 \mathrm{e}-10$ & $6.98 \mathrm{e}-10$ & $6.90 \mathrm{e}-10$ & $6.63 e-10$ & $6.23 \mathrm{e}-10$ & $5.78 \mathrm{e}-10$ \\
\hline 17 & 18 & $2.85 \mathrm{e}-09$ & $2.95 \mathrm{e}-09$ & $2.92 \mathrm{e}-09$ & $2.81 \mathrm{e}-09$ & $2.65 \mathrm{e}-09$ & $2.46 \mathrm{e}-09$ & $2.26 \mathrm{e}-09$ & $2.05 \mathrm{e}-09$ \\
\hline 17 & 19 & $3.98 \mathrm{e}-10$ & $5.61 \mathrm{e}-10$ & $7.49 \mathrm{e}-10$ & $9.48 \mathrm{e}-10$ & $1.14 \mathrm{e}-09$ & $1.30 \mathrm{e}-09$ & $1.42 \mathrm{e}-09$ & $1.49 \mathrm{e}-09$ \\
\hline 18 & 20 & $5.13 \mathrm{e}-10$ & $7.27 \mathrm{e}-10$ & $9.80 \mathrm{e}-10$ & $1.25 \mathrm{e}-09$ & $1.52 \mathrm{e}-09$ & $1.76 \mathrm{e}-09$ & $1.95 \mathrm{e}-09$ & $2.08 \mathrm{e}-09$ \\
\hline 19 & 21 & $1.16 \mathrm{e}-09$ & $1.42 \mathrm{e}-09$ & $1.63 \mathrm{e}-09$ & $1.79 \mathrm{e}-09$ & $1.87 \mathrm{e}-09$ & $1.89 \mathrm{e}-09$ & $1.86 \mathrm{e}-09$ & $1.79 \mathrm{e}-09$ \\
\hline 20 & 22 & $1.35 \mathrm{e}-09$ & $1.67 \mathrm{e}-09$ & $1.96 \mathrm{e}-09$ & $2.17 \mathrm{e}-09$ & $2.31 \mathrm{e}-09$ & $2.36 \mathrm{e}-09$ & $2.35 \mathrm{e}-09$ & $2.28 \mathrm{e}-09$ \\
\hline 21 & 23 & $1.44 \mathrm{e}-09$ & $1.57 \mathrm{e}-09$ & $1.64 \mathrm{e}-09$ & $1.63 \mathrm{e}-09$ & $1.59 \mathrm{e}-09$ & $1.50 \mathrm{e}-09$ & $1.40 \mathrm{e}-09$ & $1.29 \mathrm{e}-09$ \\
\hline 22 & 24 & $2.09 \mathrm{e}-09$ & $2.35 \mathrm{e}-09$ & $2.51 \mathrm{e}-09$ & $2.57 \mathrm{e}-09$ & $2.54 \mathrm{e}-09$ & $2.45 \mathrm{e}-09$ & $2.32 \mathrm{e}-09$ & $2.16 \mathrm{e}-09$ \\
\hline 24 & 25 & $1.99 \mathrm{e}-09$ & $2.06 \mathrm{e}-09$ & $2.05 \mathrm{e}-09$ & $1.98 \mathrm{e}-09$ & $1.87 \mathrm{e}-09$ & $1.74 \mathrm{e}-09$ & $1.59 \mathrm{e}-09$ & $1.45 \mathrm{e}-09$ \\
\hline
\end{tabular}


Table 4b. Triton collisional excitation rate coefficients for He II $\left(\mathrm{m}^{3} \mathrm{~s}^{-1}\right)$.

\begin{tabular}{|c|c|c|c|c|c|c|c|c|}
\hline \multicolumn{2}{|c|}{$\begin{array}{c}\text { Temperature } \\
(\mathrm{eV})\end{array}$} & \multirow[t]{2}{*}{10.87} & \multirow[t]{2}{*}{17.23} & \multirow[t]{2}{*}{27.31} & \multirow[t]{2}{*}{43.29} & \multirow[t]{2}{*}{68.61} & \multirow[t]{2}{*}{108.74} & \multirow[t]{2}{*}{136.90} \\
\hline $\begin{array}{l}\text { Lower } \\
\text { index }\end{array}$ & $\begin{array}{l}\text { Upper } \\
\text { index }\end{array}$ & & & & & & & \\
\hline 2 & 3 & $3.12 \mathrm{e}-11$ & $2.80 \mathrm{e}-11$ & $2.49 \mathrm{e}-11$ & $2.21 \mathrm{e}-11$ & $1.94 \mathrm{e}-11$ & $1.69 \mathrm{e}-11$ & $1.57 \mathrm{e}-11$ \\
\hline 3 & 4 & $2.56 \mathrm{e}-11$ & $2.65 \mathrm{e}-11$ & $2.64 \mathrm{e}-11$ & $2.57 \mathrm{e}-11$ & $2.44 \mathrm{e}-11$ & $2.28 \mathrm{e}-11$ & $2.20 \mathrm{e}-11$ \\
\hline 5 & 6 & $2.00 \mathrm{e}-10$ & $1.79 \mathrm{e}-10$ & $1.59 \mathrm{e}-10$ & $1.40 \mathrm{e}-10$ & $1.22 \mathrm{e}-10$ & $1.06 \mathrm{e}-10$ & $9.76 \mathrm{e}-11$ \\
\hline 5 & 7 & $1.06 \mathrm{e}-10$ & $1.05 \mathrm{e}-10$ & $1.01 \mathrm{e}-10$ & $9.61 \mathrm{e}-11$ & $8.98 \mathrm{e}-11$ & $8.27 \mathrm{e}-11$ & $7.89 \mathrm{e}-11$ \\
\hline 6 & 8 & $1.89 \mathrm{e}-10$ & $1.92 \mathrm{e}-10$ & $1.90 \mathrm{e}-10$ & $1.83 \mathrm{e}-10$ & $1.74 \mathrm{e}-10$ & $1.61 \mathrm{e}-10$ & $1.55 \mathrm{e}-10$ \\
\hline 8 & 9 & $1.55 \mathrm{e}-10$ & $1.45 \mathrm{e}-10$ & $1.34 \mathrm{e}-10$ & $1.22 \mathrm{e}-10$ & $1.10 \mathrm{e}-10$ & $9.81 \mathrm{e}-11$ & $9.22 \mathrm{e}-11$ \\
\hline 10 & 11 & $7.11 \mathrm{e}-10$ & $6.35 \mathrm{e}-10$ & $5.61 \mathrm{e}-10$ & $4.91 \mathrm{e}-10$ & $4.23 \mathrm{e}-10$ & $3.60 \mathrm{e}-10$ & $3.30 \mathrm{e}-10$ \\
\hline 10 & 12 & $4.97 \mathrm{e}-10$ & $4.93 \mathrm{e}-10$ & $4.78 \mathrm{e}-10$ & $4.54 \mathrm{e}-10$ & $4.23 \mathrm{e}-10$ & $3.87 \mathrm{e}-10$ & $3.68 \mathrm{e}-10$ \\
\hline 11 & 13 & $7.45 \mathrm{e}-10$ & $7.50 \mathrm{e}-10$ & $7.36 \mathrm{e}-10$ & $7.06 \mathrm{e}-10$ & $6.62 \mathrm{e}-10$ & $6.08 \mathrm{e}-10$ & $5.79 \mathrm{e}-10$ \\
\hline 12 & 15 & $4.48 \mathrm{e}-10$ & $4.15 \mathrm{e}-10$ & $3.79 \mathrm{e}-10$ & $3.42 \mathrm{e}-10$ & $3.05 \mathrm{e}-10$ & $2.68 \mathrm{e}-10$ & $2.50 \mathrm{e}-10$ \\
\hline 13 & 14 & $7.20 \mathrm{e}-10$ & $6.75 \mathrm{e}-10$ & $6.23 \mathrm{e}-10$ & $5.67 \mathrm{e}-10$ & $5.08 \mathrm{e}-10$ & $4.49 \mathrm{e}-10$ & $4.19 \mathrm{e}-10$ \\
\hline 14 & 16 & $5.29 \mathrm{e}-10$ & $4.80 \mathrm{e}-10$ & $4.31 \mathrm{e}-10$ & $3.82 \mathrm{e}-10$ & $3.35 \mathrm{e}-10$ & $2.89 \mathrm{e}-10$ & $2.67 \mathrm{e}-10$ \\
\hline 17 & 18 & $1.84 \mathrm{e}-09$ & $1.64 \mathrm{e}-09$ & $1.43 \mathrm{e}-09$ & $1.24 \mathrm{e}-09$ & $1.06 \mathrm{e}-09$ & $8.86 \mathrm{e}-10$ & $8.10 \mathrm{e}-10$ \\
\hline 17 & 19 & $1.52 \mathrm{e}-09$ & $1.51 \mathrm{e}-09$ & $1.45 \mathrm{e}-09$ & $1.37 \mathrm{e}-09$ & $1.27 \mathrm{e}-09$ & $1.15 \mathrm{e}-09$ & $1.08 \mathrm{e}-09$ \\
\hline 18 & 20 & $2.14 \mathrm{e}-09$ & $2.14 \mathrm{e}-09$ & $2.09 \mathrm{e}-09$ & $1.98 \mathrm{e}-09$ & $1.83 \mathrm{e}-09$ & $1.66 \mathrm{e}-09$ & $1.57 \mathrm{e}-09$ \\
\hline 19 & 21 & $1.69 \mathrm{e}-09$ & $1.57 \mathrm{e}-09$ & $1.43 \mathrm{e}-09$ & $1.29 \mathrm{e}-09$ & $1.14 \mathrm{e}-09$ & $9.97 \mathrm{e}-10$ & $9.24 \mathrm{e}-10$ \\
\hline 20 & 22 & $2.17 \mathrm{e}-09$ & $2.02 \mathrm{e}-09$ & $1.86 \mathrm{e}-09$ & $1.68 \mathrm{e}-09$ & $1.49 \mathrm{e}-09$ & $1.30 \mathrm{e}-09$ & $1.20 \mathrm{e}-09$ \\
\hline 21 & 23 & $1.18 \mathrm{e}-09$ & $1.06 \mathrm{e}-09$ & $9.43 \mathrm{e}-10$ & $8.29 \mathrm{e}-10$ & $7.18 \mathrm{e}-10$ & $6.12 \mathrm{e}-10$ & $5.62 \mathrm{e}-10$ \\
\hline 22 & 24 & $1.99 \mathrm{e}-09$ & $1.80 \mathrm{e}-09$ & $1.61 \mathrm{e}-09$ & $1.42 \mathrm{e}-09$ & $1.24 \mathrm{e}-09$ & $1.06 \mathrm{e}-09$ & $9.70 \mathrm{e}-10$ \\
\hline 24 & 25 & $1.30 \mathrm{e}-09$ & $1.16 \mathrm{e}-09$ & $1.02 \mathrm{e}-09$ & $8.82 \mathrm{e}-10$ & $7.54 \mathrm{e}-10$ & $6.36 \mathrm{e}-10$ & $5.81 \mathrm{e}-10$ \\
\hline
\end{tabular}


Table 5a. $\alpha$-particle collisional excitation rate coefficients for $\mathrm{He}$ II $\left(\mathrm{m}^{3} \mathrm{~s}^{-1}\right)$.

\begin{tabular}{|c|c|c|c|c|c|c|c|c|c|}
\hline \multicolumn{2}{|c|}{$\begin{array}{c}\text { Temperature } \\
(\mathrm{eV})\end{array}$} & \multirow[t]{2}{*}{0.273} & \multirow[t]{2}{*}{0.43} & \multirow[t]{2}{*}{0.69} & \multirow[t]{2}{*}{1.09} & \multirow[t]{2}{*}{1.72} & \multirow[t]{2}{*}{2.73} & \multirow[t]{2}{*}{4.33} & \multirow[t]{2}{*}{6.86} \\
\hline $\begin{array}{l}\text { Lower } \\
\text { index }\end{array}$ & $\begin{array}{l}\text { Upper } \\
\text { index }\end{array}$ & & & & & & & & \\
\hline 2 & 3 & $5.87 \mathrm{e}-11$ & $7.78 \mathrm{e}-11$ & $9.49 \mathrm{e}-11$ & $1.08 \mathrm{e}-10$ & $1.16 \mathrm{e}-10$ & $1.19 \mathrm{e}-10$ & $1.18 \mathrm{e}-10$ & $1.12 \mathrm{e}-10$ \\
\hline 3 & 4 & $1.93 \mathrm{e}-12$ & $4.41 \mathrm{e}-12$ & $8.31 \mathrm{e}-12$ & $1.39 \mathrm{e}-11$ & $2.12 \mathrm{e}-11$ & $3.02 \mathrm{e}-11$ & $4.04 \mathrm{e}-11$ & $5.11 \mathrm{e}-11$ \\
\hline 5 & 6 & $5.42 \mathrm{e}-10$ & $6.56 \mathrm{e}-10$ & $7.47 \mathrm{e}-10$ & $8.06 \mathrm{e}-10$ & $8.29 \mathrm{e}-10$ & $8.21 \mathrm{e}-10$ & $7.88 \mathrm{e}-10$ & $7.41 \mathrm{e}-10$ \\
\hline 5 & 7 & $2.34 \mathrm{e}-11$ & $4.08 \mathrm{e}-11$ & $6.49 \mathrm{e}-11$ & $9.58 \mathrm{e}-11$ & $1.33 \mathrm{e}-10$ & $1.74 \mathrm{e}-10$ & $2.16 \mathrm{e}-10$ & $2.52 \mathrm{e}-10$ \\
\hline 6 & 8 & $3.39 \mathrm{e}-11$ & $5.90 \mathrm{e}-11$ & $9.45 \mathrm{e}-11$ & $1.42 \mathrm{e}-10$ & $2.01 \mathrm{e}-10$ & $2.71 \mathrm{e}-10$ & $3.44 \mathrm{e}-10$ & $4.15 \mathrm{e}-10$ \\
\hline 8 & 9 & $1.18 \mathrm{e}-10$ & $1.74 \mathrm{e}-10$ & $2.39 \mathrm{e}-10$ & $3.08 \mathrm{e}-10$ & $3.73 e-10$ & $4.26 \mathrm{e}-10$ & $4.62 \mathrm{e}-10$ & $4.80 \mathrm{e}-10$ \\
\hline 10 & 11 & $2.34 \mathrm{e}-09$ & $2.71 \mathrm{e}-09$ & $2.97 \mathrm{e}-09$ & $3.10 \mathrm{e}-09$ & $3.11 \mathrm{e}-09$ & $3.02 \mathrm{e}-09$ & $2.87 \mathrm{e}-09$ & $2.69 \mathrm{e}-09$ \\
\hline 10 & 12 & $1.48 \mathrm{e}-10$ & $2.36 \mathrm{e}-10$ & $3.54 \mathrm{e}-10$ & $5.03 \mathrm{e}-10$ & $6.78 \mathrm{e}-10$ & $8.66 \mathrm{e}-10$ & $1.05 \mathrm{e}-09$ & $1.21 \mathrm{e}-09$ \\
\hline 11 & 13 & $1.94 \mathrm{e}-10$ & $3.10 \mathrm{e}-10$ & $4.70 \mathrm{e}-10$ & $6.75 \mathrm{e}-10$ & $9.22 \mathrm{e}-10$ & $1.20 \mathrm{e}-09$ & $1.48 \mathrm{e}-09$ & $1.73 \mathrm{e}-09$ \\
\hline 12 & 15 & $5.19 \mathrm{e}-10$ & $7.11 \mathrm{e}-10$ & $9.18 \mathrm{e}-10$ & $1.12 \mathrm{e}-09$ & $1.28 \mathrm{e}-09$ & $1.40 \mathrm{e}-09$ & $1.45 \mathrm{e}-09$ & $1.46 \mathrm{e}-09$ \\
\hline 13 & 14 & $6.57 \mathrm{e}-10$ & $9.23 \mathrm{e}-10$ & $1.22 \mathrm{e}-09$ & $1.53 \mathrm{e}-09$ & $1.81 \mathrm{e}-09$ & $2.03 \mathrm{e}-09$ & $2.18 \mathrm{e}-09$ & $2.24 \mathrm{e}-09$ \\
\hline 14 & 16 & $1.11 \mathrm{e}-09$ & $1.39 \mathrm{e}-09$ & $1.64 \mathrm{e}-09$ & $1.84 \mathrm{e}-09$ & $1.95 \mathrm{e}-09$ & $1.99 \mathrm{e}-09$ & $1.96 \mathrm{e}-09$ & $1.88 \mathrm{e}-09$ \\
\hline 17 & 18 & $6.90 \mathrm{e}-09$ & $7.75 \mathrm{e}-09$ & $8.26 \mathrm{e}-09$ & $8.44 \mathrm{e}-09$ & $8.34 \mathrm{e}-09$ & $8.04 \mathrm{e}-09$ & $7.60 \mathrm{e}-09$ & $7.08 \mathrm{e}-09$ \\
\hline 17 & 19 & $5.48 \mathrm{e}-10$ & $8.38 \mathrm{e}-10$ & $1.22 \mathrm{e}-09$ & $1.69 \mathrm{e}-09$ & $2.22 \mathrm{e}-09$ & $2.79 \mathrm{e}-09$ & $3.33 \mathrm{e}-09$ & $3.80 \mathrm{e}-09$ \\
\hline 18 & 20 & $6.98 \mathrm{e}-10$ & $1.07 \mathrm{e}-09$ & $1.57 \mathrm{e}-09$ & $2.19 \mathrm{e}-09$ & $2.91 \mathrm{e}-09$ & $3.69 \mathrm{e}-09$ & $4.48 \mathrm{e}-09$ & $5.19 \mathrm{e}-09$ \\
\hline 19 & 21 & $2.02 \mathrm{e}-09$ & $2.72 \mathrm{e}-09$ & $3.46 \mathrm{e}-09$ & $4.16 \mathrm{e}-09$ & $4.75 \mathrm{e}-09$ & $5.17 \mathrm{e}-09$ & $5.41 \mathrm{e}-09$ & $5.49 \mathrm{e}-09$ \\
\hline 20 & 22 & $2.29 \mathrm{e}-09$ & $3.12 \mathrm{e}-09$ & $4.03 e-09$ & $4.92 \mathrm{e}-09$ & $5.70 \mathrm{e}-09$ & $6.30 \mathrm{e}-09$ & $6.69 \mathrm{e}-09$ & $6.87 \mathrm{e}-09$ \\
\hline 21 & 23 & $3.10 \mathrm{e}-09$ & $3.72 \mathrm{e}-09$ & $4.22 \mathrm{e}-09$ & $4.55 \mathrm{e}-09$ & $4.69 \mathrm{e}-09$ & $4.67 \mathrm{e}-09$ & $4.53 \mathrm{e}-09$ & $4.31 \mathrm{e}-09$ \\
\hline 22 & 24 & $4.23 \mathrm{e}-09$ & $5.24 \mathrm{e}-09$ & $6.13 \mathrm{e}-09$ & $6.80 \mathrm{e}-09$ & $7.21 \mathrm{e}-09$ & $7.37 \mathrm{e}-09$ & $7.31 \mathrm{e}-09$ & $7.08 \mathrm{e}-09$ \\
\hline 24 & 25 & $4.76 \mathrm{e}-09$ & $5.38 \mathrm{e}-09$ & $5.77 \mathrm{e}-09$ & $5.92 \mathrm{e}-09$ & $5.86 \mathrm{e}-09$ & $5.65 \mathrm{e}-09$ & $5.34 \mathrm{e}-09$ & $4.97 \mathrm{e}-09$ \\
\hline
\end{tabular}


Table 5b. $\alpha$-particle collisional excitation rate coefficients for $\mathrm{He}$ II $\left(\mathrm{m}^{3} \mathrm{~s}^{-1}\right)$.

\begin{tabular}{|c|c|c|c|c|c|c|c|c|}
\hline \multicolumn{2}{|c|}{$\begin{array}{c}\text { Temperature } \\
(\mathrm{eV})\end{array}$} & \multirow[t]{2}{*}{10.87} & \multirow[t]{2}{*}{17.23} & \multirow[t]{2}{*}{27.31} & \multirow[t]{2}{*}{43.29} & \multirow[t]{2}{*}{68.61} & \multirow[t]{2}{*}{108.74} & \multirow[t]{2}{*}{136.90} \\
\hline $\begin{array}{l}\text { Lower } \\
\text { index }\end{array}$ & $\begin{array}{l}\text { Upper } \\
\text { index }\end{array}$ & & & & & & & \\
\hline 2 & 3 & $1.05 \mathrm{e}-10$ & $9.64 \mathrm{e}-11$ & $8.75 \mathrm{e}-11$ & $7.87 \mathrm{e}-11$ & $7.02 \mathrm{e}-11$ & $6.22 \mathrm{e}-11$ & $5.83 \mathrm{e}-11$ \\
\hline 3 & 4 & $6.09 \mathrm{e}-11$ & $6.86 \mathrm{e}-11$ & $7.37 \mathrm{e}-11$ & $7.60 \mathrm{e}-11$ & $7.58 \mathrm{e}-11$ & $7.39 \mathrm{e}-11$ & $7.23 \mathrm{e}-11$ \\
\hline 5 & 6 & $6.85 \mathrm{e}-10$ & $6.27 \mathrm{e}-10$ & $5.68 \mathrm{e}-10$ & $5.10 \mathrm{e}-10$ & $4.53 \mathrm{e}-10$ & $3.97 \mathrm{e}-10$ & $3.70 \mathrm{e}-10$ \\
\hline 5 & 7 & $2.80 \mathrm{e}-10$ & $2.98 \mathrm{e}-10$ & $3.05 \mathrm{e}-10$ & $3.03 \mathrm{e}-10$ & $2.94 \mathrm{e}-10$ & $2.79 \mathrm{e}-10$ & $2.71 \mathrm{e}-10$ \\
\hline 6 & 8 & $4.76 \mathrm{e}-10$ & $5.21 \mathrm{e}-10$ & $5.49 \mathrm{e}-10$ & $5.59 \mathrm{e}-10$ & $5.55 \mathrm{e}-10$ & $5.37 \mathrm{e}-10$ & $5.24 \mathrm{e}-10$ \\
\hline 8 & 9 & $4.80 \mathrm{e}-10$ & $4.67 \mathrm{e}-10$ & $4.44 \mathrm{e}-10$ & $4.17 \mathrm{e}-10$ & $3.85 \mathrm{e}-10$ & $3.51 \mathrm{e}-10$ & $3.33 \mathrm{e}-10$ \\
\hline 10 & 11 & $2.48 \mathrm{e}-09$ & $2.26 \mathrm{e}-09$ & $2.04 \mathrm{e}-09$ & $1.82 \mathrm{e}-09$ & $1.60 \mathrm{e}-09$ & $1.38 \mathrm{e}-09$ & $1.28 \mathrm{e}-09$ \\
\hline 10 & 12 & $1.33 \mathrm{e}-09$ & $1.41 \mathrm{e}-09$ & $1.45 \mathrm{e}-09$ & $1.45 \mathrm{e}-09$ & $1.40 \mathrm{e}-09$ & $1.33 \mathrm{e}-09$ & $1.29 \mathrm{e}-09$ \\
\hline 11 & 13 & $1.95 \mathrm{e}-09$ & $2.11 \mathrm{e}-09$ & $2.20 \mathrm{e}-09$ & $2.22 \mathrm{e}-09$ & $2.17 \mathrm{e}-09$ & $2.08 \mathrm{e}-09$ & $2.01 \mathrm{e}-09$ \\
\hline 12 & 15 & $1.43 \mathrm{e}-09$ & $1.37 \mathrm{e}-09$ & $1.29 \mathrm{e}-09$ & $1.20 \mathrm{e}-09$ & $1.10 \mathrm{e}-09$ & $9.85 \mathrm{e}-10$ & $9.29 \mathrm{e}-10$ \\
\hline 13 & 14 & $2.24 \mathrm{e}-09$ & $2.19 \mathrm{e}-09$ & $2.09 \mathrm{e}-09$ & $1.96 \mathrm{e}-09$ & $1.81 \mathrm{e}-09$ & $1.64 \mathrm{e}-09$ & $1.55 \mathrm{e}-09$ \\
\hline 14 & 16 & $1.78 \mathrm{e}-09$ & $1.66 \mathrm{e}-09$ & $1.52 \mathrm{e}-09$ & $1.38 \mathrm{e}-09$ & $1.23 \mathrm{e}-09$ & $1.09 \mathrm{e}-09$ & $1.02 \mathrm{e}-09$ \\
\hline 17 & 18 & $6.51 \mathrm{e}-09$ & $5.91 \mathrm{e}-09$ & $5.29 \mathrm{e}-09$ & $4.66 \mathrm{e}-09$ & $4.05 \mathrm{e}-09$ & $3.46 \mathrm{e}-09$ & $3.18 \mathrm{e}-09$ \\
\hline 17 & 19 & $4.17 \mathrm{e}-09$ & $4.40 \mathrm{e}-09$ & $4.49 \mathrm{e}-09$ & $4.45 \mathrm{e}-09$ & $4.28 \mathrm{e}-09$ & $4.02 \mathrm{e}-09$ & $3.85 \mathrm{e}-09$ \\
\hline 18 & 20 & $5.77 \mathrm{e}-09$ & $6.17 \mathrm{e}-09$ & $6.36 \mathrm{e}-09$ & $6.35 \mathrm{e}-09$ & $6.15 \mathrm{e}-09$ & $5.79 \mathrm{e}-09$ & $5.57 \mathrm{e}-09$ \\
\hline 19 & 21 & $5.42 \mathrm{e}-09$ & $5.23 \mathrm{e}-09$ & $4.94 \mathrm{e}-09$ & $4.57 \mathrm{e}-09$ & $4.16 \mathrm{e}-09$ & $3.71 \mathrm{e}-09$ & $3.48 \mathrm{e}-09$ \\
\hline 20 & 22 & $6.85 \mathrm{e}-09$ & $6.67 \mathrm{e}-09$ & $6.35 \mathrm{e}-09$ & $5.91 \mathrm{e}-09$ & $5.39 \mathrm{e}-09$ & $4.82 \mathrm{e}-09$ & $4.53 \mathrm{e}-09$ \\
\hline 21 & 23 & $4.04 \mathrm{e}-09$ & $3.73 \mathrm{e}-09$ & $3.39 \mathrm{e}-09$ & $3.05 \mathrm{e}-09$ & $2.69 \mathrm{e}-09$ & $2.34 \mathrm{e}-09$ & $2.17 \mathrm{e}-09$ \\
\hline 22 & 24 & $6.73 \mathrm{e}-09$ & $6.28 \mathrm{e}-09$ & $5.77 \mathrm{e}-09$ & $5.21 \mathrm{e}-09$ & $4.63 \mathrm{e}-09$ & $4.04 \mathrm{e}-09$ & $3.75 \mathrm{e}-09$ \\
\hline 24 & 25 & $4.57 \mathrm{e}-09$ & $4.15 \mathrm{e}-09$ & $3.72 \mathrm{e}-09$ & $3.29 \mathrm{e}-09$ & $2.87 \mathrm{e}-09$ & $2.47 \mathrm{e}-09$ & $2.27 \mathrm{e}-09$ \\
\hline
\end{tabular}




\section{Figure captions}

Figure 1. Heavy particle collisional data for the fine-structure transitions within the $n=2$ shell of He II. Cross sections in atomic units $\left(a_{0}^{2}\right)$ for a) the $2 p^{2} P_{1 / 2}-2 s{ }^{2} S_{1 / 2}$, b) the $2 s^{2} S_{1 / 2}$ $2 p^{2} \mathrm{P}_{3 / 2}$ and $\left.\mathrm{c}\right)$ the $2 \mathrm{p}\left({ }^{2} \mathrm{P}_{1 / 2}{ }^{2} \mathrm{P}_{3 / 2}\right)$ transitions. Excitation rate coefficients for $\left.\mathrm{d}\right)$ the $2 \mathrm{p}^{2} \mathrm{P}_{1 / 2}$ $2{ }^{2} \mathrm{~S}_{1 / 2}$ and $2 \mathrm{~s}{ }^{2} \mathrm{~S}_{1 / 2}-2 \mathrm{p}{ }^{2} \mathrm{P}_{3 / 2}$ transitions and e) the $2 \mathrm{p}\left({ }^{2} \mathrm{P}_{1 / 2}{ }^{2} \mathrm{P}_{3 / 2}\right)$ transition. Full lines show $\alpha$-particle impact data and dashed lines d impact data.

Figure 2. Comparison of the present calculations (full lines) and those of Ryans et al. (1998) (dashed lines) of the heavy particle collisional data for the fine-structure transitions within the $2 s 2 p{ }^{3} \mathrm{P}$ multiplet of C III. a) $\alpha$-particle impact cross sections for the $2 \mathrm{~s} 2 \mathrm{p}\left({ }^{3} \mathrm{P}_{0}{ }^{3} \mathrm{P}_{2}\right)$ and $2 \mathrm{~s} 2 \mathrm{p}$ $\left({ }^{3} \mathrm{P}_{1}-{ }^{3} \mathrm{P}_{2}\right)$ transitions and $\mathrm{d}$ impact cross sections for the $2 \mathrm{~s} 2 \mathrm{p}\left({ }^{3} \mathrm{P}_{0}-{ }^{3} \mathrm{P}_{2}\right)$ and $2 \mathrm{~s} 2 \mathrm{p}\left({ }^{3} \mathrm{P}_{1}-{ }^{3} \mathrm{P}_{2}\right)$ transitions in atomic units $\left(\mathrm{a}_{0}{ }^{2}\right)$. b) $\alpha$-particle impact rate coefficients for the $2 \mathrm{~s} 2 \mathrm{p}\left({ }^{3} \mathrm{P}_{0}{ }^{3} \mathrm{P}_{2}\right)$ and $2 \mathrm{~s} 2 \mathrm{p}\left({ }^{3} \mathrm{P}_{1-}{ }^{3} \mathrm{P}_{2}\right)$ transitions and $\mathrm{d}$ impact cross sections for the $2 \mathrm{~s} 2 \mathrm{p}\left({ }^{3} \mathrm{P}_{0^{-}}{ }^{3} \mathrm{P}_{2}\right)$ and $2 \mathrm{~s} 2 \mathrm{p}\left({ }^{3} \mathrm{P}_{1^{-}}\right.$ $\left.{ }^{3} \mathrm{P}_{2}\right)$ transitions.

Figure 3. Comparison of the cross sections in atomic units $\left(\mathrm{a}_{0}{ }^{2}\right)$ for proton impact of transitions within the $n=2$ shell of He II calculated by Zygelman and Dalgarno (1987) (+) and the present calculations (full line). a) For the $2 p{ }^{2} \mathrm{P}_{1 / 2}-2 \mathrm{~s}^{2} \mathrm{~S}_{1 / 2}, \mathrm{~b}$ ) the $2 \mathrm{~s}^{2} \mathrm{~S}_{1 / 2}-2 \mathrm{p}{ }^{2} \mathrm{P}_{3 / 2}$ and c) the $2 \mathrm{p}\left({ }^{2} \mathrm{P}_{1 / 2{ }^{-}}{ }^{2} \mathrm{P}_{3 / 2}\right)$ transitions.

Figure 4. Schematic diagram of the levels within the He II $n=1-4$ shells, illustrating representative populating and depopulating channels of the $3 \mathrm{~d}^{2} \mathrm{D}_{3 / 2}$ level. These include radiative decay, electron and heavy particle collisions.

Figure 5. a) The populations as a fraction of the ground state population of the levels within the $n=2$ (full lines) and 3 (dashed lines) shells of He II at a temperature of $3.4 \mathrm{eV} .{ }^{2} \mathrm{~S}_{1 / 2}$, ${ }^{2} \mathrm{P}_{1 / 2},{ }^{2} \mathrm{P}_{3 / 2},{ }^{2} \mathrm{D}_{3 / 2}$ and ${ }^{2} \mathrm{D}_{5 / 2}$ levels. b) The populations as a fraction of the ground-state population normalized to the electron density of the levels within the $n=4$ shell of He II at a temperature of $3.4 \mathrm{eV} .{ }^{2} \mathrm{~S}_{1 / 2},{ }^{2} \mathrm{P}_{1 / 2},{ }^{2} \mathrm{P}_{3 / 2},{ }^{2} \mathrm{D}_{3 / 2},{ }^{2} \mathrm{D}_{5 / 2},{ }^{2} \mathrm{~F}_{5 / 2}$ and ${ }^{2} \mathrm{~F}_{7 / 2}$ levels. $\alpha$-particle impact excitation is included assuming a He ion density of $47 \%$ of $n_{e}$. The dotted lines show the effect of excluding the $\alpha$-particle rate coefficients for the ${ }^{2} \mathrm{P}_{1 / 2}-{ }^{2} \mathrm{~S}_{1 / 2}$ transitions in the $n=3-5$ shells.

Figure 6. Ratio of populations from a model for He II at a temperature of $3.4 \mathrm{eV}$ using rate coefficients of a) only intershell transitions and b) intershell and fine-structure electron transitions to those from a model using intershell and both electron and $\alpha$-particle fine structure rate coefficients. Full lines denote $n=2$ and dashed lines the $n=3$ levels ${ }^{2} \mathrm{~S}_{1 / 2},{ }^{2} \mathrm{P}_{1 / 2}$, ${ }^{2} \mathrm{P}_{3 / 2},{ }^{2} \mathrm{D}_{3 / 2}$ and ${ }^{2} \mathrm{D}_{5 / 2}$.

Figure 7. Ratio of populations from a model for He II at a temperature of $3.4 \mathrm{eV}$ that includes rate coefficients for all near-degenerate levels to those from a model with the rate coefficients only for the ${ }^{2} \mathrm{P}_{1 / 2}-{ }^{2} \mathrm{~S}_{1 / 2}$ transitions from among the near-degenerate levels. Full lines denote $n$ $=3$ and dashed lines the $n=4$ levels ${ }^{2} \mathrm{~S}_{1 / 2},{ }^{2} \mathrm{P}_{1 / 2},{ }^{2} \mathrm{P}_{3 / 2},{ }^{2} \mathrm{D}_{3 / 2},{ }^{2} \mathrm{D}_{5 / 2},{ }^{2} \mathrm{~F}_{5 / 2}$ and ${ }^{2} \mathrm{~F}_{7 / 2}$.

Figure 8. Ratio of populations from a model for He II at a temperature of $3.4 \mathrm{eV}$ in which the electric quadrupole transition rate coefficients have been increased by $\times 100$. Full lines denote $n=3$ and dashed lines the $n=4$ levels ${ }^{2} \mathrm{~S}_{1 / 2},{ }^{2} \mathrm{P}_{1 / 2},{ }^{2} \mathrm{P}_{3 / 2},{ }^{2} \mathrm{D}_{3 / 2},{ }^{2} \mathrm{D}_{5 / 2},{ }^{2} \mathrm{~F}_{5 / 2}$ and ${ }^{2} \mathrm{~F}_{7 / 2}$.

Figure 9. Minimum densities required to ensure that the level populations are in proportion to the statistical weights. - give present calculations using ${ }^{2} \mathrm{~S}_{1 / 2}$ levels to give limit and ..... using ${ }^{2} \mathrm{P}_{1 / 2}$ levels, ---- have a population within 5\% of statistical, -.-.- from Sampson (1977) and -...- from Tallents (1985). $n=2, n=3, n=4$ and $n=5$ shells. 
Figure 10. Spectral line intensity ratios when the assumption is made of statistical populations within an $n$ shell to that of the full population model for the first four Lyman series members at a density of $10^{18} \mathrm{~m}^{-3} . n=1-2,1-3,1-4$ and 1-5.

Figure 11. Spectral line intensity ratios when the assumption is made of statistical populations within an $n$ shell to that of the full population model for the Lyman-delta, $n=1-5$ transition at densities of $10^{18}, 10^{19}, 10^{20}, 10^{21} \mathrm{~m}^{-3}$.

Figure 12. Spectral line intensity ratio of the $1 \mathrm{~s}-2 \mathrm{p} / 1 \mathrm{~s}-3 \mathrm{p}$ He II transitions at electron densities of $10^{18}, 10^{19}, 10^{20}, 10^{21}, 10^{22}$ and $10^{27} \mathrm{~m}^{-3}$. Full line corresponds to a population model which includes $\alpha$-particle impact, the ion density being $47 \%$ of $n_{e}$, the dashed line a model without $\alpha$-particle impact and the dotted line a model with only intershell transitions.

Figure 13. Spectral line intensity ratio of the $n=3-4 / 3-5$ He II transitions at electron densities of $10^{18}, 10^{19}, 10^{20}, 10^{21}$ and $10^{27} \mathrm{~m}^{-3}$. Full line corresponds to a population model which includes $\alpha$-particle impact, the ion density being $47 \%$ of $n_{e}$, the dashed line a model without $\alpha$-particle impact and the dotted line a model with only intershell transitions.

Figure 14. He II 'branching ratio' with the $n=1-4 / 3-4$ transitions at electron densities of $10^{18}, 10^{19}, 10^{20}, 10^{21}$ and $10^{27} \mathrm{~m}^{-3}$. Full line corresponds to a population model which includes $\alpha$-particle impact, the ion density being $47 \%$ of $n_{e}$, the dashed line a model without $\alpha$-particle impact and the dotted line a model with only intershell transitions.

Figure 15. a) $\beta_{1}$, b) $\beta_{2}$, c) $\beta_{3}$ and d) $\gamma$ ratios for the resolved components of the Lyman- $\alpha$, Balmer- $\alpha$, Balmer- $\beta$ and Paschen- $\alpha$ He II spectral lines, respectively, at electron temperatures of $0.54,1.37,3.43,8.62$ and $21.65 \mathrm{eV}$. The full lines of figure $15 \mathrm{~d}$ illustrate the $\gamma$ ratio, the dashed lines show the difference when all components are included. The population model includes $\alpha$-particle impact, the ion density being $47 \%$ of $n_{e}$. + show the results of Tallents (1985).

Figure 16. Ratios of level populations when the ion temperature is double the electron temperature. Full lines represent the $2 \mathrm{~s}^{2} \mathrm{~S}_{1 / 2}$ and dashed lines the $3 \mathrm{~s}{ }^{2} \mathrm{~S}_{1 / 2}$ levels. The ion density is $47 \%$ of the electron densities, which are $10^{18}, 10^{19}, 10^{20}, 10^{21}$ and $10^{22} \mathrm{~m}^{-3}$.

Figure 17. Ratio of the $\beta_{1}$ ratio when the ion temperature is double the electron temperature. The ion density is $47 \%$ of the electron densities, which are $10^{18}, 10^{19}, 10^{20}, 10^{21}$ and $10^{22} \mathrm{~m}^{-3}$.

Figure 18. Ratios of the effective collision strengths a) of Ballance et al. (2003) Aggarwal et al (1991) ---- and ADAS 97 data -.-.- to those of Aggarwal et al. (2017) for transitions from the He II ground state, $1 \mathrm{~s}{ }^{2} \mathrm{~S}-2 \mathrm{~s}{ }^{2} \mathrm{~S},-2 \mathrm{p}{ }^{2} \mathrm{P},-3 \mathrm{~s}{ }^{2} \mathrm{~S},-3 \mathrm{p}{ }^{2} \mathrm{P},-3 \mathrm{~d}{ }^{2} \mathrm{D},-4 \mathrm{~s}^{2} \mathrm{~S},-4 \mathrm{p}$ ${ }^{2} \mathrm{P},-4 \mathrm{~d}^{2} \mathrm{D}$ and $-4 \mathrm{f}^{2} \mathrm{~F}$ and $\mathrm{b}$ ) of Kisielius et al. (1996) to those of Aggarwal et al. (2017) for ground state transitions, $1 \mathrm{~s}{ }^{2} \mathrm{~S}_{1 / 2}-2 \mathrm{p}^{2} \mathrm{P}_{1 / 2}-,-2 \mathrm{~s}{ }^{2} \mathrm{~S}_{1 / 2}-,-2 \mathrm{p}^{2} \mathrm{P}_{3 / 2}-,-3 \mathrm{p}^{2} \mathrm{P}_{1 / 2}-,-3 \mathrm{~s}{ }^{2} \mathrm{~S}_{1 / 2}$ $-,-3 d{ }^{2} \mathrm{D}_{3 / 2}----,-3 p{ }^{2} \mathrm{P}_{3 / 2}----,-3 \mathrm{~d}^{2} \mathrm{D}_{5 / 2}----,-4 \mathrm{p}^{2} \mathrm{P}_{1 / 2}----,-4 \mathrm{~s}^{2} \mathrm{~S}_{1 / 2}----,,-4 \mathrm{~d}^{2} \mathrm{D}_{3 / 2}-.-.-,-4 \mathrm{p}$ ${ }^{2} \mathrm{P}_{3 / 2-.-.-,}-4 \mathrm{~d}^{2} \mathrm{D}_{5 / 2}-. .-.-,-4 \mathrm{f}^{2} \mathrm{~F}_{5 / 2}-. .--$ and $-4 \mathrm{f}^{2} \mathrm{~F}_{7 / 2}-.-.-$.

Figure 19. Ratios of line intensities derived from ADAS 97 data, + , and from Ballance et al. (2003), $\times$, to those of Aggarwal et al. (2017). a) $n=1-2,1-3,1-4$ transitions and b) $n=2-3$, 2-4, 3-4 transitions. $-n_{e}=10^{18} \mathrm{~m}^{-3}, \ldots . .10^{19} \mathrm{~m}^{-3},----10^{20} \mathrm{~m}^{-3},-.-.-10^{21} \mathrm{~m}^{-3}$.

Figure 20. Ratios of line intensities derived from ADAS 97 data to those from Ballance et al. (2003). $n=1-2,1-3,1-4$ transitions. $-n_{e}=10^{18} \mathrm{~m}^{-3}, \ldots . .10^{19} \mathrm{~m}^{-3},----10^{20} \mathrm{~m}^{-3},-.-.-10^{21}$ $\mathrm{m}-3,-\ldots-10^{22} \mathrm{~m}^{-3}$. 

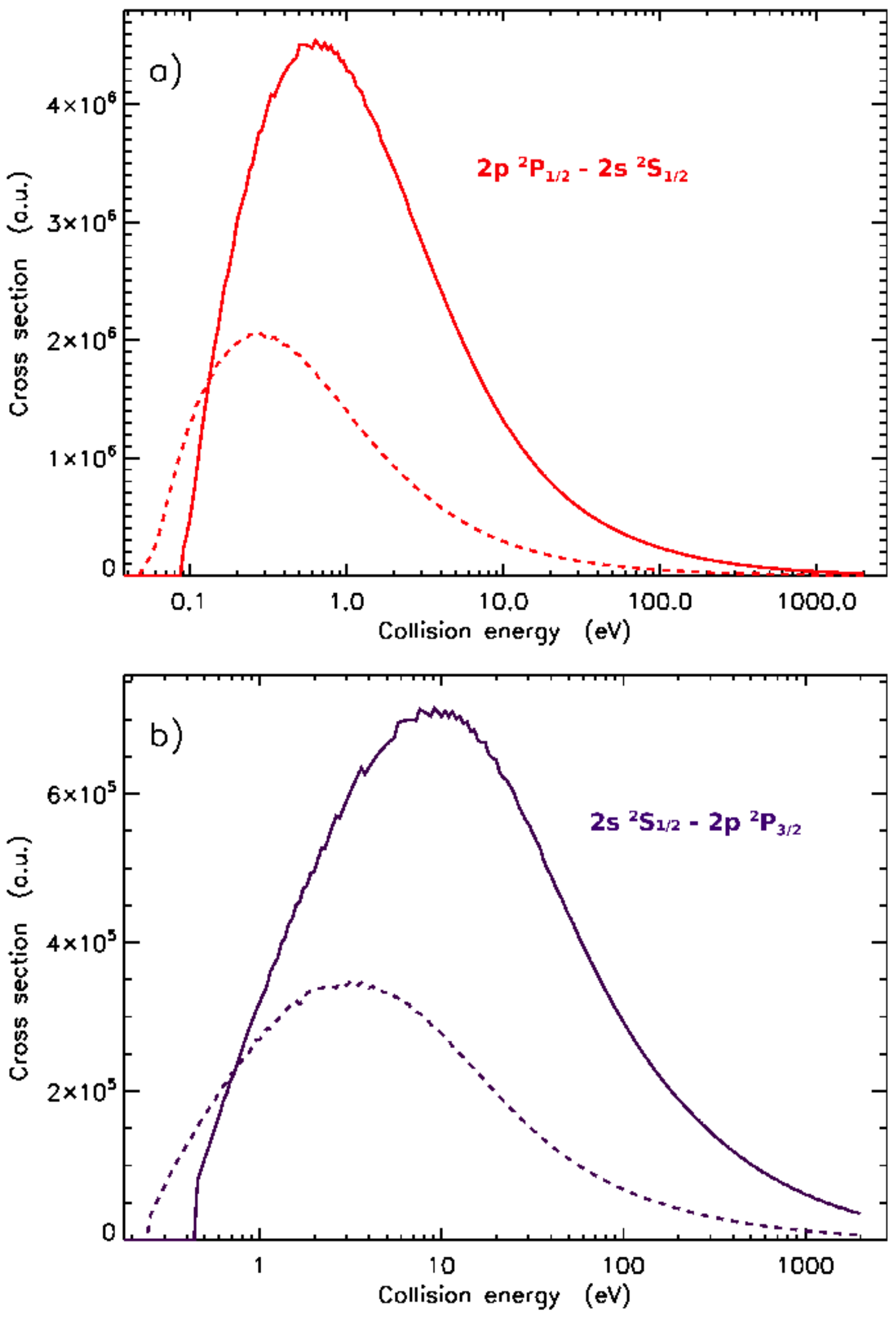

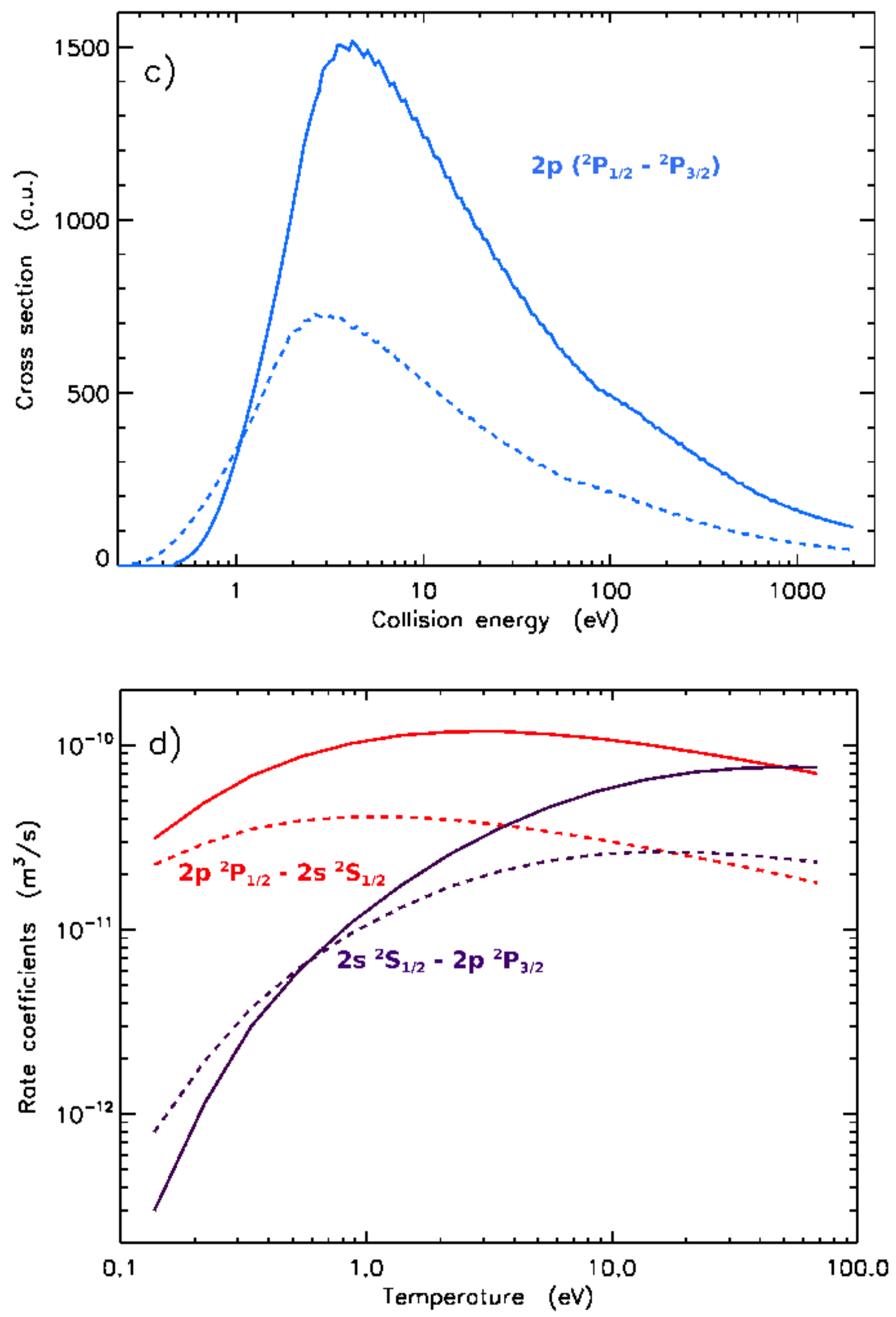


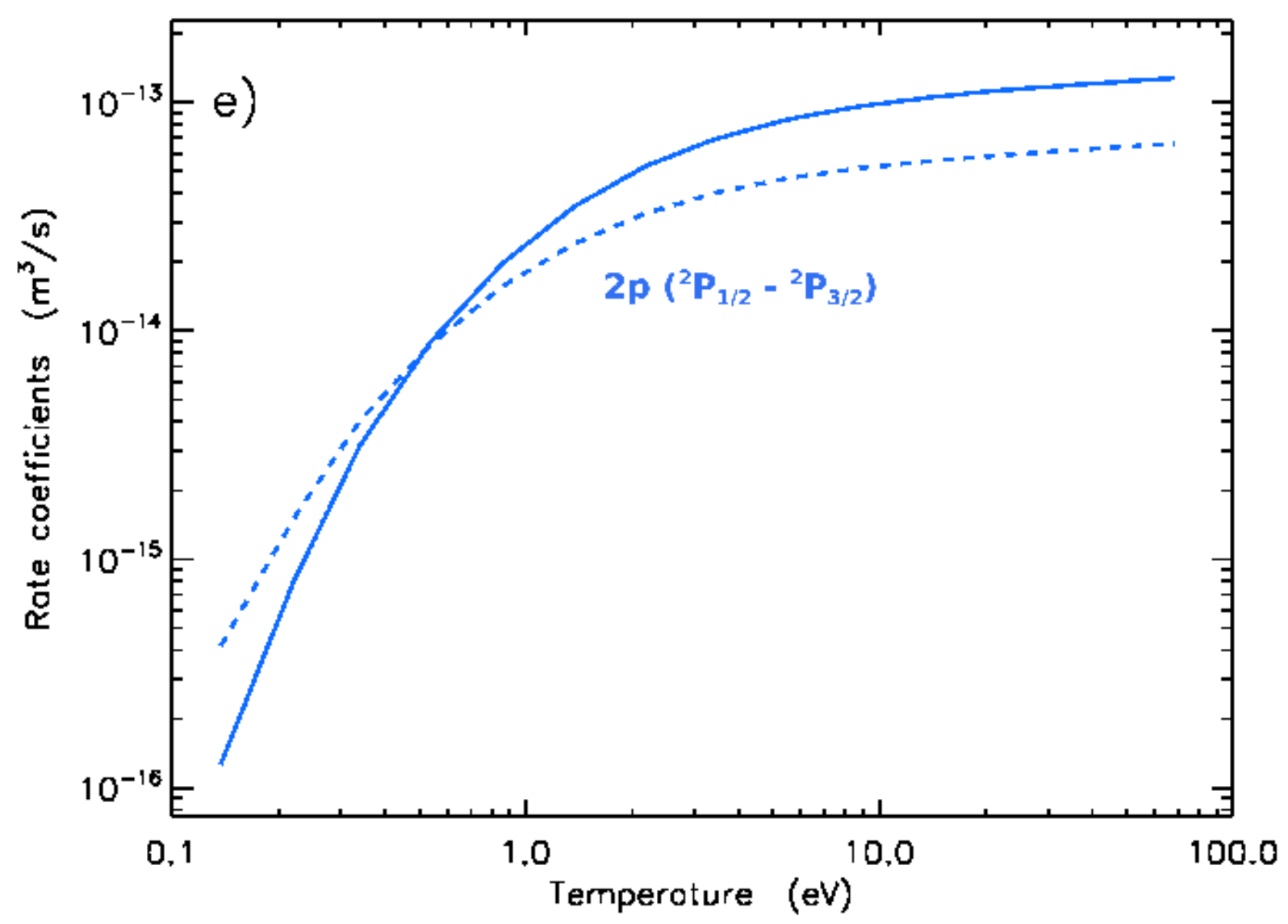

Figure 1.

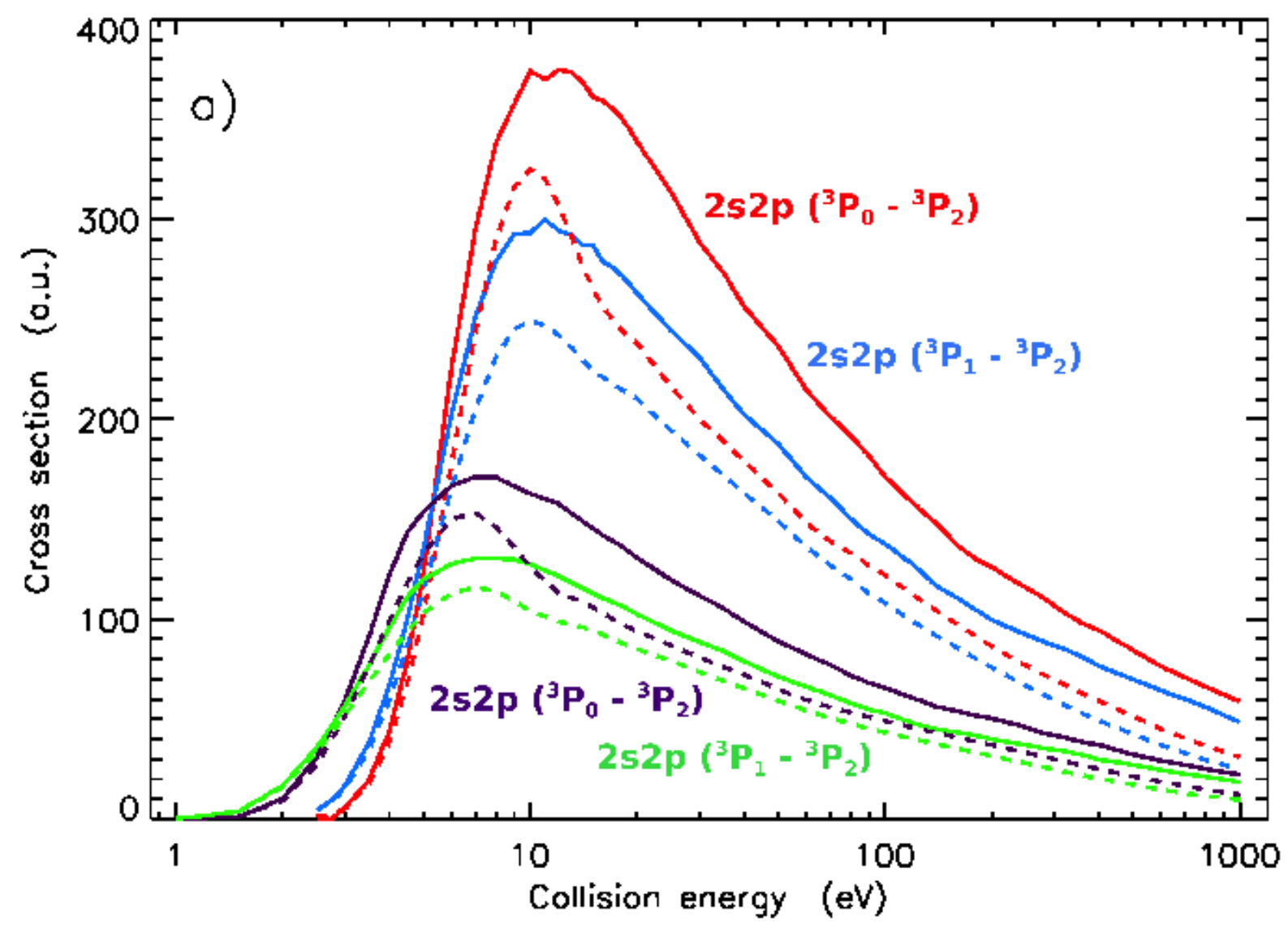




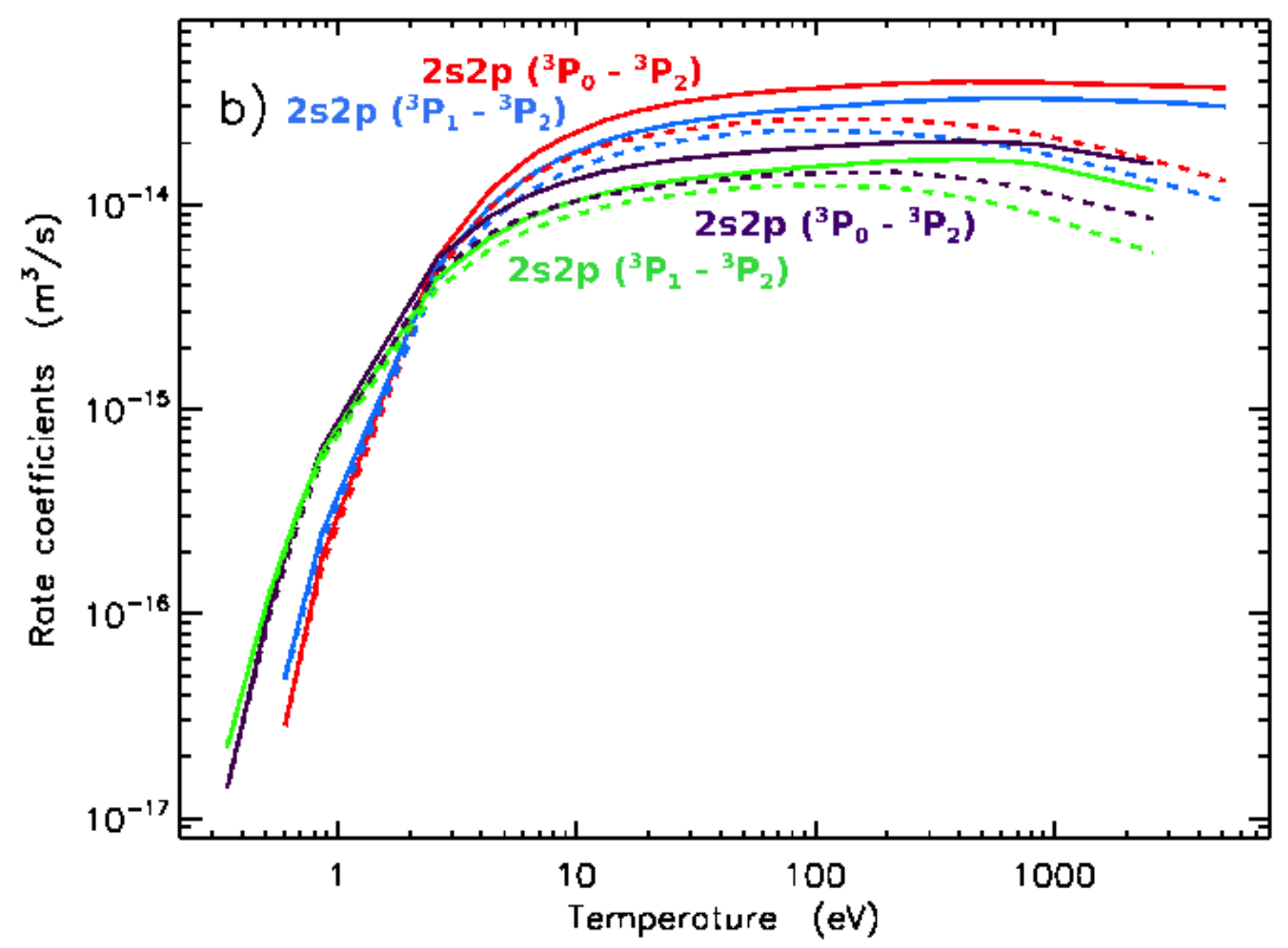

Figure 2.

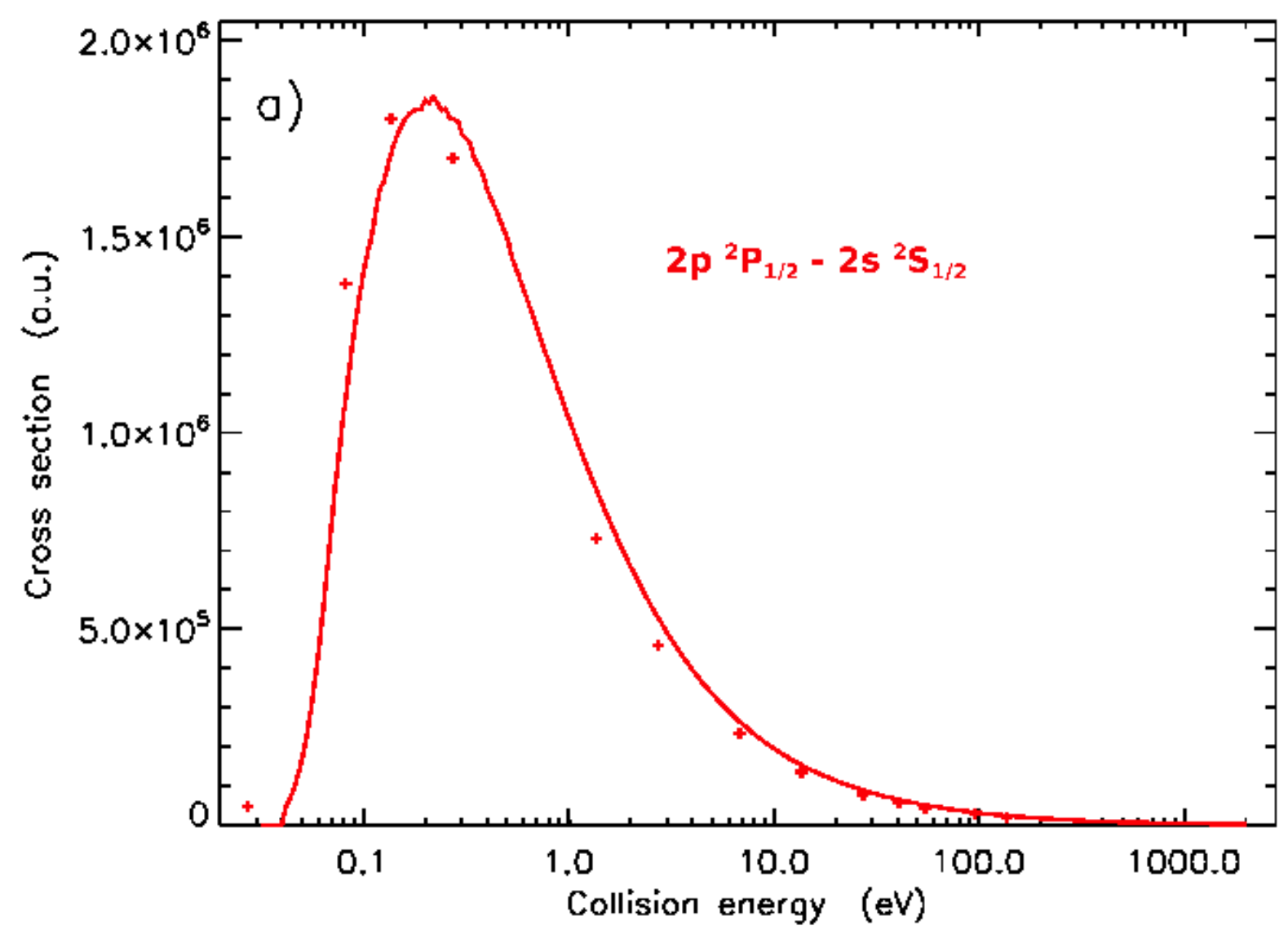



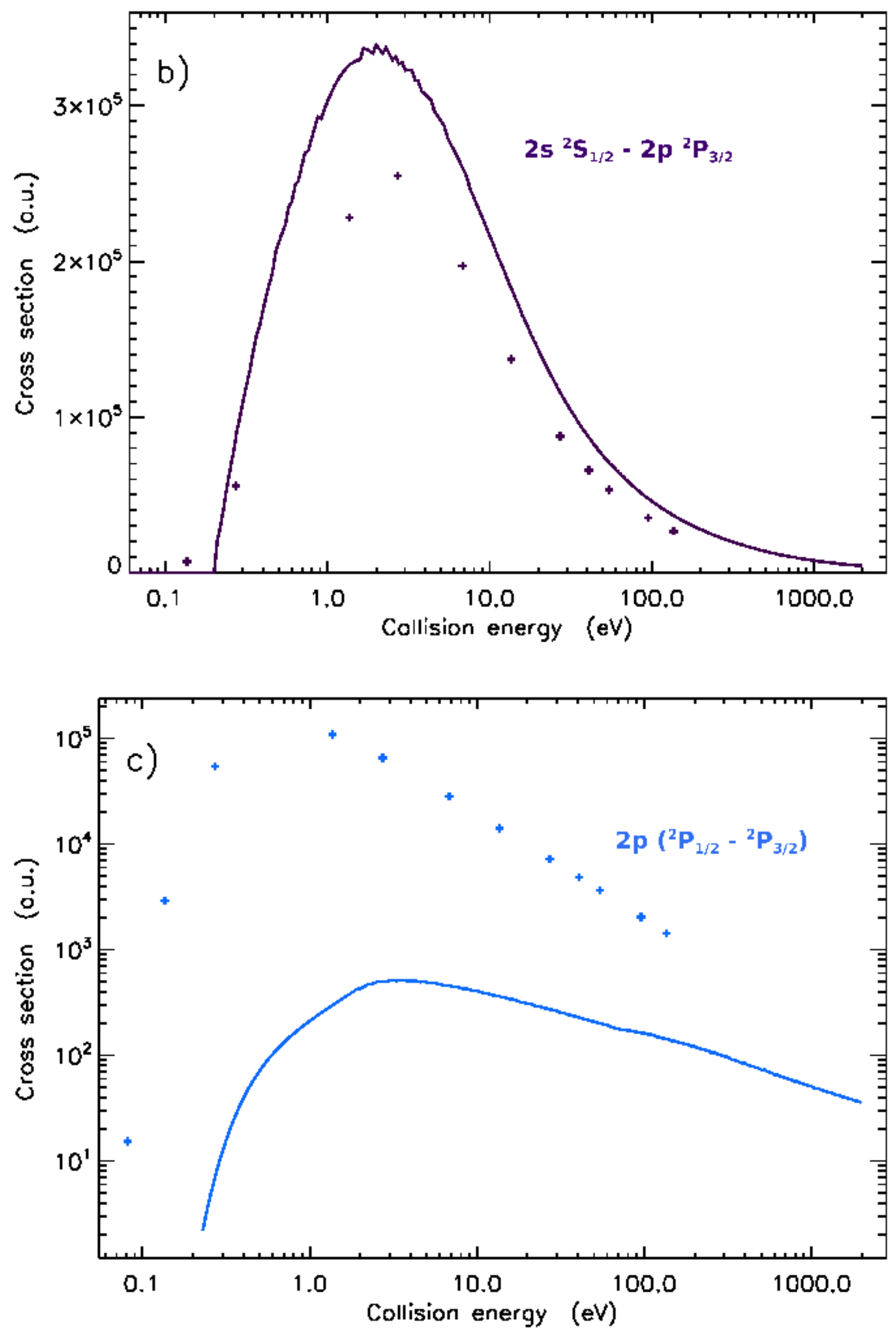

Figure 3. 


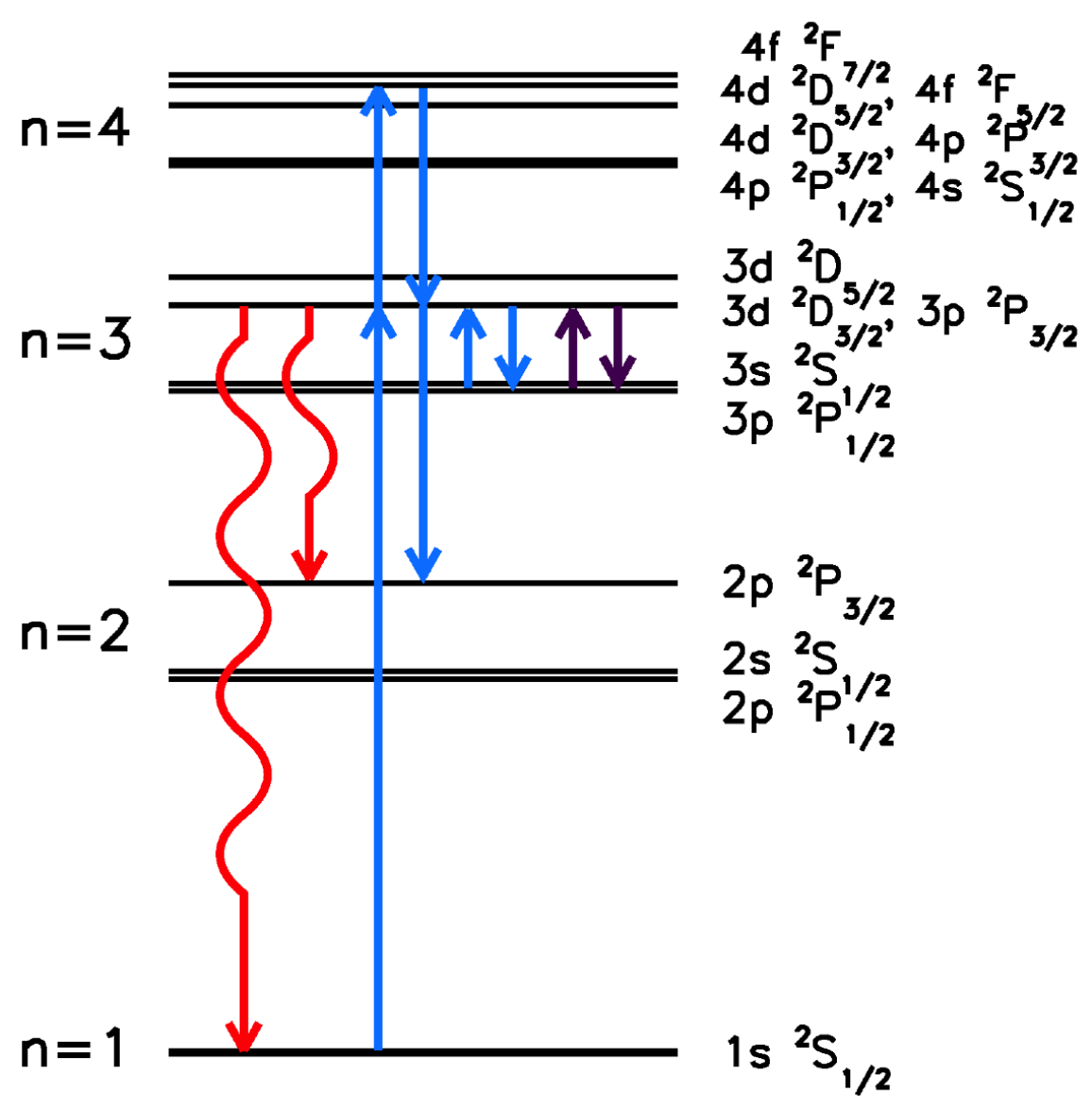

Figure 4.

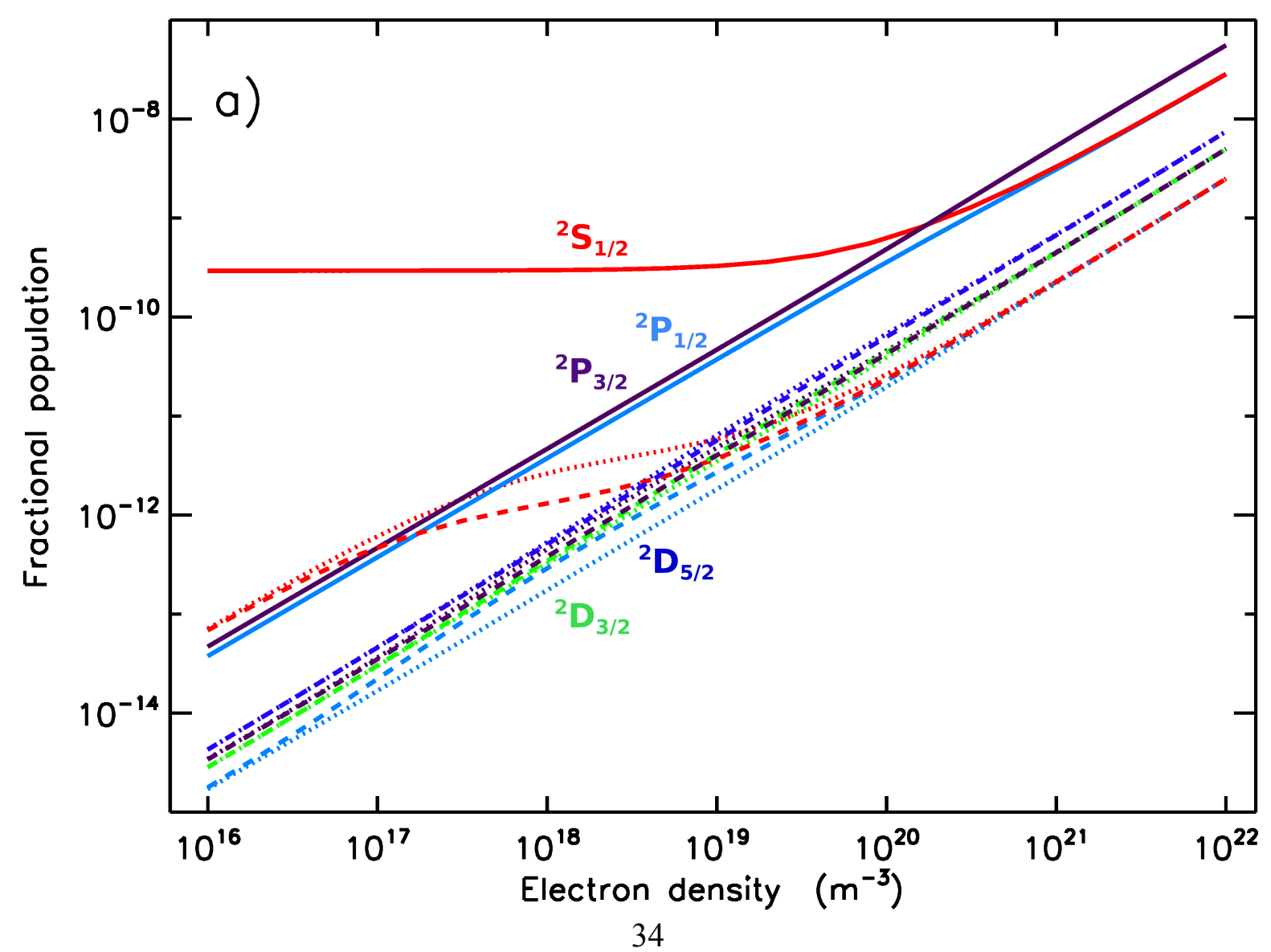




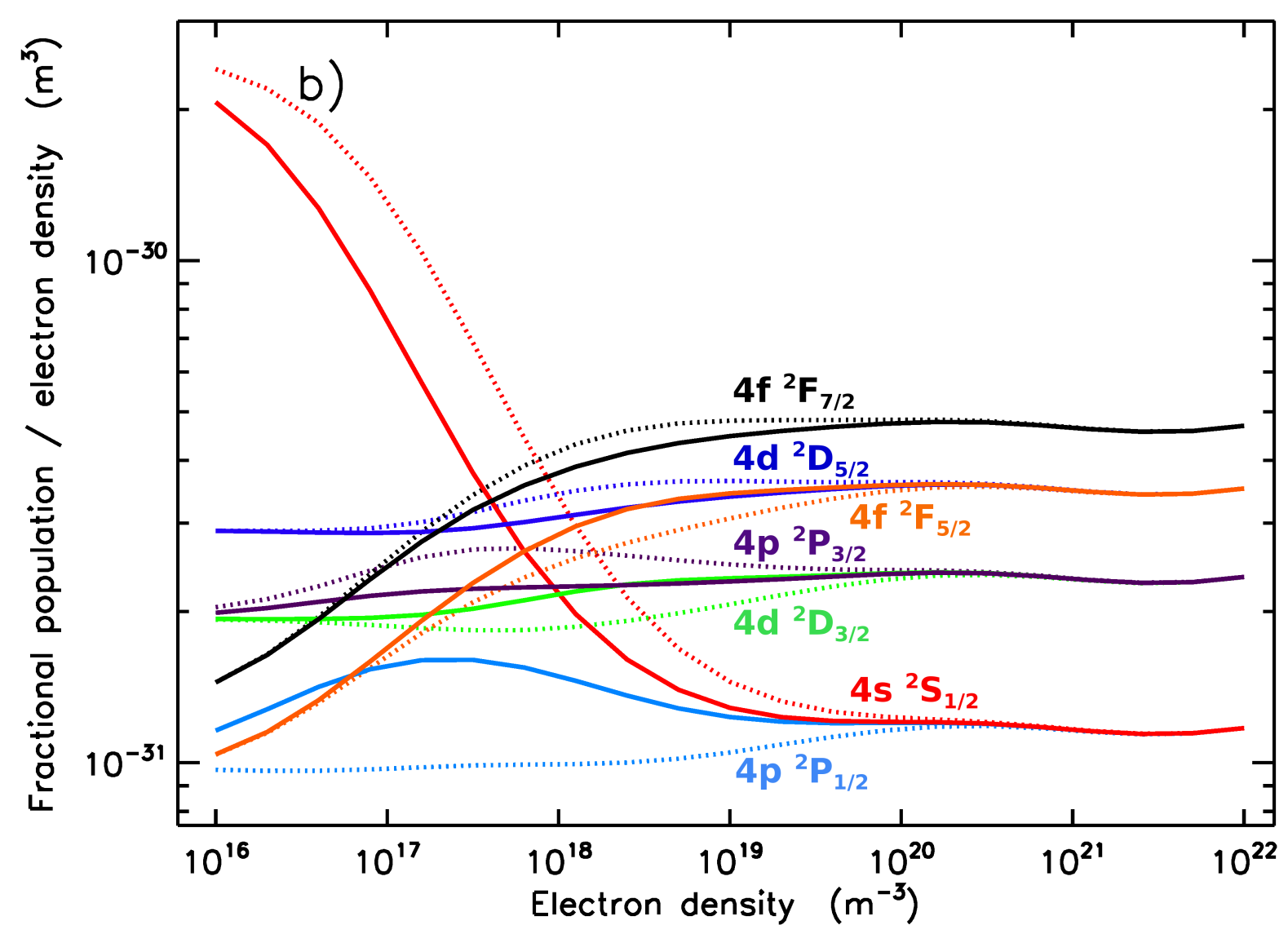

Figure 5.

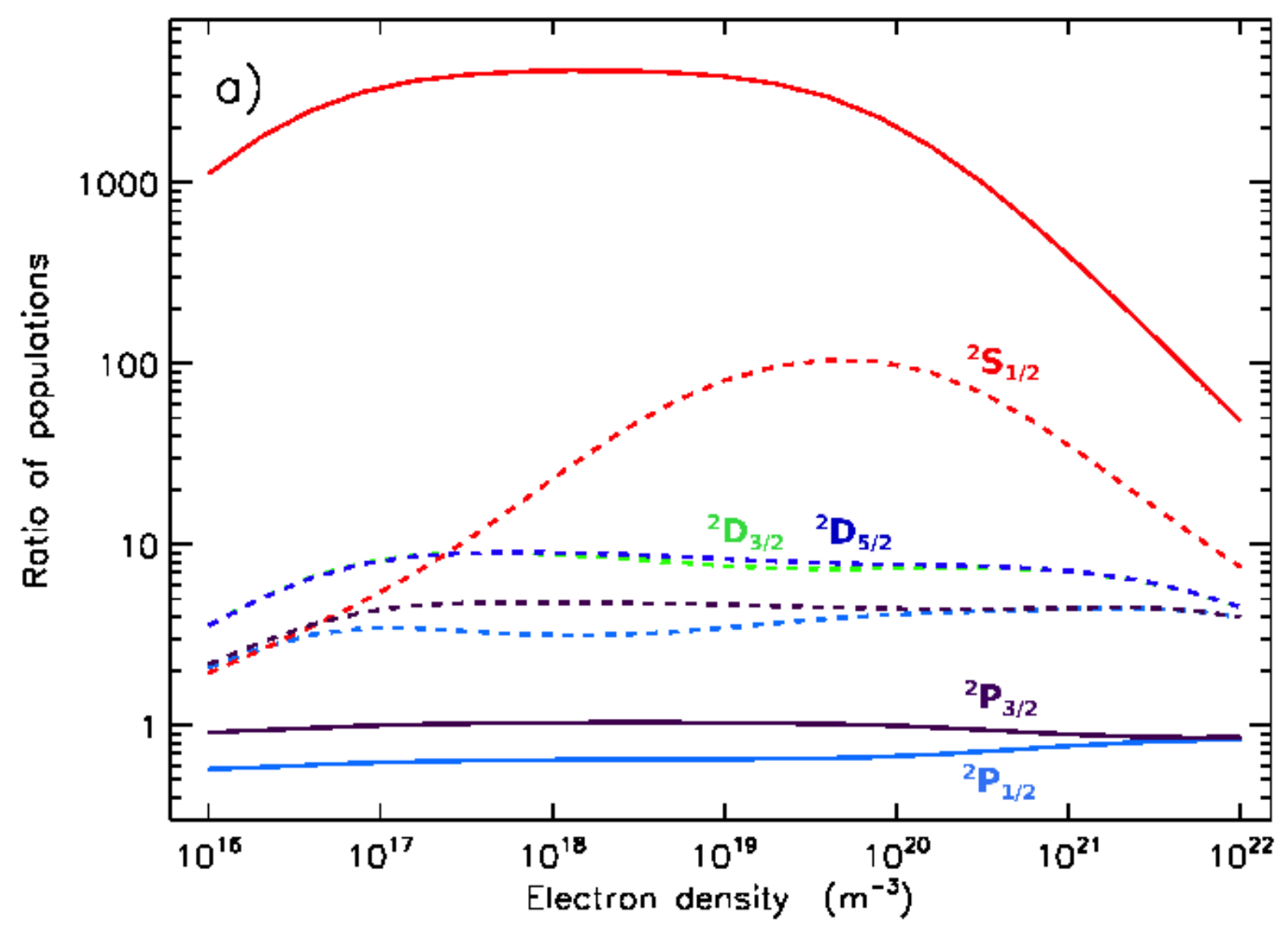




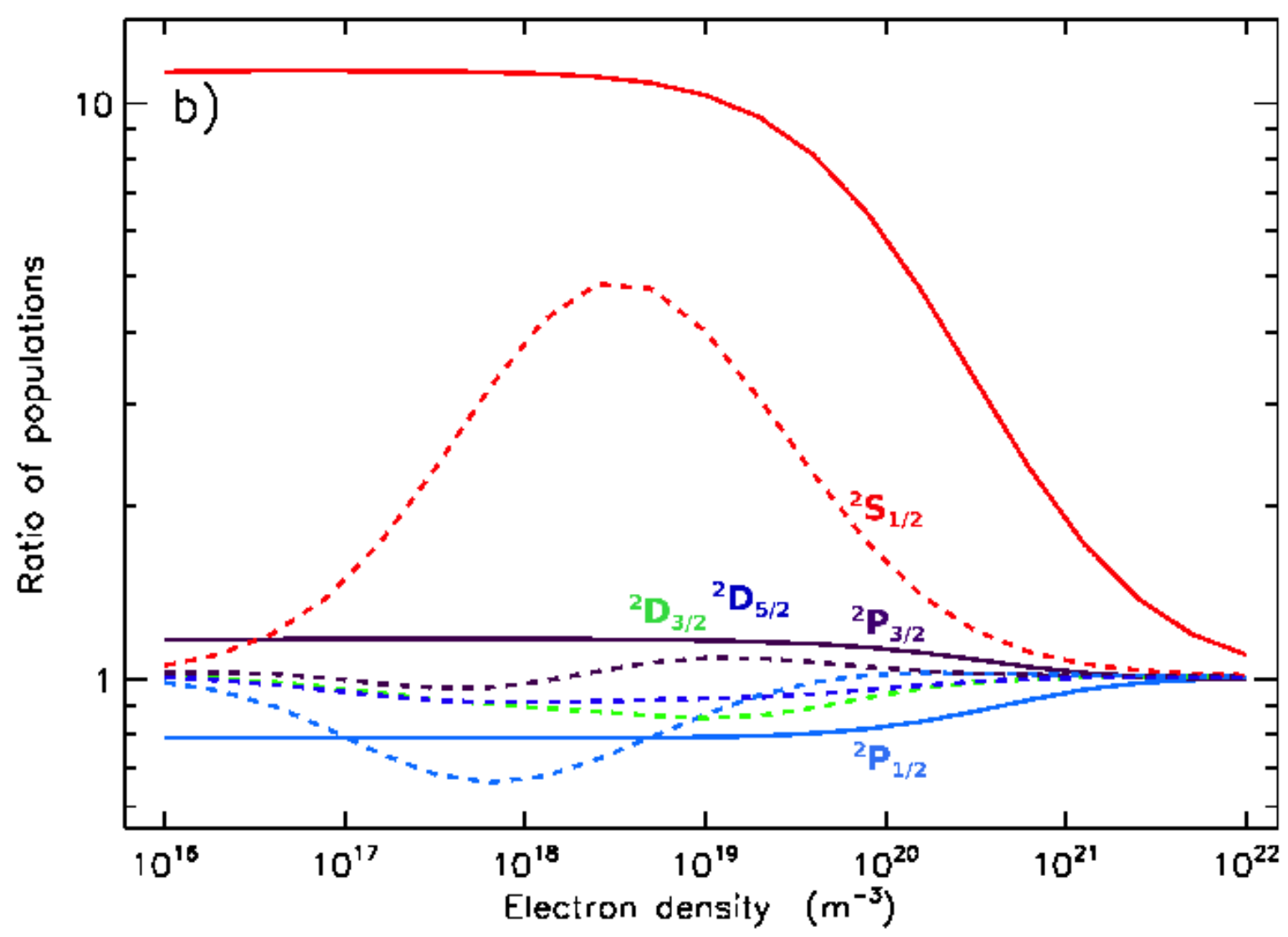

Figure 6.

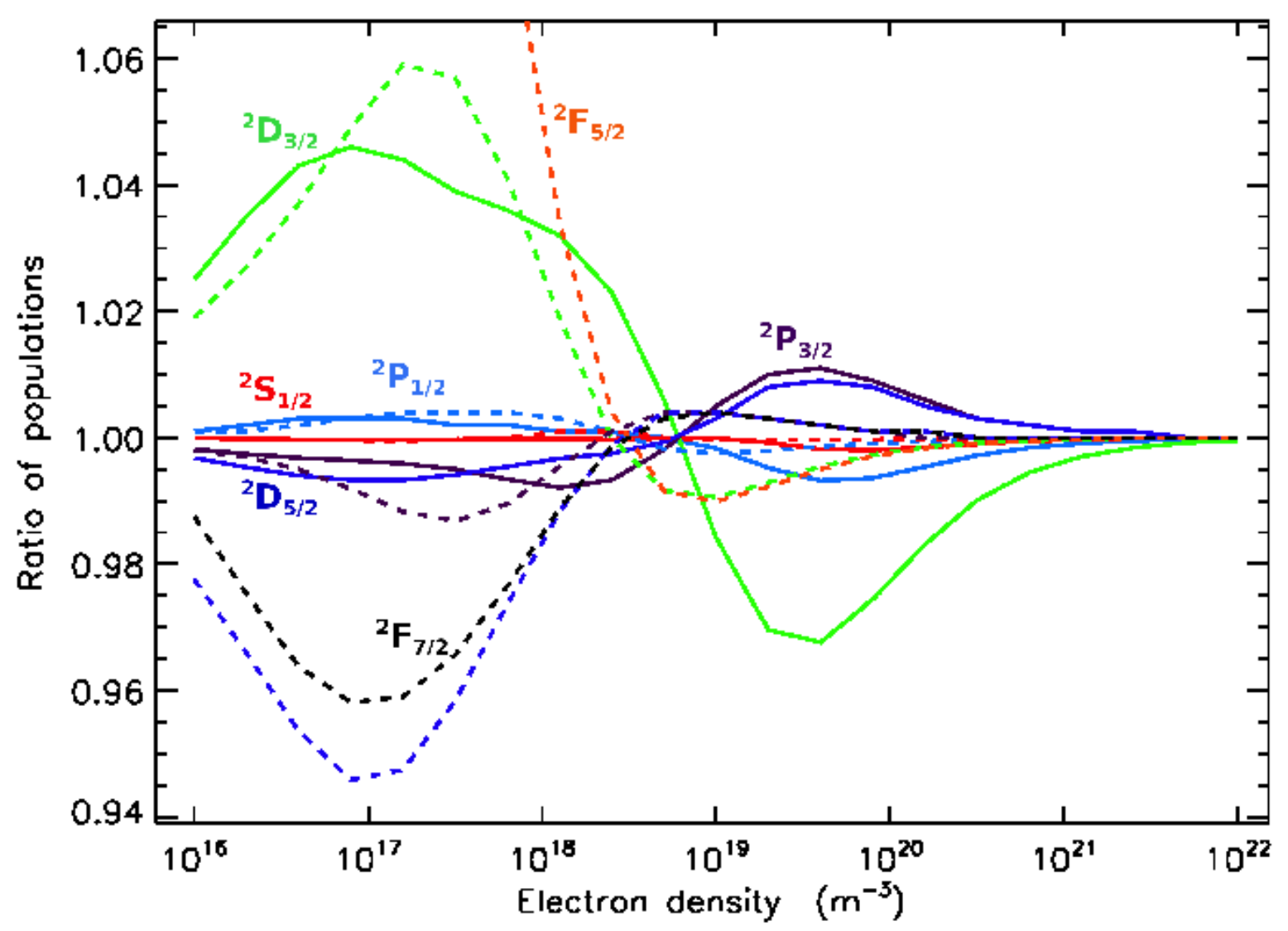

Figure 7. 


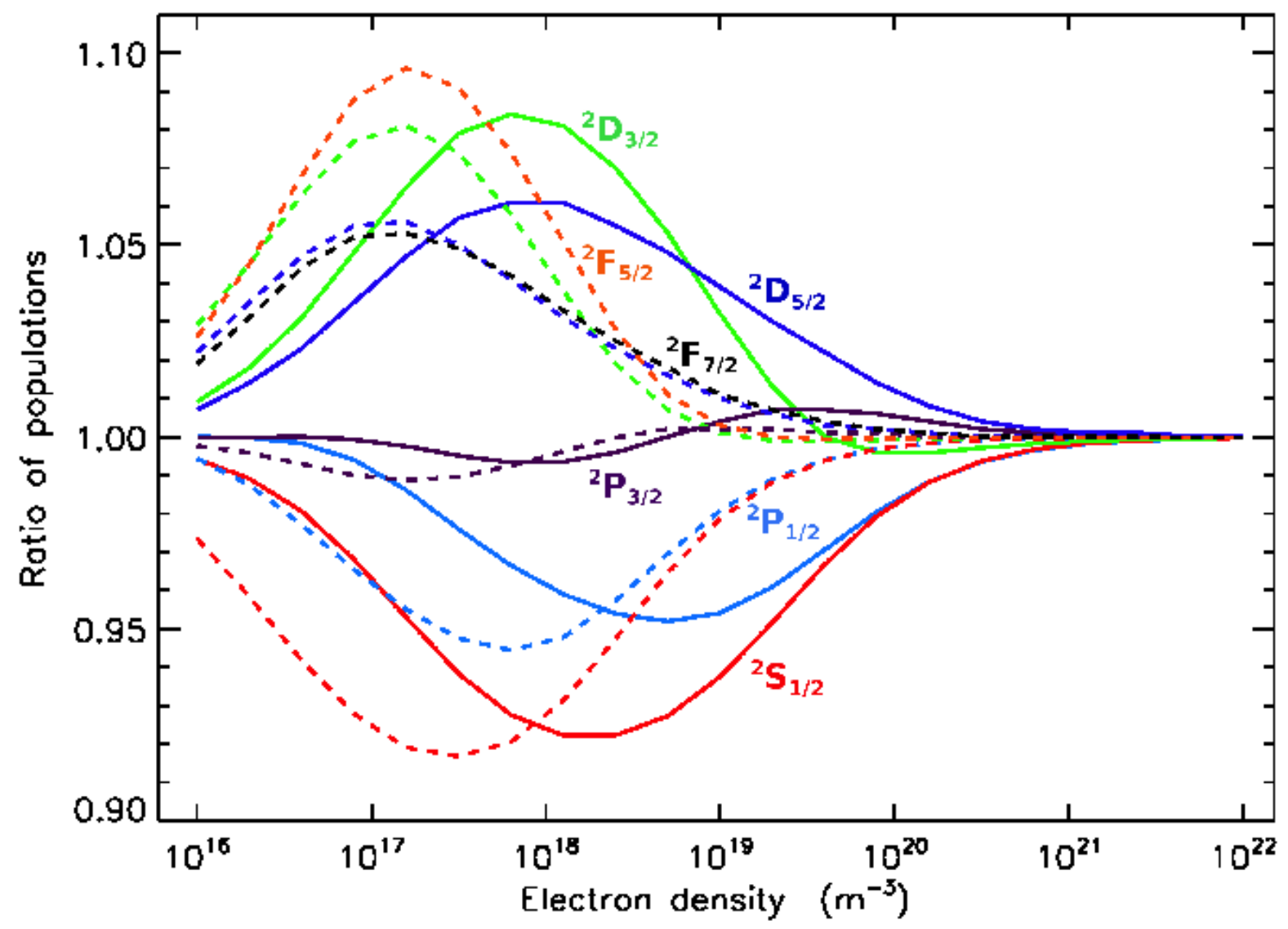

Figure 8.

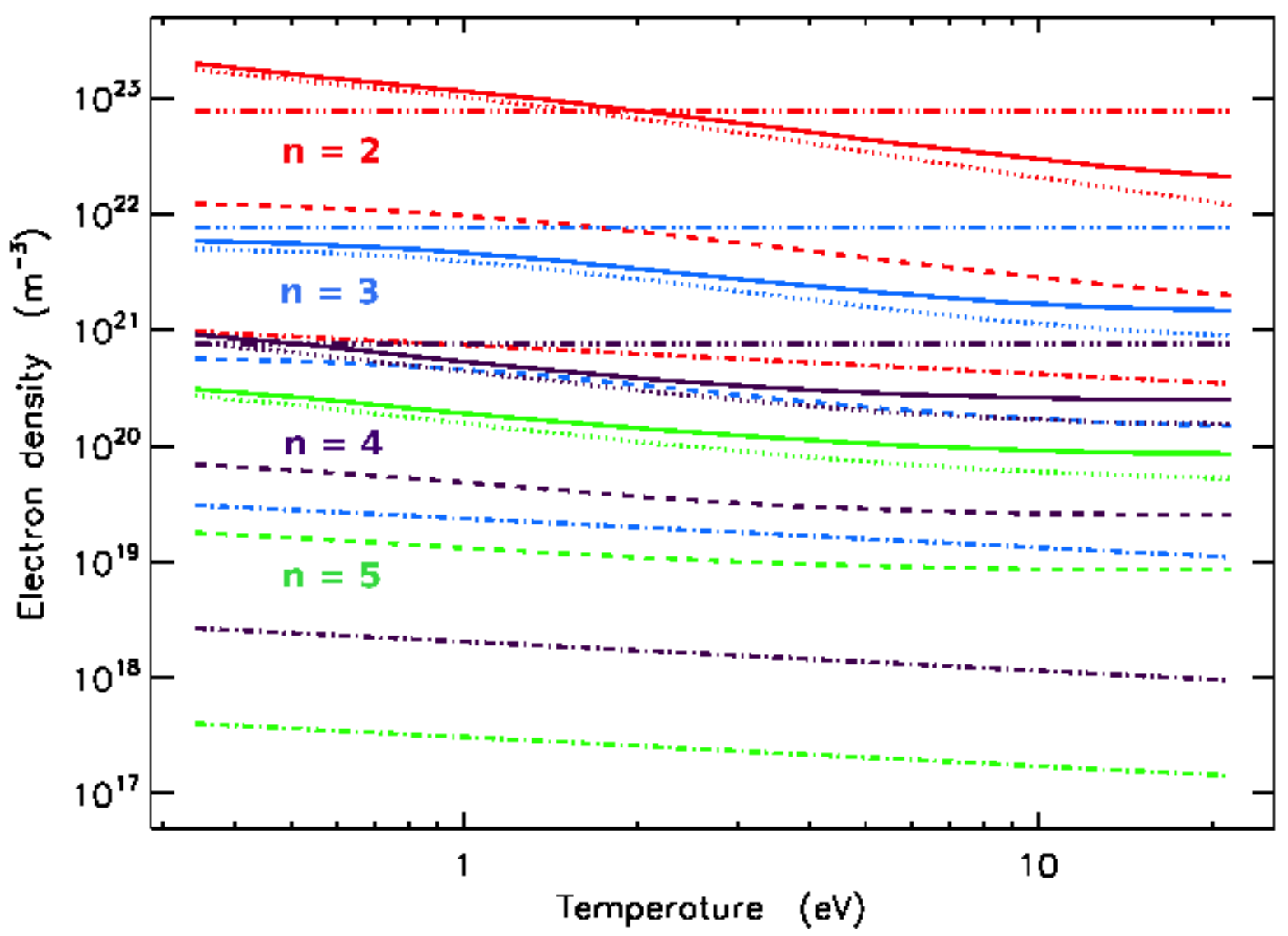

Figure 9. 


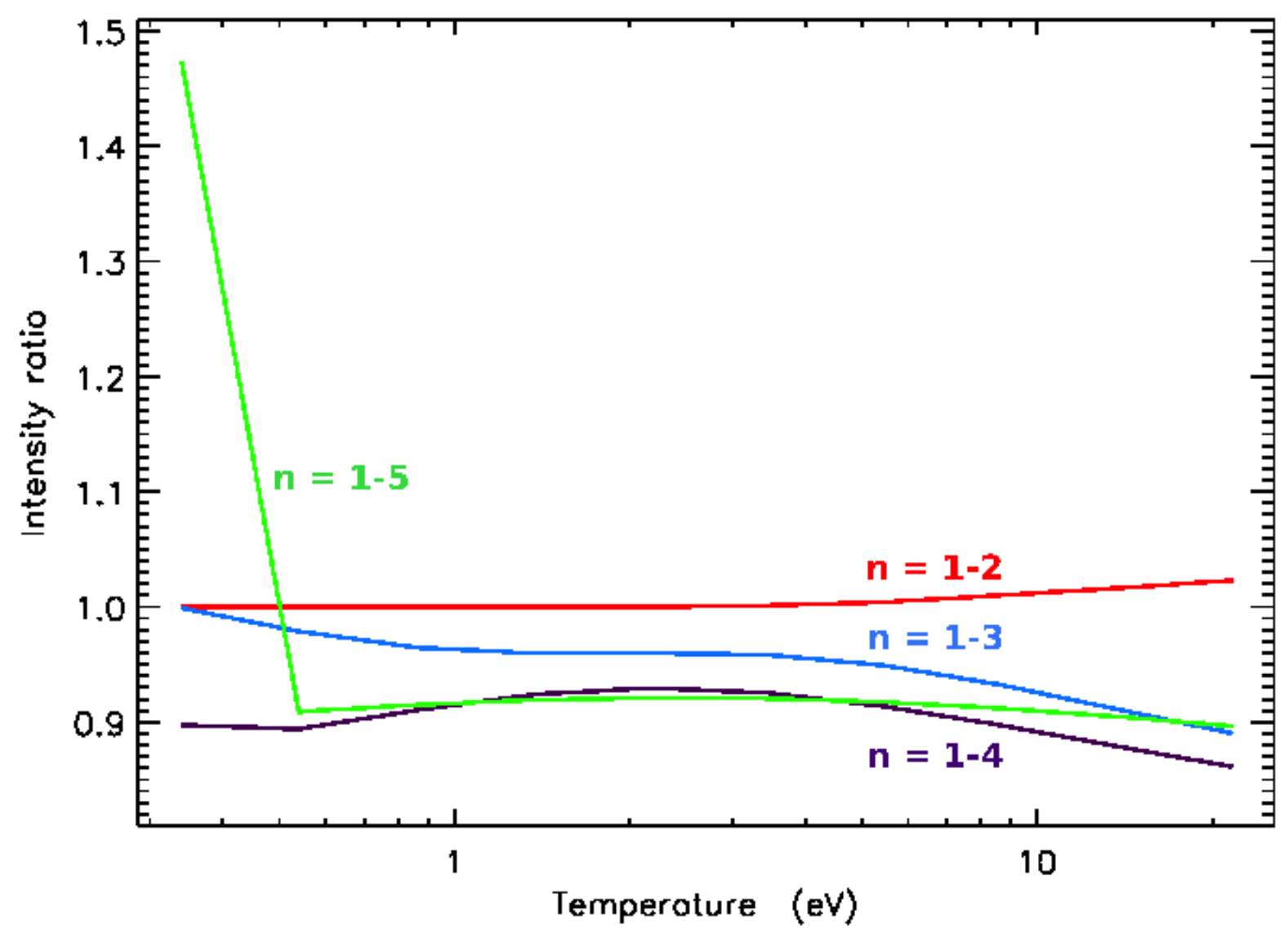

Figure 10.

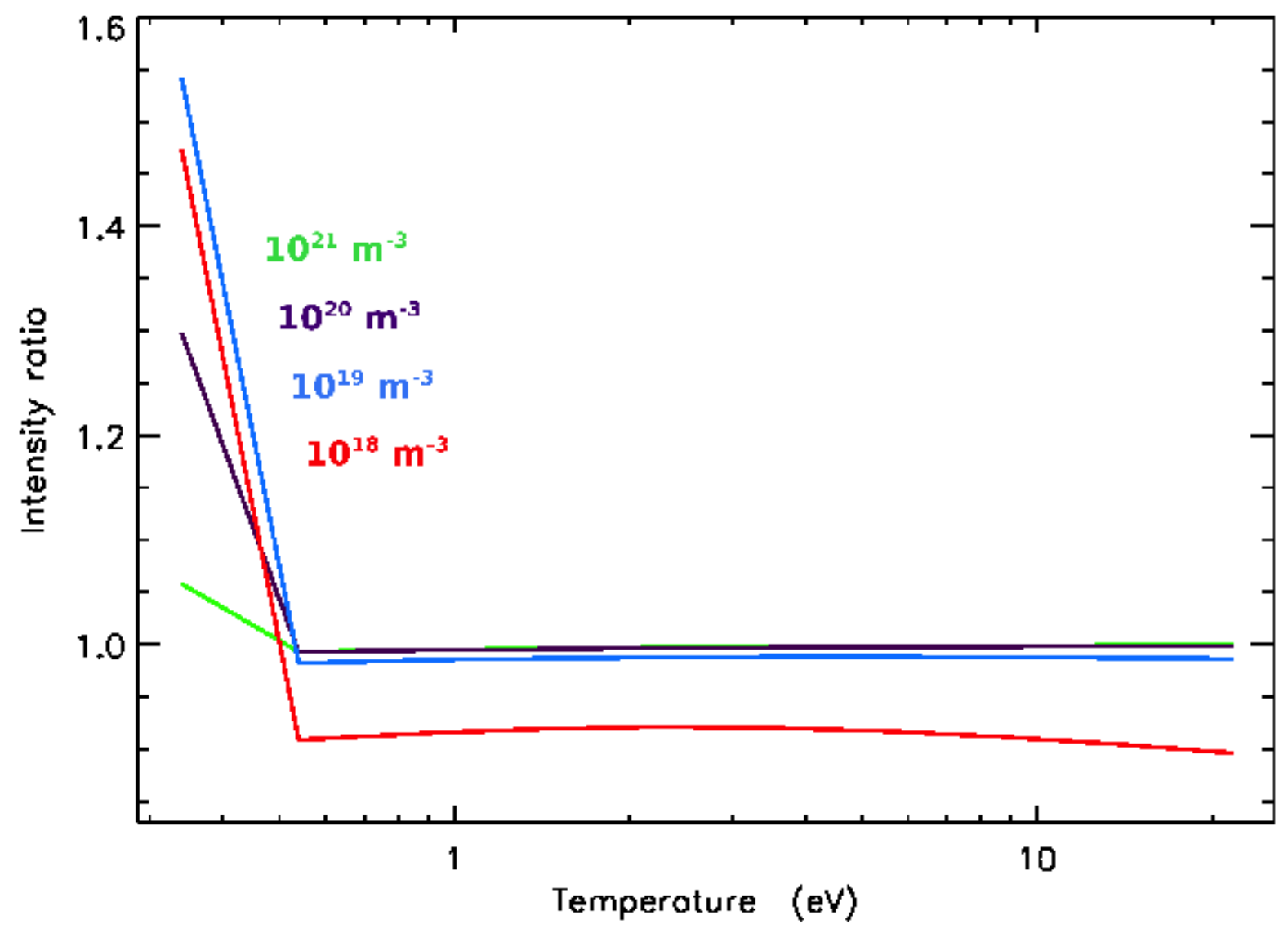

Figure 11. 


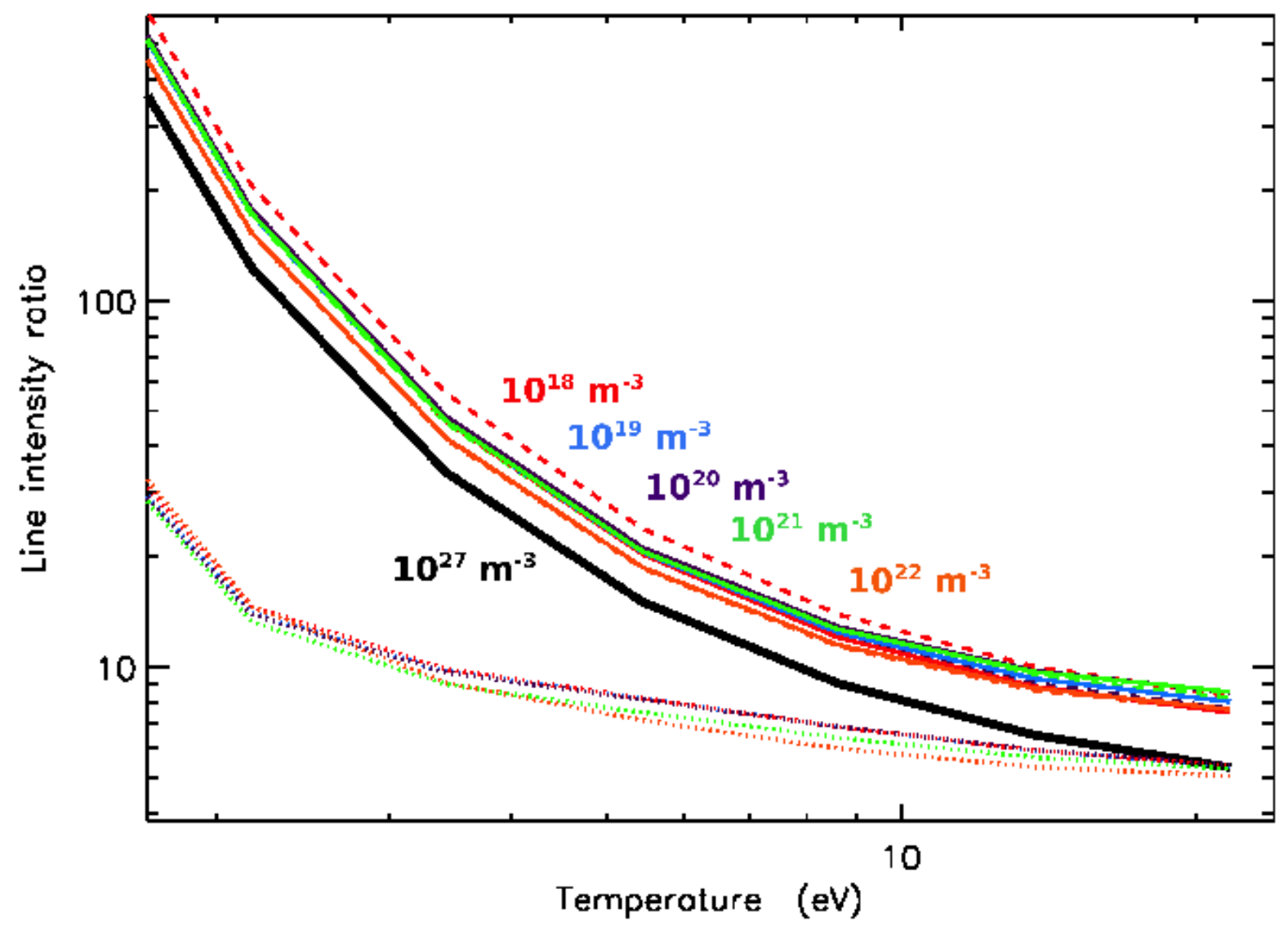

Figure 12.

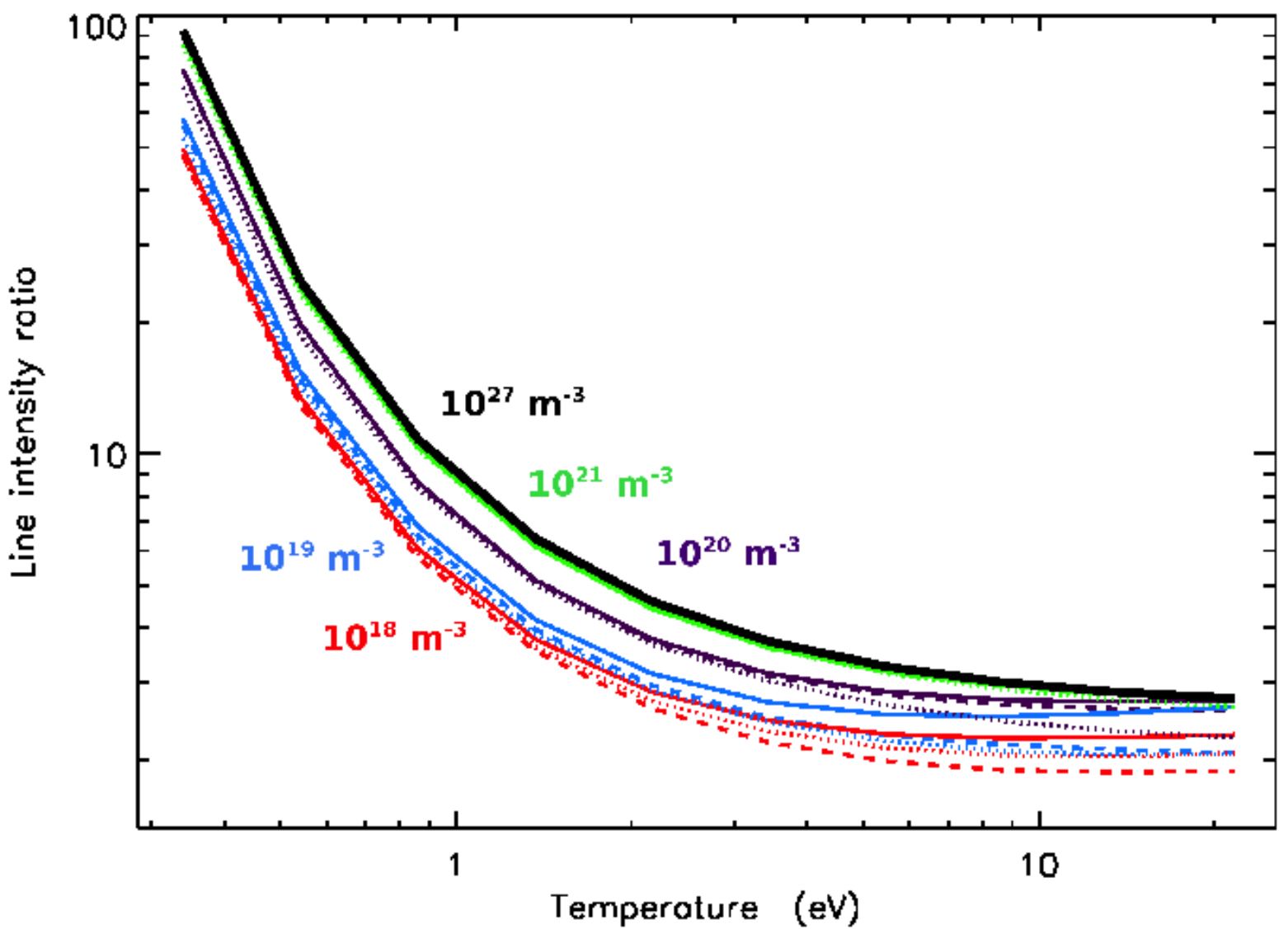

Figure 13. 


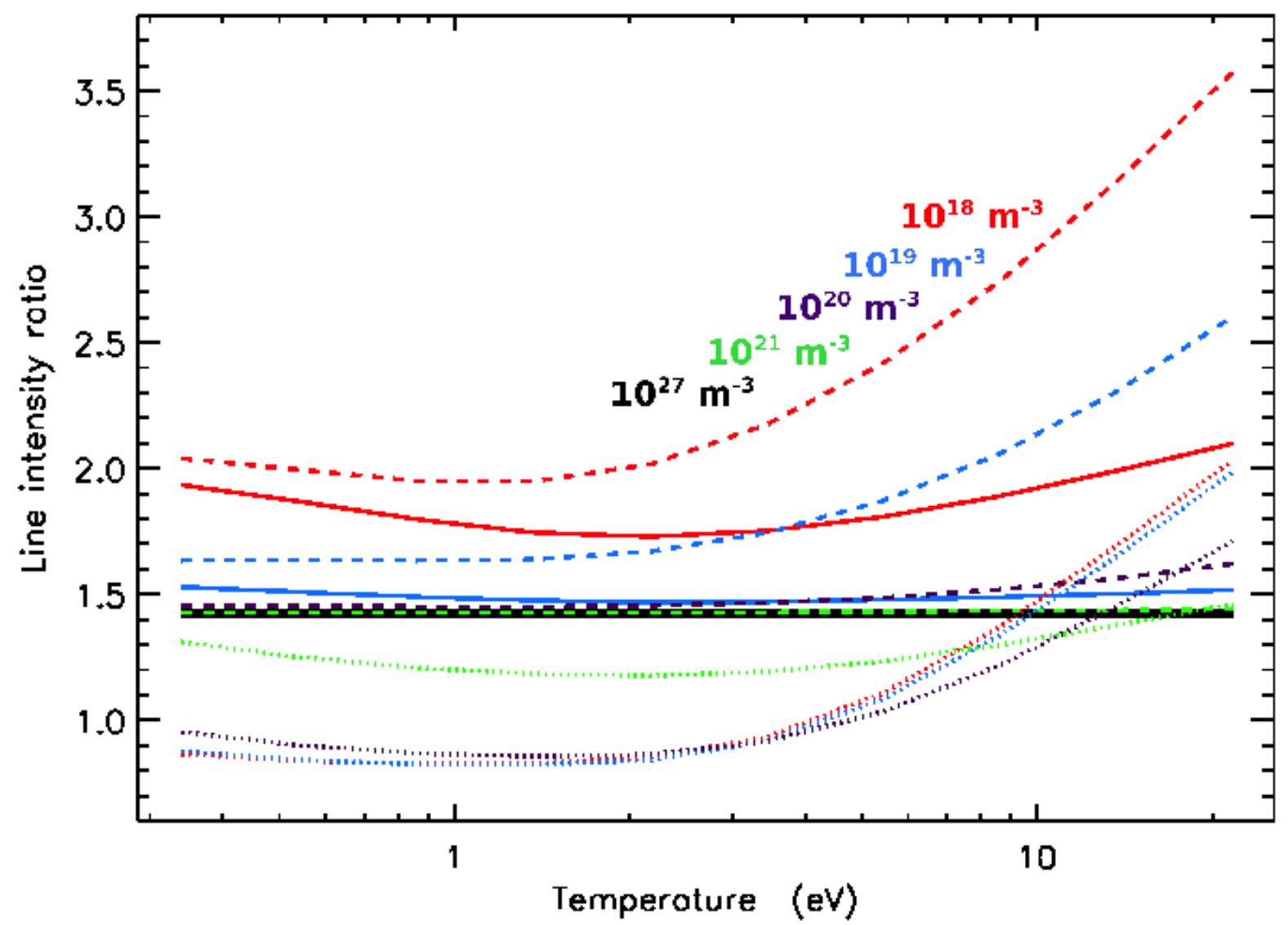

Figure 14.

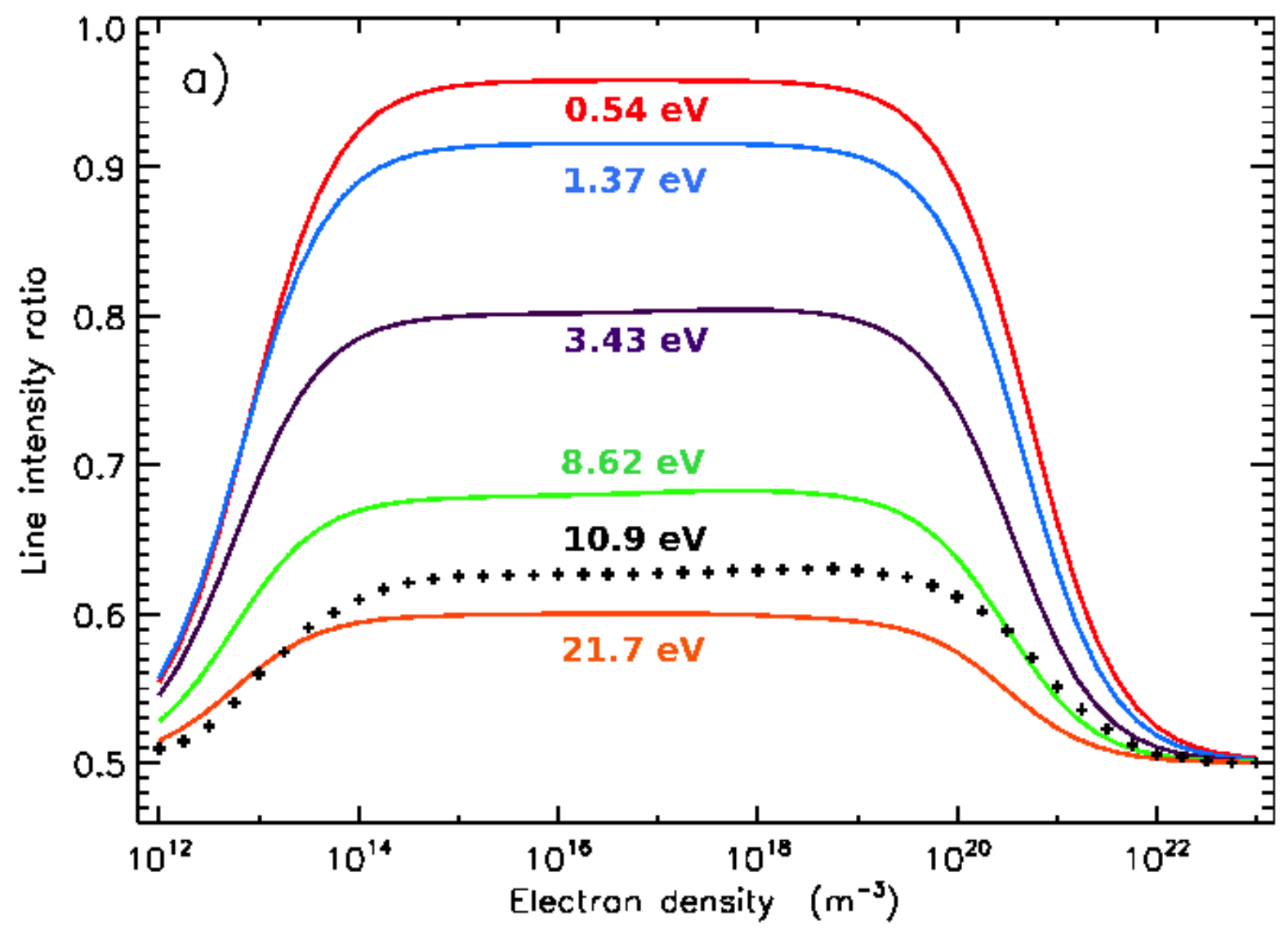



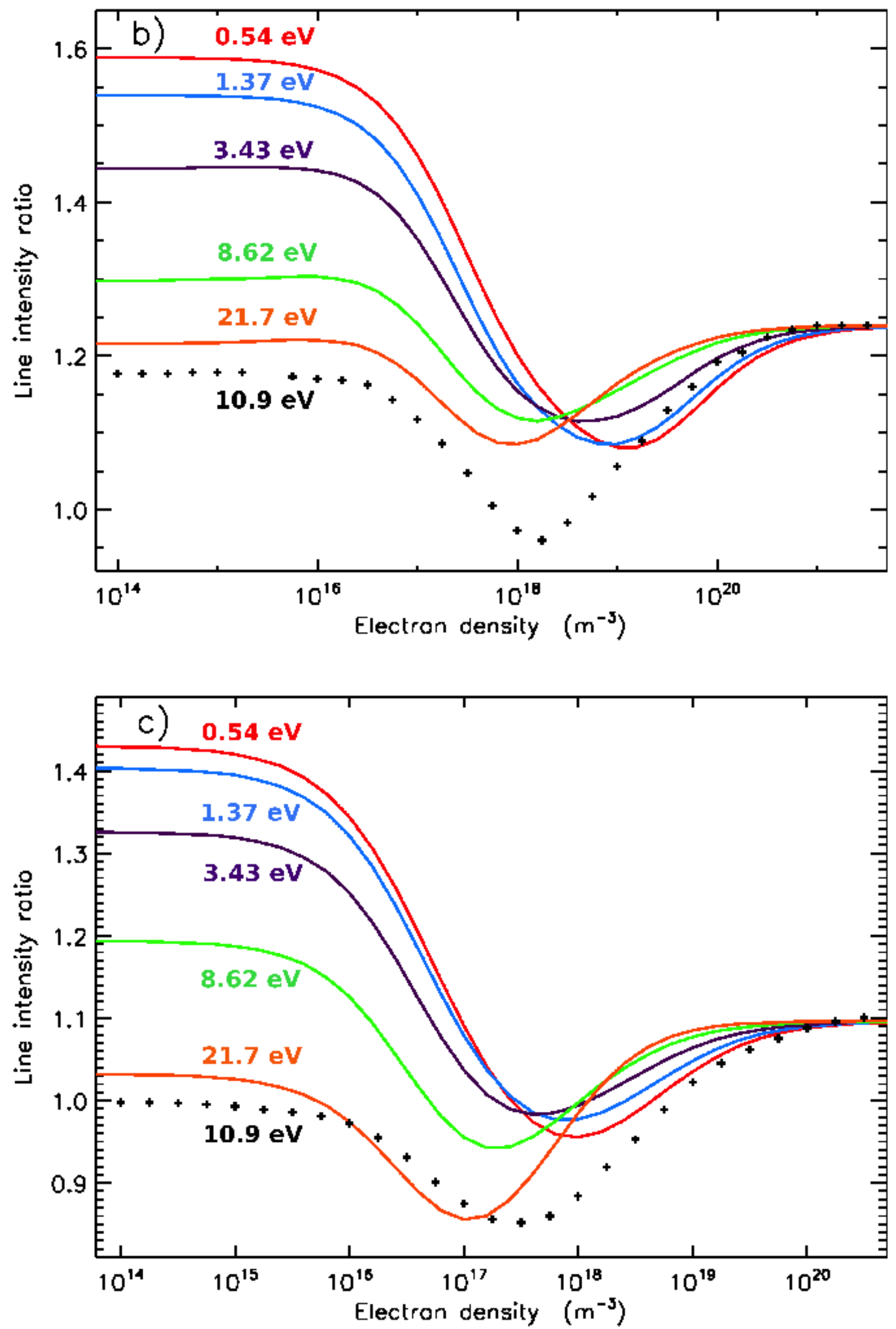


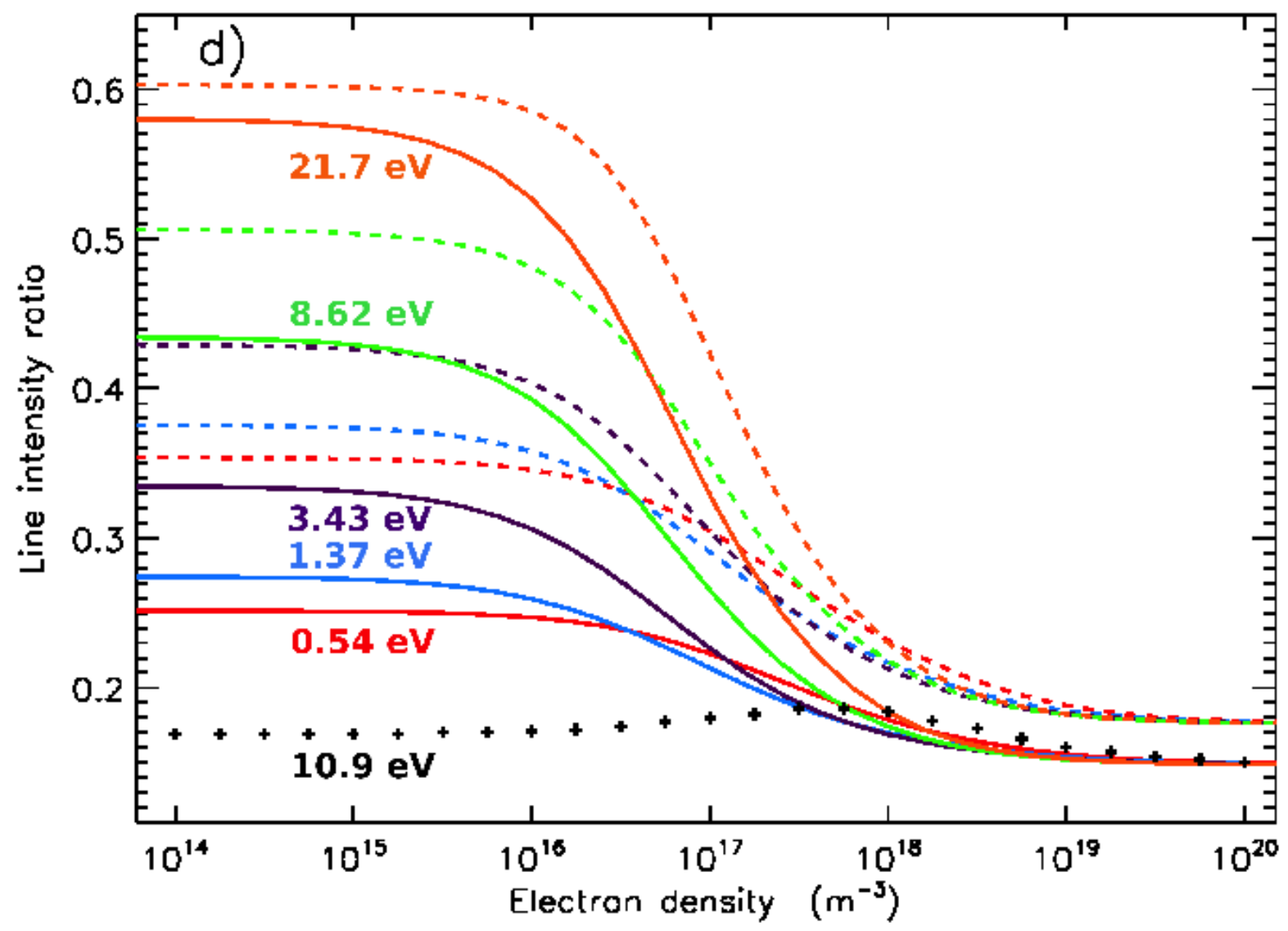

Figure 15.

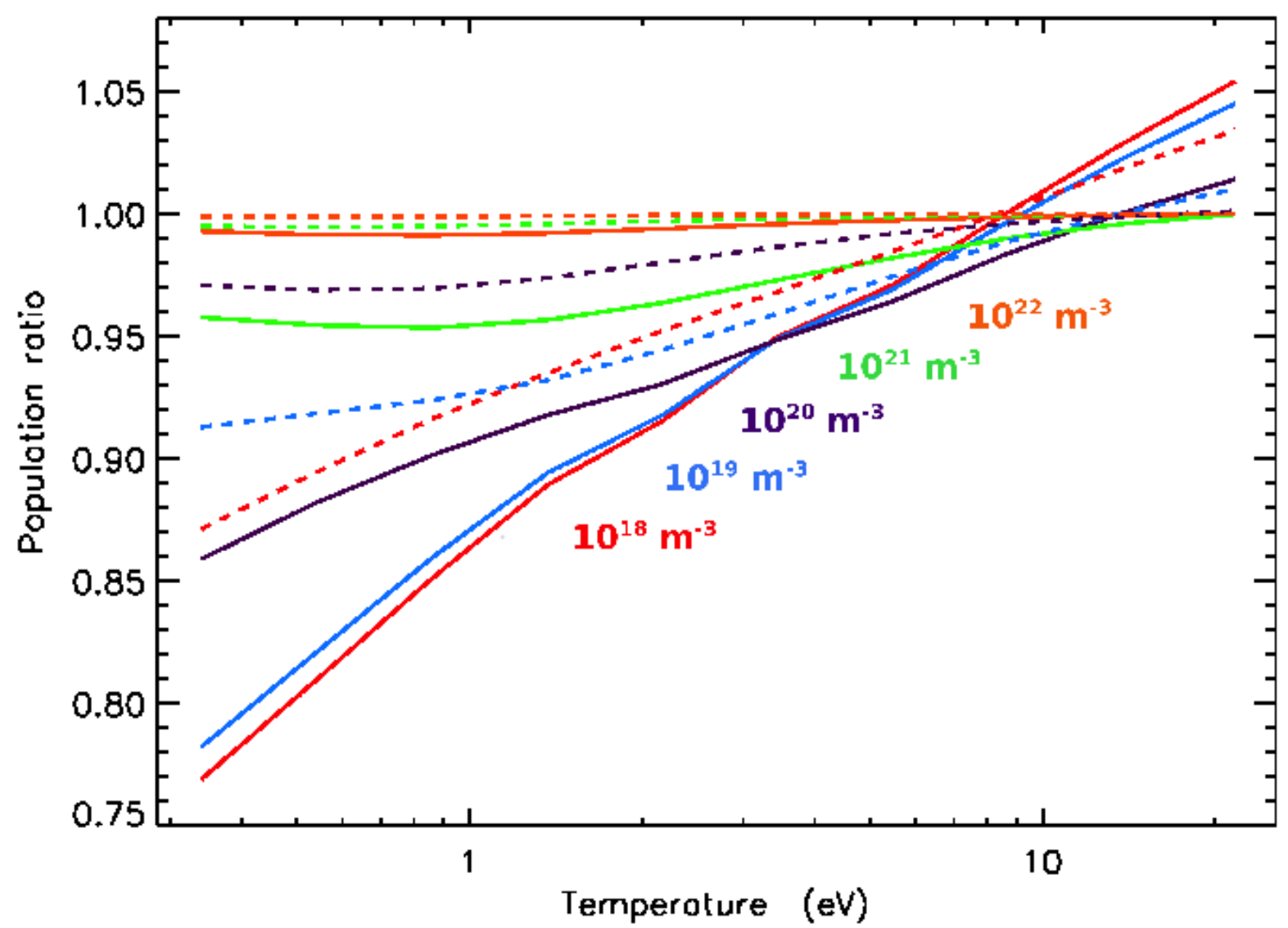

Figure 16. 


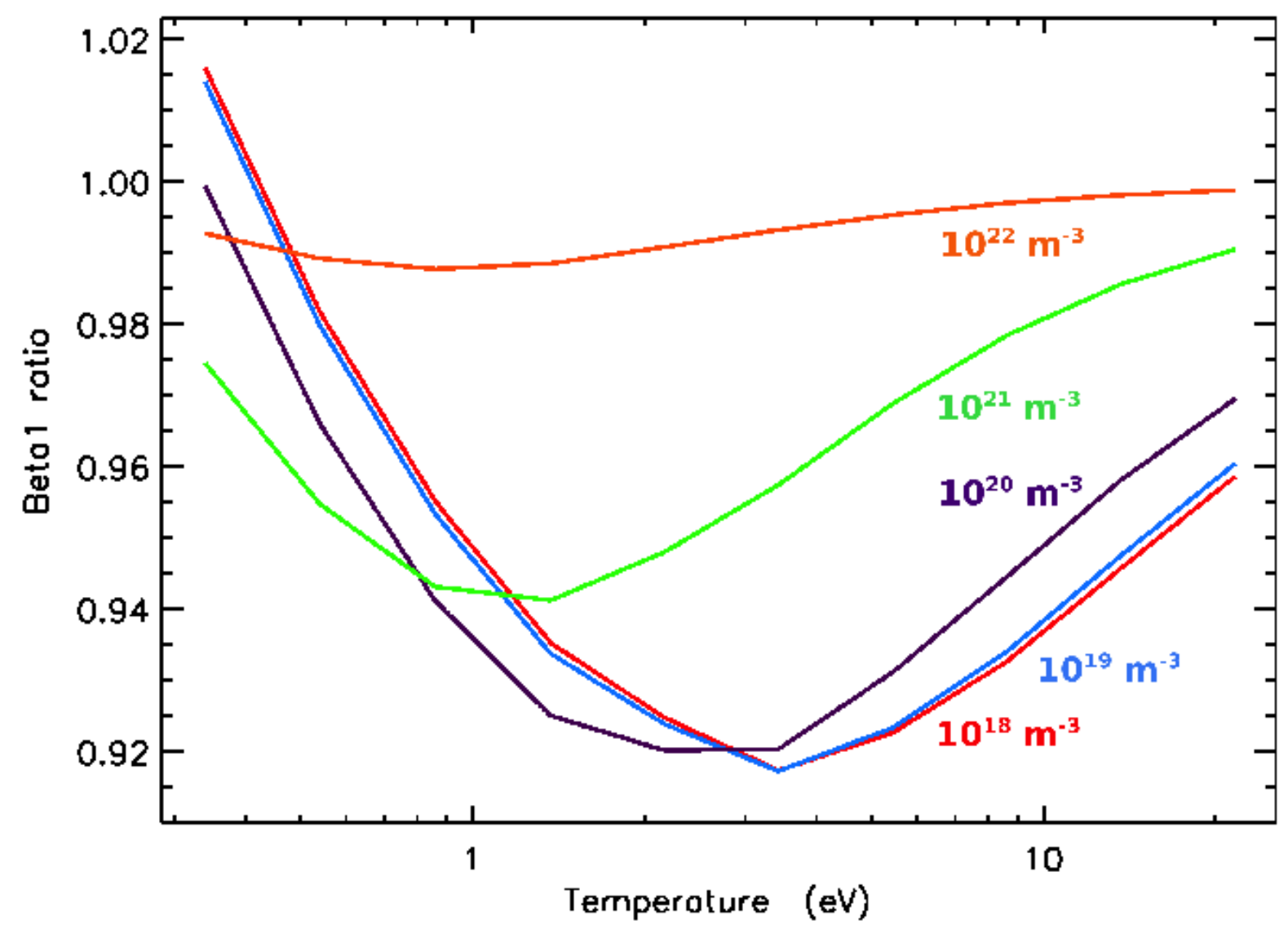

Figure 17.

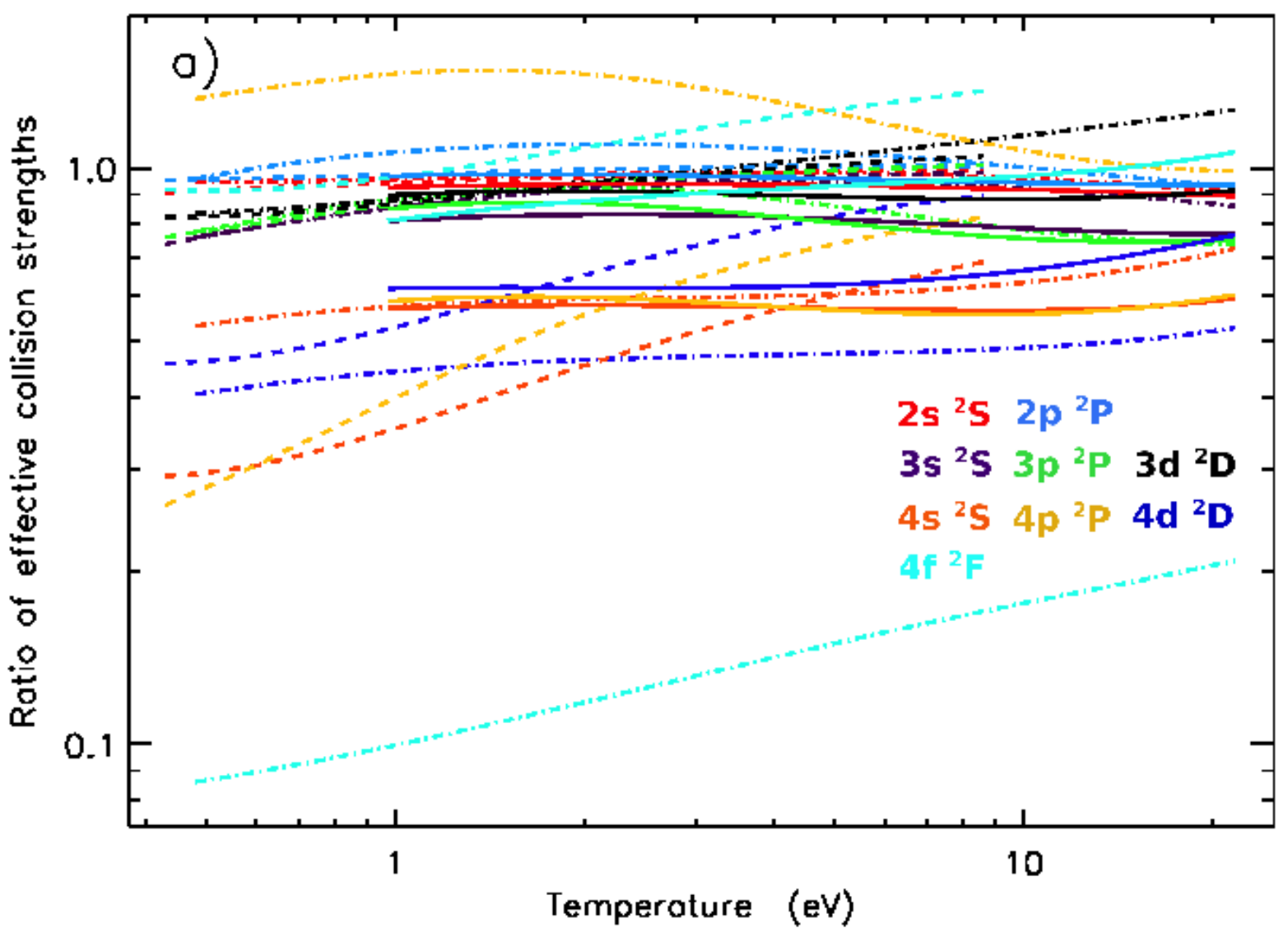




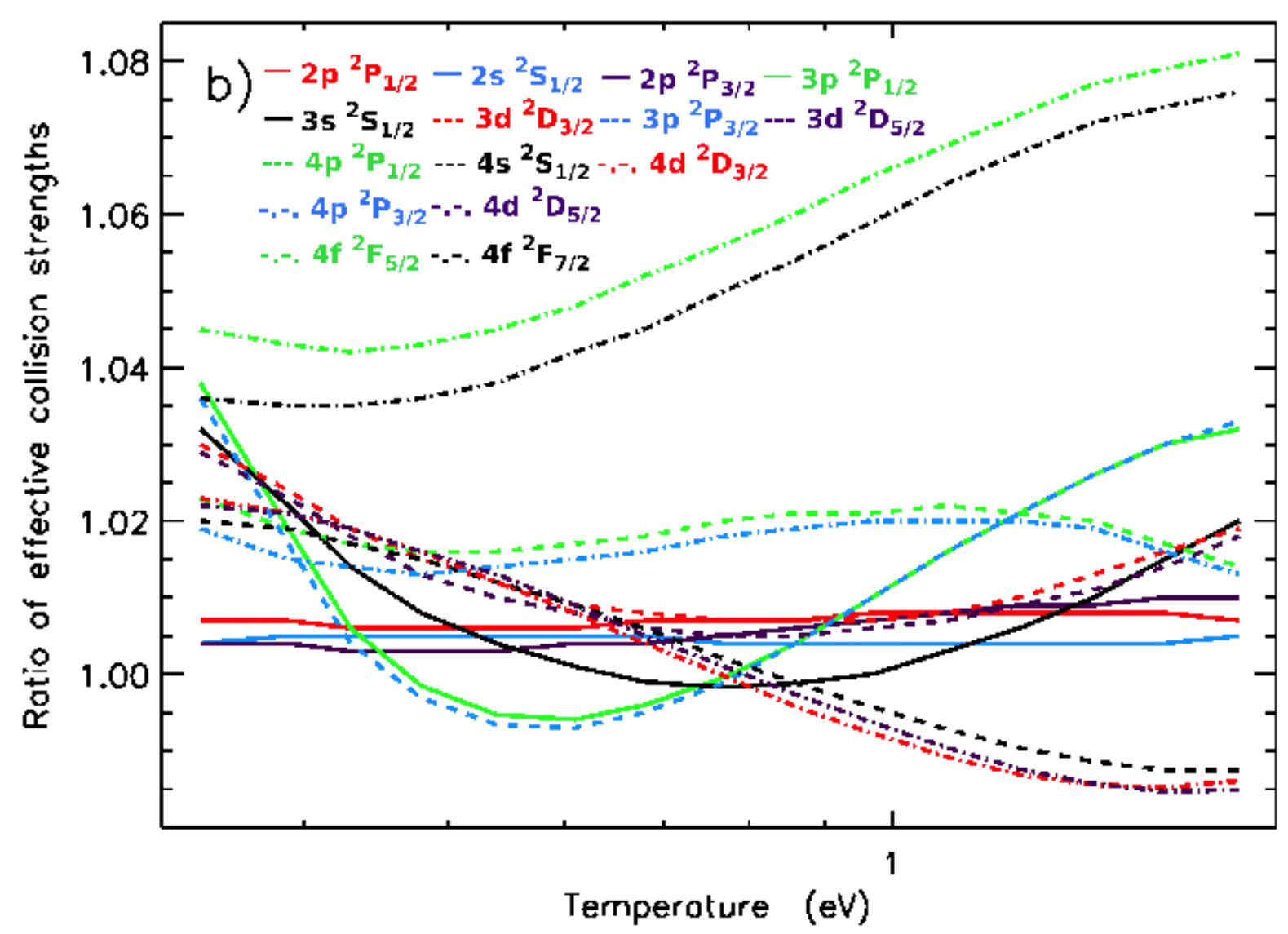

Figure 18.

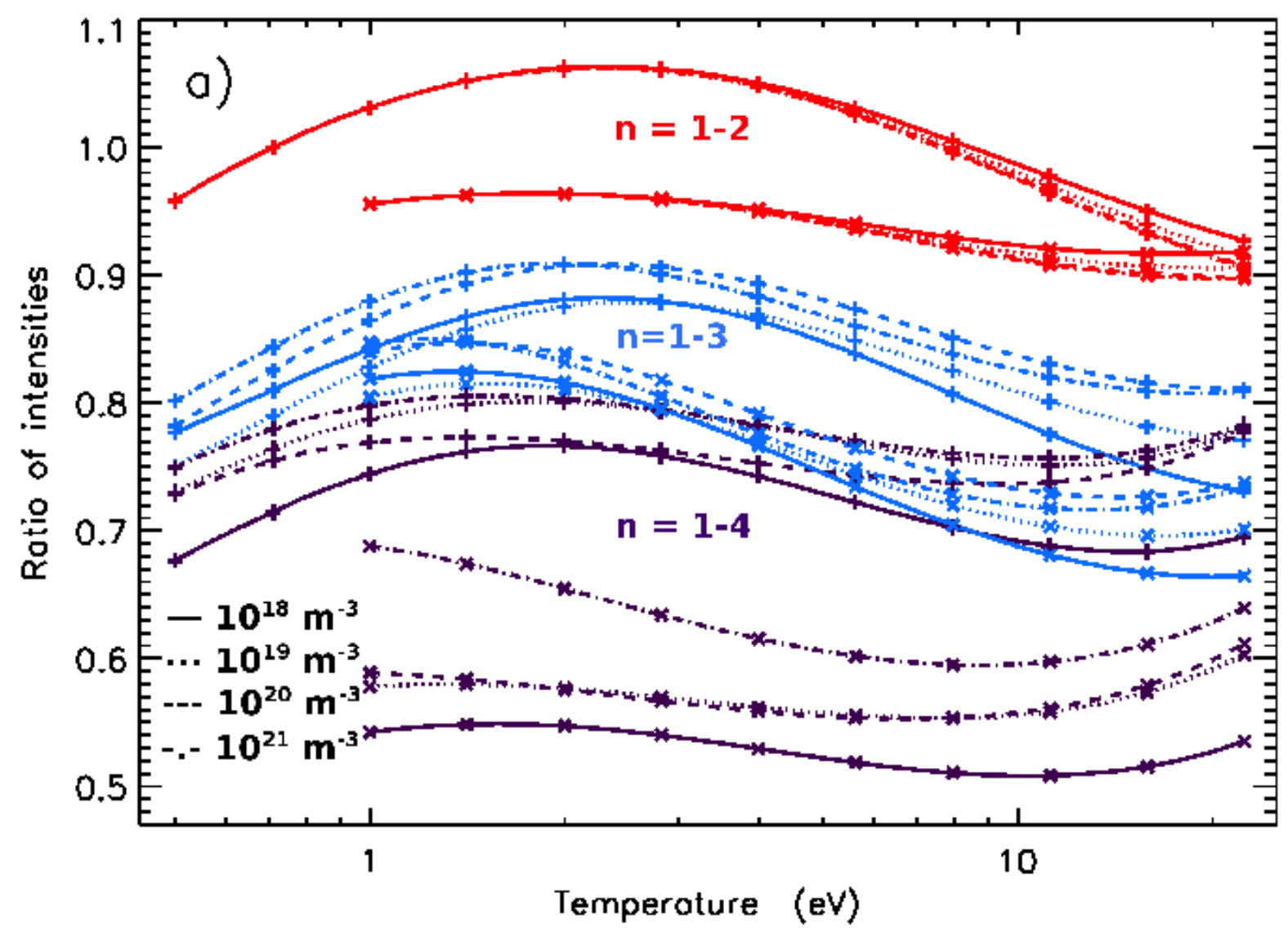




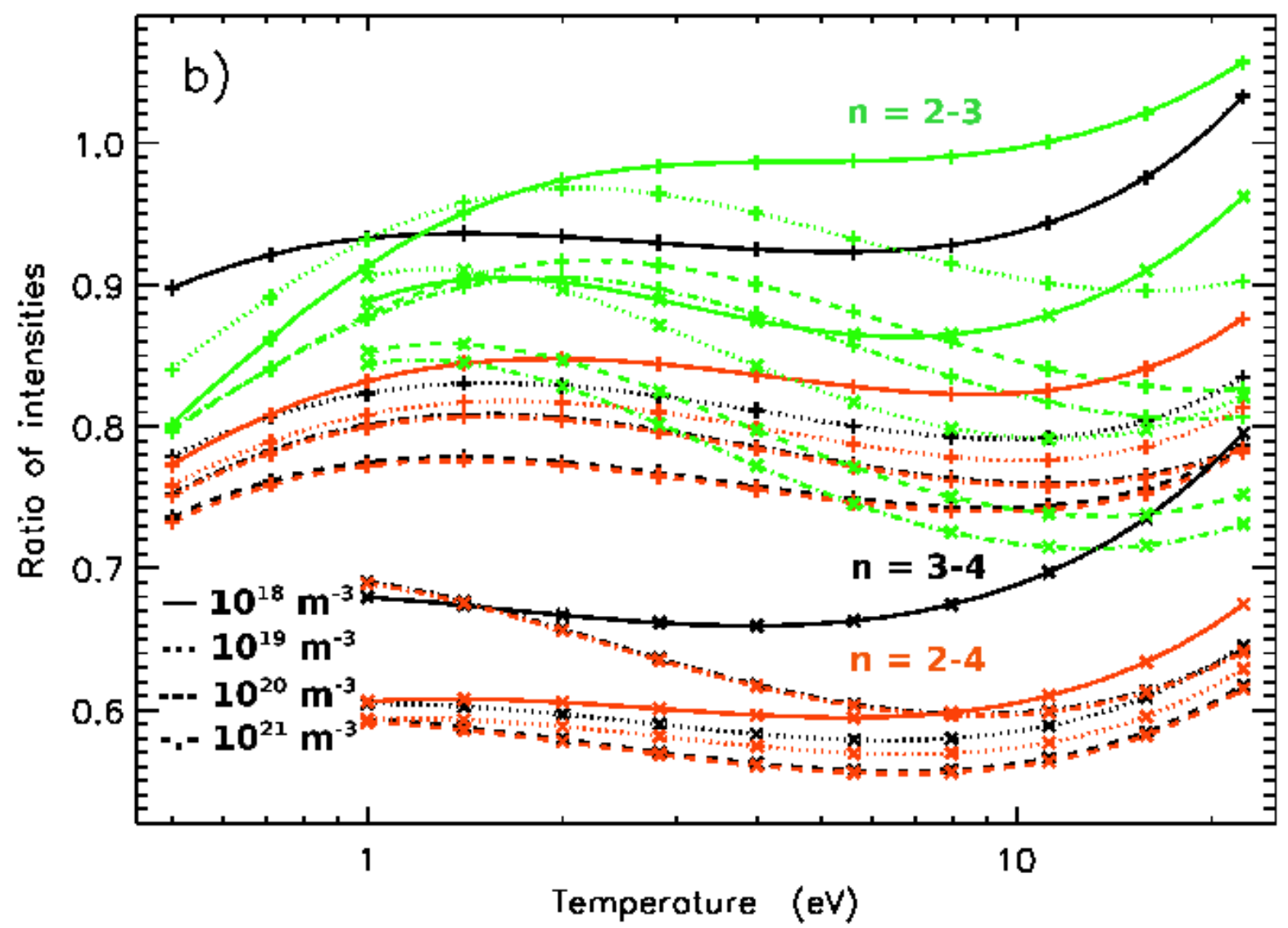

Figure 19.

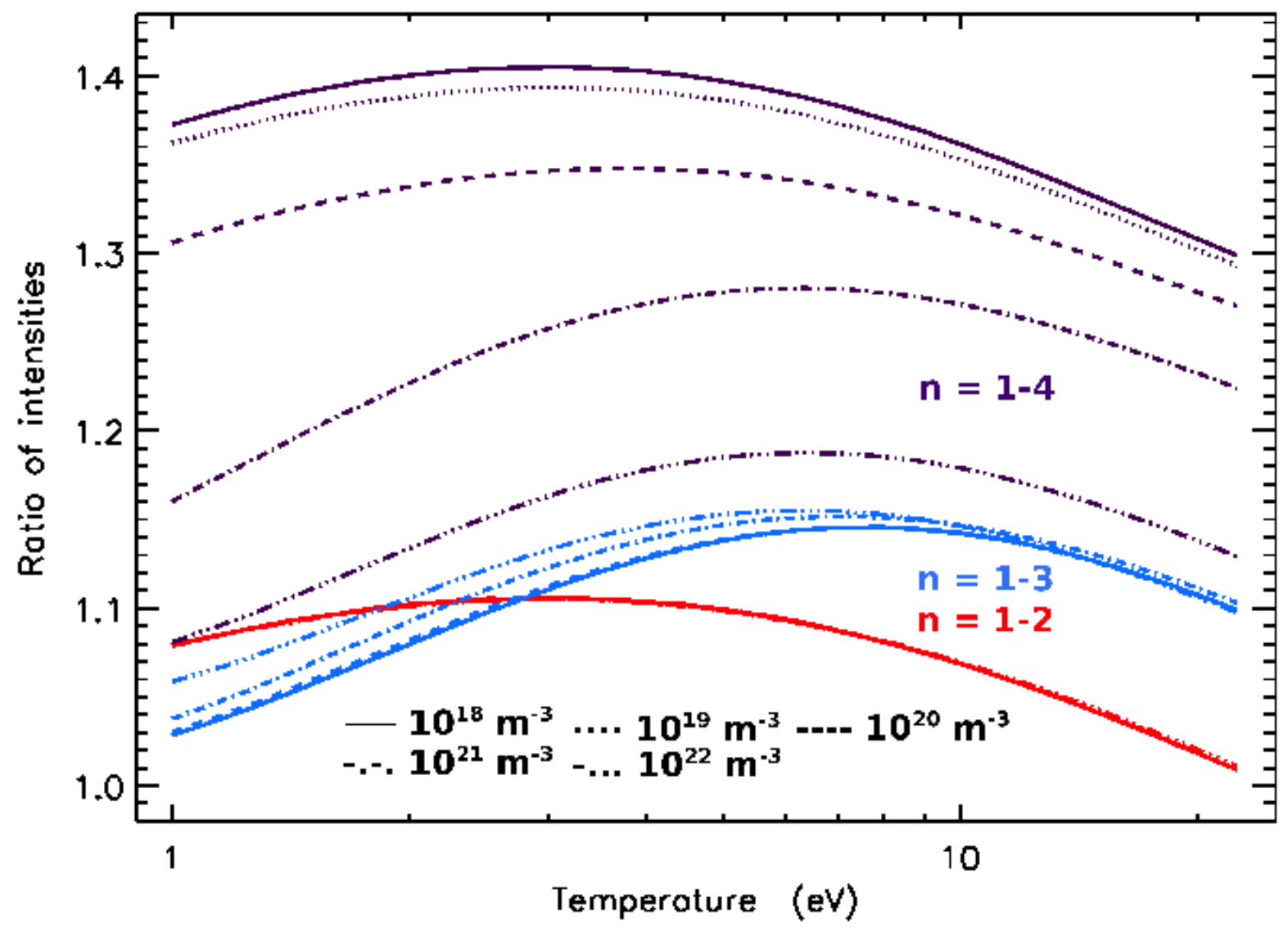

Figure 20. 